Universidade de São Paulo

Instituto de Física

\title{
Diagnóstico Bolométrico no TCABR
}

\section{Valdemar Bellintani Júnior}

Comissão Examinadora:

Prof. Dr. Ricardo M. Osório Galvão - IFUSP

Prof. Dr. Alvaro Vannuci - IFUSP

Prof. Dr. Munemasa Machida - UNICAMP

Prof. Dr. Mario Ueda - INPE

Profa. Dra. Marisa Roberto - ITA

SBI-IFUSP

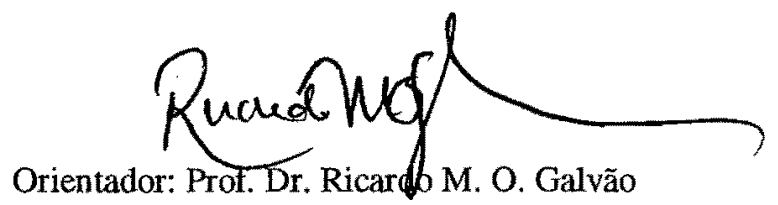

Tese de doutorado apresentada ao Instituto de Física para a obtenção do título de Doutor em Ciências
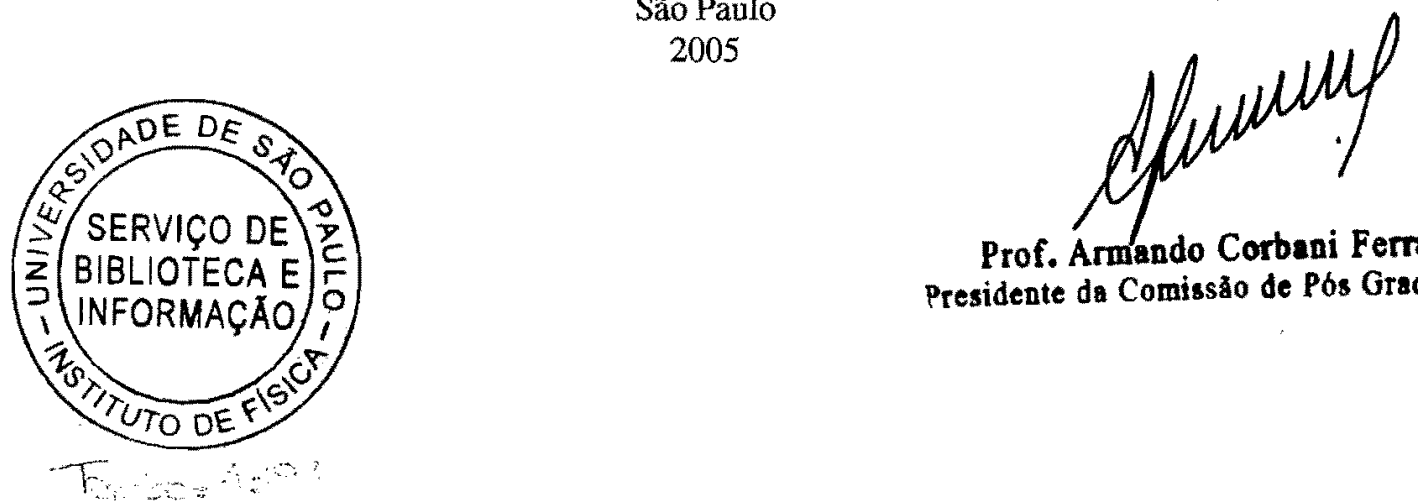

Prof. Armando Corbani Ferras Presidente da Comissão de Pós Graduaplo 
FICHA CATALOGRÁFICA

Preparada pelo Serviço de Biblioteca e Informação

do Instituto de Física da Universidade de São

Paulo

Bellintani Jr, Valdemar

Diagnóstico Bolométrico no TCABR.

São Paulo 2005.

Tese (Doutoramento) - Universidade de São Paulo Instituto de Física - Depto. de Física Geral

Orientador: Prof. Dr. Ricardo Magnus Osório Galvão Área de Concentração: Física

Unitermos:

1. Tokamaks;

2. Radiação (Energia Radiante);

3. Sensores Óticos. 


\section{Índice}

Índice 2

Resumo 4

Summary 5

Agradecimentos 6

\section{Capítulo 17}

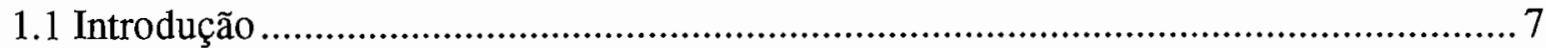

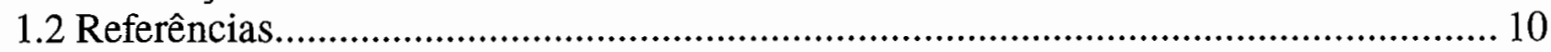

\section{Capítulo 211}

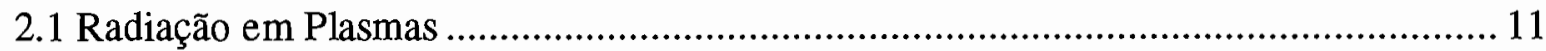

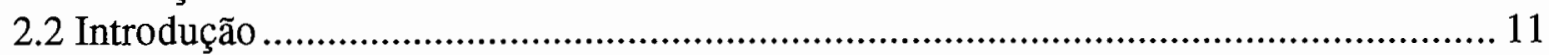

2.3 Processos Radiativos e Taxas de Emissão Radiativa ...................................................... 11

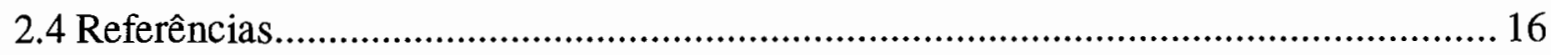

Capítulo $3 \quad 17$

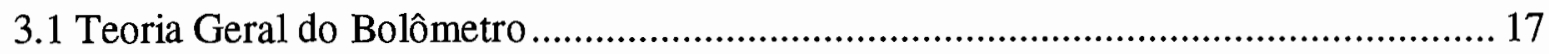

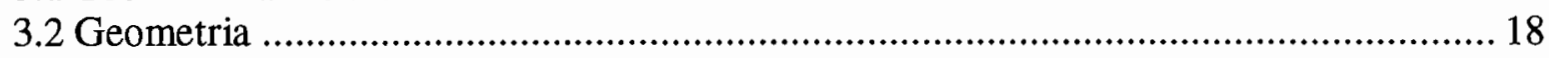

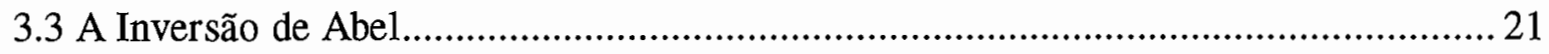

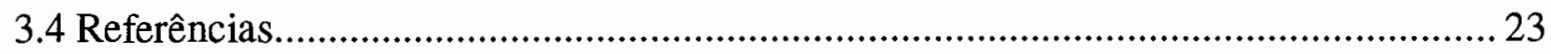

Capítulo $4 \quad 25$

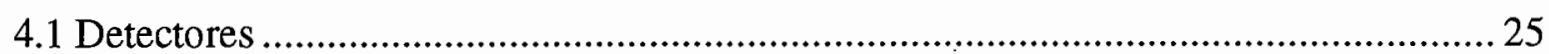

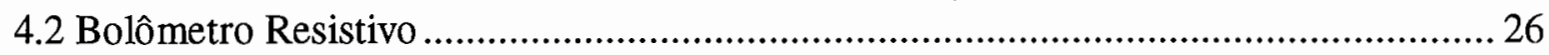

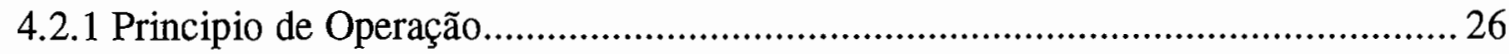

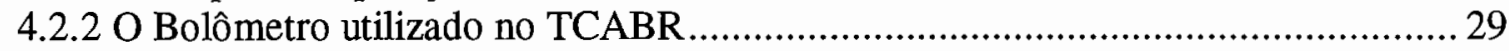

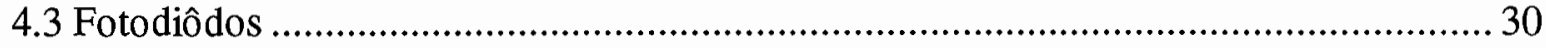

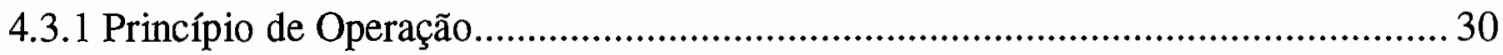

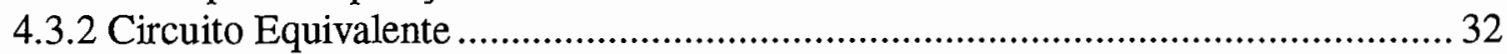

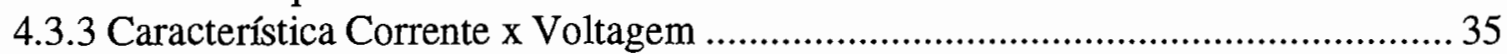

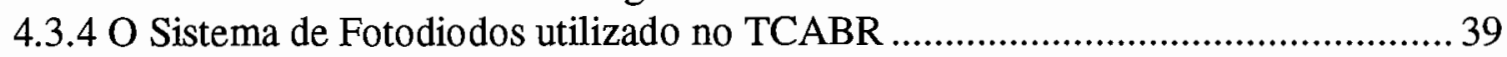

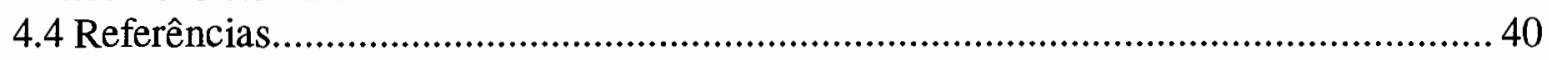

Capítulo $5 \quad 41$

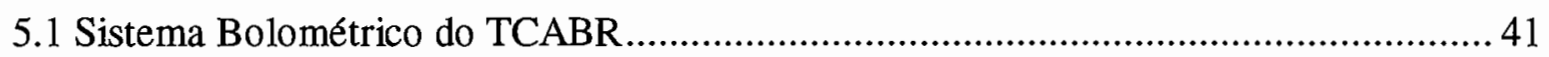

5.2 Eletrônica de Aquisição do Sinal Bolométrico ............................................................... 44

5.3 Arquitetura do Sistema de Aquisição ....................................................................... 45

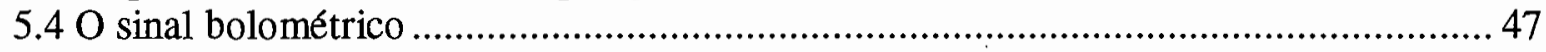

5.5 Parâmetros Geométricos dos Bolômetros.................................................................... 48

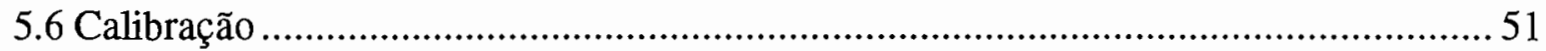

\section{Capítulo 655}

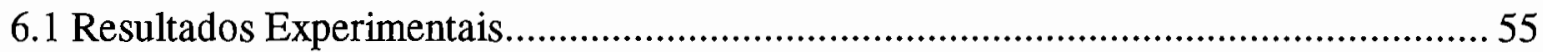

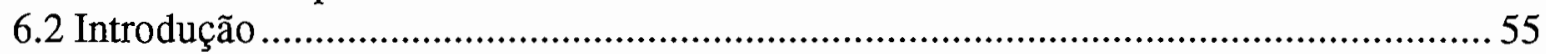

6.3 Método para obtenção do perfil da potência irradiada. ................................................... 56

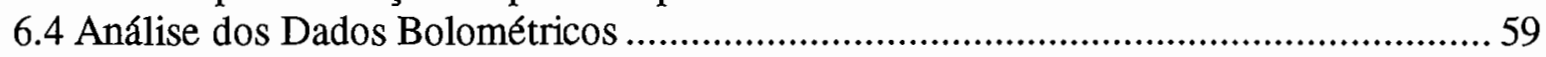

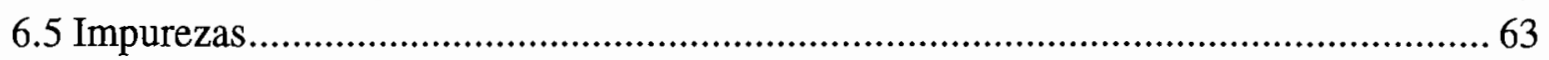


6.6 Dependência da Potência Total Emitida com a Densidade Eletrônica 66

6.7 O bolômetro em Descargas com Aquecimento Adicional por Ondas de Alfvén. ......... 69

6.8 O Bolômetro em Descargas em Regime Runaway .................................................... 72

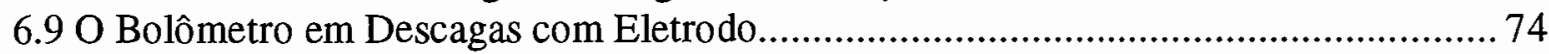

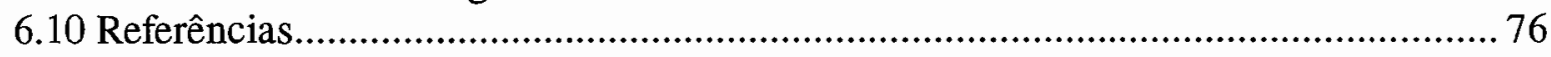

\section{Capítulo $7 \quad 78$}

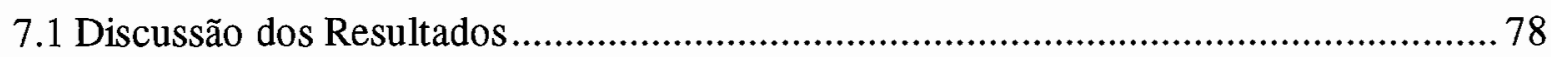

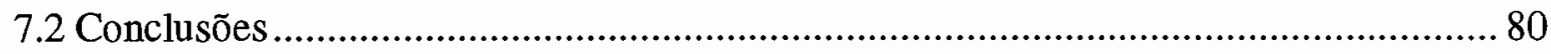

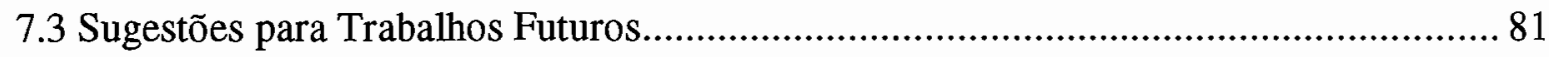

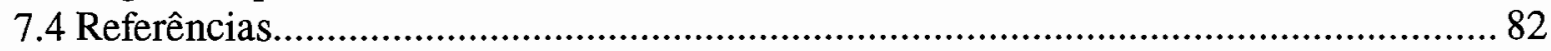

Apêndice A 83

O bolômetro resistivo

83

Apêndice B 85

Sistema Bolométrico do TCABR - Parâmetros Geométricos . 85

Apêndice C 87

Circuitos Eletrônicos

Apêndice D 90

Fotos do Sistema Bolométrico. .90 


\section{Resumo}

Foi projetado, construído e instalado um sistema bolométrico para a análise das descargas de plasma do TCABR. Este sistema possibilita a observação da coluna de plasma através de cordas caracterizadas por diferentes direções e ângulos. Os bolômetros utilizados são fotodiodos especiais, acondicionados em câmeras dotadas de colimadores para observação do plasma. A faixa espectral da sensibilidade dos fotodiodos abrange desde o visível até a região de raios-X moles, energia de fótons desde $7 \mathrm{eV}$ até $6.000 \mathrm{eV}$. Para este diagnóstico, foi construída uma eletrônica específica para amplificação dos sinais bolométricos. A resolução temporal do diagnóstico é de $3 \mathrm{~ms}$ devido a interferência gerada pelo tokamak.

Com este sistema, foi obtido pela primeira vez no TCABR, o perfil da potência emitida pela coluna de plasma, sendo este o principal resultado deste trabalho. Para isto, foi desenvolvido um programa destinado a inverter os dados bolométricos utilizando como princípio o método de Abel.

Uma série de descargas ôhmicas $\left(0,9 \times 10^{19}<n_{e}<2,0 \times 10^{19} \mathrm{~m}^{-3}\right.$ e $\left.67<I_{p}<100 \mathrm{kA}\right)$ foram estudadas com o diagnóstico. Obteve-se para o volume da coluna uma fração Prad/Poh não maior que $30 \%$, valor semelhante ao obtido para o tokamak TCA.

Observou-se também diferenças acentuadas para o perfil de potência emitido por descargas com baixos e altos valores da corrente de plasma. Estas diferenças são atribuídas principalmente ao aumento da temperatura eletrônica. A concentração de impurezas metálicas foi calculada no eixo da coluna, obtendo-se valores entre $0,9-1,2 \times 10^{17} \mathrm{~m}^{-3}$. 


\section{Summary}

In this work, a bolometric diagnostic system was projected, built and installed in the TCABR tokamak, in order to measure the total power radiation loss from the plasma. The system allows plasma observation through 27 lines of sight with different directions and angles. The detector used was a silicon $\mathrm{p}-\mathrm{n}$ junction photodiode array, for applications in the vacuum ultraviolet, extreme ultraviolet and the soft x-ray (XUV, energy range $7 \mathrm{eV}$ to 6 $\mathrm{keV}$ ) spectral region.

An electronic system for amplification of the bolometer signal was also projected and built. This system was projected taking into account the strong electromagnetic noise due to the tokamak operation.

Using this bolometric system, the shape of the emitted power was obtained for the first time in the TCABR, and this is the main result of this work.

To deal with the bolometric data, we developed a program based on the Abel inversion. A serie of ôhmic discharges were studied with this diagnostic. The value of the Prad/Poh obtained for this serie was below $30 \%$, in agreement with old TCA data.

The shape for discharges with high and low plasma current were also analyzed. We find a big difference in the two cases, showing the effect of electron temperature change.

The metallic impurity density on axis were calculated using the value of $\operatorname{Prad}(0)$ experimentally obtained. For the serie of discharges analyzed, this value remained between $0.9-1.2 \times 10^{17} \mathrm{~m}^{-3}$. 


\section{Agradecimentos}

Gostaria de agradecer aqueles que contribuíram para a execução deste trabalho.

Ao Prof. Dr. Ricardo M. O. Galvão, pela orientação, como também pelo apoio e incentivo.

Ao Prof. Dr. Ivan Cunha Nascimento pela simpática acolhida ao grupo de Física de Plasmas do IFUSP e pelo interesse demonstrado neste trabalho.

Aos Profs. Drs. Leonid Ruchko, Ruy Peppe da Silva, José Henrique Vuolo, Alvaro Vannucci, Aluísio Fagundes e Artur Elfimov pelas discussões e colaborações das mais diversas formas.

Aos técnicos de nível superior Wandeley Pires de Sá, Juan e Edson Kenzo pela amizade e estimada ajuda em suas áreas de trabalho.

Ao engenheiro Nelson Cuevas, grande amigo e sempre prestativo.

Aos técnicos de eletrônica, Nélio, Rogério, Ablicio e Ivan pela colaboração na parte eletrônica. Ao Antonio, pelo competente trabalho de usinagem e solda, sem o qual este trabalho não seria possível.

Aos companheiros de trabalho, Helder, Antonio, André , Edson Ozono, José Antonio Sevidanes e Eric, pela amizade e cooperação.

Enfim, a todas as pessoas que, trabalhando no grupo de Plasmas, fizeram parte do meu dia-a-dia.

A minha mãe, Maria Aparecida e minha namorada Adriana, pelo grande apoio. Ao meu pai, Waldemar Bellintani. 


\section{Capítulo 1}

\subsection{Introdução}

O objetivo das pesquisas em fusão é a produção controlada de energia a partir de reações nucleares entre núcleos leves, em particular as reações entre os isótopos mais pesados do hidrogênio,

$\mathrm{d}+\mathrm{t}=>{ }^{4} \mathrm{He}+\mathrm{n}+17.6 \mathrm{MeV}$

Reações de fusão só ocorrem se os núcleos reagentes estiverem suficientemente próximos. Para isto, os gases reagentes devem ser aquecidos a uma temperatura bastante alta, para que uma quantidade significativa de núcleos possuam energia suficiente para vencer a enorme repulsão Coulombiana. A reação entre o deutério e o trítio requer energia térmica entre 10 e $20 \mathrm{keV}$, correspondentes a valores de temperatura superiores às do centro solar.

Ao atingir tais temperaturas, a mistura é denominada plasma totalmente ionizado, e deve estar termicamente isolado de paredes materiais da câmara que contém o plasma. A eficiência de isolamento térmico é expressa pelo tempo de confinamento global de energia $\tau_{\mathrm{E}}$, que representa o tempo característico de decaimento da energia cinética do plasma quanto são removidas todas as fontes responsáveis pelo seu aquecimento. No início, uma fonte externa de aquecimento é necessária para atingir a temperatura de reação. Contudo, a energia liberada neste processo cresce com o aumento da temperatura. Um quinto desta energia se apresenta sob a forma de partículas alfa $\left({ }^{4} \mathrm{He}\right)$, as quais são re-utilizadas para aquecer o plasma. Em uma mistura contendo partes iguais de deutério e trítio, o aquecimento devido às partículas alfa irá equilibrar as perdas energéticas, tornando a reação auto-sustentada quando o produto da densidade iônica, do tempo de confinamento de energia e da temperatura iônica, $n_{i} \tau_{E} T_{i} \approx 5 \times 10^{21} \mathrm{~m}^{-3} \mathrm{~s} \mathrm{keV}$. 
Existem duas rotas alternativas para obtenção da relação necessária entre a temperatura, densidade e tempo de confinamento. Uma delas é o denominado confinamento inercial, onde uma pastilha de combustível é aquecida e comprimida por lasers ou feixe de partículas, até atingir alta densidade $\left(\mathrm{n}_{\mathrm{i}} \approx 10^{31} \mathrm{~m}^{-3}\right)$ em um curto período de confinamento $\left(\tau_{\mathrm{E}} \approx 10^{-11} \mathrm{~s}\right)$. A outra forma é chamada confinamento magnético, onde um plasma de baixa densidade $\left(\mathrm{n}_{\mathrm{i}} \approx 10^{20} \mathrm{~m}^{-3}\right)$ é confinado por períodos mais longos $\left(\tau_{\mathrm{E}}>1 \mathrm{~s}\right)$, pela aplicação de campos magnéticos intensos. Os sistemas de confinamento mais promissores são os de geometria toroidal e, dentre eles, os mais avançados em termos de pesquisa são os tokamaks [1]. Este dispositivo combina um intenso campo magnético toroidal produzido por bobinas externas, com um campo magnético poloidal moderado, produzido por uma corrente elétrica que circula pelo plasma. Outros sistemas toroidais diferem em detalhes relacionados aos campos magnéticos confinantes. Existem os stellarators, onde o campo poloidal é produzido por bobinas externas, e os pinches, onde o campo poloidal é bem mais intenso que o campo toroidal.

Atualmente, os experimentos de confinamento magnético são realizados com plasmas de hidrogênio ou deutério. As reações de fusão para o deutério ( existem dois caminhos com igual probabilidade),

$\mathrm{d}+\mathrm{d}=>3 \mathrm{He}+\mathrm{n}+3.27 \mathrm{MeV}$

$\mathrm{d}+\mathrm{d}=>\mathrm{t}+\mathrm{p}+4.03 \mathrm{MeV}$

necessitam de temperaturas ainda mais altas que a reação $d$ - $t$. Estas reações produzem um fluxo de nêutrons bem menor que a mistura de deutério e trítio na mesma temperatura, e portanto são convenientes na investigação de regimes de confinamento sem as dificuldades adicionais introduzidas pelo enorme fluxo destas partículas.

As perdas por radiação em um plasma irão sempre existir, principalmente devido a aceleração dos elétrons. Esta aceleração é produzida de duas maneiras: por colisões (bremsstrahlung), ou movimento ciclotrônico. 
Na presença de impurezas, a emissão via bremsstrahlung sofre um acréscimo, bem como aparecem perdas devido aos processos atômicos de radiação de linha e recombinação. $\mathrm{O}$ aumento da emissão de bremsstrahlung é consequiência da maior carga iônica característica das impurezas. Portanto, o controle da concentração de impurezas é essencial para atingir temperaturas termonucleares.

O diagnóstico bolométrico fornece informações importantes sobre a potência emitida pelo plasma de tokamak, auxiliando no estudo do balanço energético. Em geral, as medidas são feitas por um sensor térmico, porém recentes avanços tecnológicos permitiram a fabricação de fotodiodos especiais que atualmente vem sendo utilizados como bolômetros.

Neste trabalho, medidas bolométricas utilizando estes dois tipos de bolômetros foram feitas para as descargas do tokamak TCABR, instalado no Laboratório de Física de Plasmas da Universidade de São Paulo. O estudo vem se somar ao trabalho desenvolvido no mestrado, ocasião em que um sensor resistivo foi calibrado absolutamente no Laboratório Nacional de Luz Síncrotron (Campinas-SP) e utilizado na obtenção de dados.

O TCABR corresponde ao antigo tokamak TCA, instalado em Lausanne até o início da década de 90 . Trata-se de uma máquina de médio porte $\left(R=0,61 \mathrm{~m} ; a=0,18 \mathrm{~m} ; B_{T}=1\right.$ T), dedicada principalmente ao estudo do aquecimento adicional via ondas de Alfvén. Após sua transferência para o Brasil, sua montagem em nosso laboratório teve início, sendo que a primeira descarga foi realizada em 1998. Seguiram-se experimentos destinados a caracterizar o plasma produzido sob as novas condições de operação. Aproximadamente 17.000 descargas já foram realizadas desde o inicio dos trabalhos em nosso laboratório.

O que torna este trabalho atual é o obtenção do perfil da potência emitida para 0 TCABR em sua nova fase de operação. O estudo permite comparar as atuais condições da máquina com as do TCA.

No capítulo 2, apresentamos a teoria referente á radiação emitida por plasmas de tokamak. Princípios de radiometria são discutidos no capítulo 3. No capítulo 4 são descritas as características dos bolômetros utilizados neste trabalho. O sistema bolométrico projetado e instalado no TCABR é mostrado no capítulo 5. No capítulo 6 mostramos e discutimos os 
resultados obtidos a partir das medidas realizadas. Finalmente, as conclusões e sugestões para trabalhos futuros são mostradas no capítulo 7 .

\subsection{Referências}

[1] Wesson J. 1997 Tokamaks (Oxford : Clarendon) 


\section{Capítulo 2}

\subsection{Radiação em Plasmas}

\subsection{Introdução}

A maior parte da potência irradiada pelo plasma em um tokamak é devido à presença de impurezas e está relacionada com sua quantidade através de uma grandeza conhecida por Taxa de Emissão Radiativa, a qual é uma função da temperatura eletrônica. A Potência Irradiada é diretamente obtida pelo diagnóstico bolométrico, porque grande parte da radiação do plasma é absorvida de maneira eficiente por vários materiais e posteriormente convertida em energia térmica ou elétrica.

\subsection{Processos Radiativos e Taxas de Emissão Radiativa}

Os mecanismos radiativos de um plasma submetido ao confinamento magnético podem ser classificados em três categorias: transição "não ligada-não ligada", radiação "não ligada-ligada"(recombinação), radiação "ligada-ligada"(radiação de linhas).

Uma carga elétrica se movendo irá irradiar sempre que sofrer uma aceleração ou uma desaceleração. A transição "não ligada-não ligada" pode ser subdividida em duas categorias: Bremsstrahlung e radiação síncrotron.

Bremsstrahlung é causado pela aceleração de partículas carregadas devido ao campo coulombiano produzido por outras partículas. A maior parte da radiação de Bremsstrahlung é devida às colisões dos elétrons com os íons. Quando a função de distribuição das 
velocidades dos elétrons é Maxwelliana, um calculo clássico prevê uma dependência com a frequência da radiação "não ligada-não ligada" do tipo $\exp \left(-h v / T_{e}\right)$. A emissão em um intervalo unitário de frequência é dada por [1-2]:

$$
\frac{d E f f}{d v}=\frac{32 \pi}{3} \frac{Z_{e f f} e^{6}}{\left(4 \pi \varepsilon_{0}\right) c^{3} m}\left(\frac{2 \pi}{3 m T_{e}}\right)^{1 / 2} n_{e}^{2} \exp \left(-\frac{h v}{T_{e}}\right)
$$

Integrando a expressão acima para todos os comprimentos de onda vamos obter:

$$
\begin{aligned}
& P_{b}=1.5 \times 10^{-38} Z_{e f f} n_{e}^{2} T_{e}^{1 / 2} \quad\left(W / m^{3}\right) \\
& \left(T_{e} \mathrm{em} e V, n_{e} \mathrm{em} m^{-3}\right)
\end{aligned}
$$

onde o $Z_{e f f}$ é o estado de ionização efetiva definido por:

$$
Z_{\text {eff }}=\sum_{i} \frac{n_{i} Z_{i}^{2}}{n_{e}}
$$

A radiação de Bremsstrahlung é mais propriamente calculada considerando-se as transições entre estados quânticos não ligados em um espectro contínuo. O resultado obtido utilizando-se um tratamento quântico difere do resultado clássico por um fator próximo da unidade, chamado fator de Gaunt.

Na radiação síncrotron, a aceleração é devida á partículas carregadas que giram ao redor das linhas do campo magnético. A maior contribuição é devida aos elétrons e o espectro de radiação é composto de harmônicos da frequência ciclotônica.

A radiação síncrotron é calculada inicialmente tomando-se a expressão geral para a emissão:

$$
\frac{d U}{d t}=\frac{e^{4} v_{\perp}^{2} B^{2}}{6 \pi \varepsilon_{0} c^{3} m^{3}\left(1-\beta^{2}\right)}
$$


onde $\beta$ é $v / c$. A emissão total para um plasma em equilíbrio térmico é obtida desta equação integrando-se sobre a distribuição Maxwelliana. O resultado é [2]:

$P_{c}=6.2 \times 10^{-20} B^{2} n_{e} T_{e}\left[1+4.88 \times 10^{-6} T_{e}+\ldots\right] \quad\left(W / m^{3}\right)$.

Esta equação descreve o resultado para um plasma opticamente fino. No caso de o plasma ser opticamente espesso, a quantidade emitida decresce devido a absorção. Assim, a expressão acima deve ser entendida como um limite superior para a emissão considerada. A radiação síncrotron emitida por um plasma de tokamak (Campo Magnético Toriodal $\sim 3 T$, densidade eletrônica $\sim 5 \times 10^{19} \mathrm{~m}^{-3}, T_{e} \sim 1000 \mathrm{eV}$ ) é extremamente pequena comparada com outros tipos de radiação.

A radiação de recombinação ocorre quando um elétron se recombina com um íon. Uma vez que o nível quântico superior é contínuo, o espectro da radiação emitida também o será. Contudo, algumas estruturas estão presentes devido á natureza discreta dos níveis de baixa energia. Para um elétron de massa $m$ e velocidade $\mathrm{v}$, a recombinação no estado $p$ fornece:

$h v_{p}=E(\infty)+\frac{1}{2} m v^{2}-E(q)$

onde $E(\infty)$ representa o limite de ionização. Quando a função de distribuição das velocidades eletrônicas é Maxwelliana, um calculo clássico fornece a dependência do espectro com a frequência segundo $\exp \left(-h v / T_{e}\right)$. A expressão para radiação de recombinação é dada por:

$$
P_{r}=1.69 \times 10^{-26} n_{e} T_{e}^{1 / 2} \sum_{i}\left\{n_{i} Z_{i}^{2}\left[\frac{E^{Z_{i}-1}(\infty)}{T_{e}}\right]\right\} \quad\left(W / m^{3}\right)
$$

A radiação de linhas ocorre para transições eletrônicas entre os níveis quânticos discretos, fornecendo um espectro discreto. Quando ocorre uma transição entre o nível de 
número quântico principal $p$ com energia $E(p)$ para o nível $q$ com energia $E(q)$, a frequência da radiação emitida $v_{p q}$ é expressa por:

$$
h v_{p q}=E(p)-E(q)
$$

Para as transições permitidas, as regras de seleção usuais utilizadas na espectroscopia são utilizadas.

A potência total irradiada devido à presença de impurezas é calculada a partir de taxas de ionização, recombinação e excitação. A população dos estados excitados é obtida utilizando-se o modelo corona, uma aproximação frequentemente utilizada em vários tokamaks. Neste modelo, a excitação e ionização são devidas às colisões com elétrons no estado fundamental.

O decaimento ocorre somente através da emissão de radiação, incluindo também a recombinação dieletrônica. Cálculos explícitos das taxas de emissão radiativas foram feitos [3-5] para o equilíbrio corona. Os resultados relativos ao Carbono, Oxigênio e Ferro, impurezas encontradas com maior frequência em plasmas de tokamak são mostradas na figura 2.1.[3]

A contribuição devida ao Bremsstrahlung é bastante pequena para temperaturas menores que $1000 \mathrm{eV}$.

Nota-se que a radiação de linhas para o Ferro é dominante no processo de radiação. A emissão radiativa total do plasma é obtida através da expressão:

$$
P=n_{e} n_{i m p} L\left(T_{e}\right)
$$

onde $L\left(T_{e}\right)$ é a taxa de emissão radiativa. A densidade de impurezas pode ser avaliada através do diagnóstico bolométrico utilizando-se esta equação. 
$O$ estado de ionização efetivo $Z_{\text {eff }}$ dado pela equação (2.3) fornece a informação necessária para a determinação da densidade de impurezas. O estado de ionização efetivo relaciona-se com a temperatura eletrônica $T_{e}$, tensão de enlace e corrente de plasma através da resistividade $\eta$ segundo a expressão:

$\eta=1.03 \times 10^{-4} \frac{Z_{e f f} \ln \Lambda}{T_{e}^{3 / 2} f_{T}}\left(\frac{0.457}{1.077+Z_{\text {eff }}}+0.29\right)$

onde $\ln \Lambda$ é o logaritmo Coulombiano, $f_{T}$ é uma correção para os elétrons aprisionados. $O$ valor de $Z_{\text {eff }}$ assim obtido é representativo da região central da coluna de plasma $(r<a / 2)$ porque praticamente toda a corrente de plasma flui através desta região.

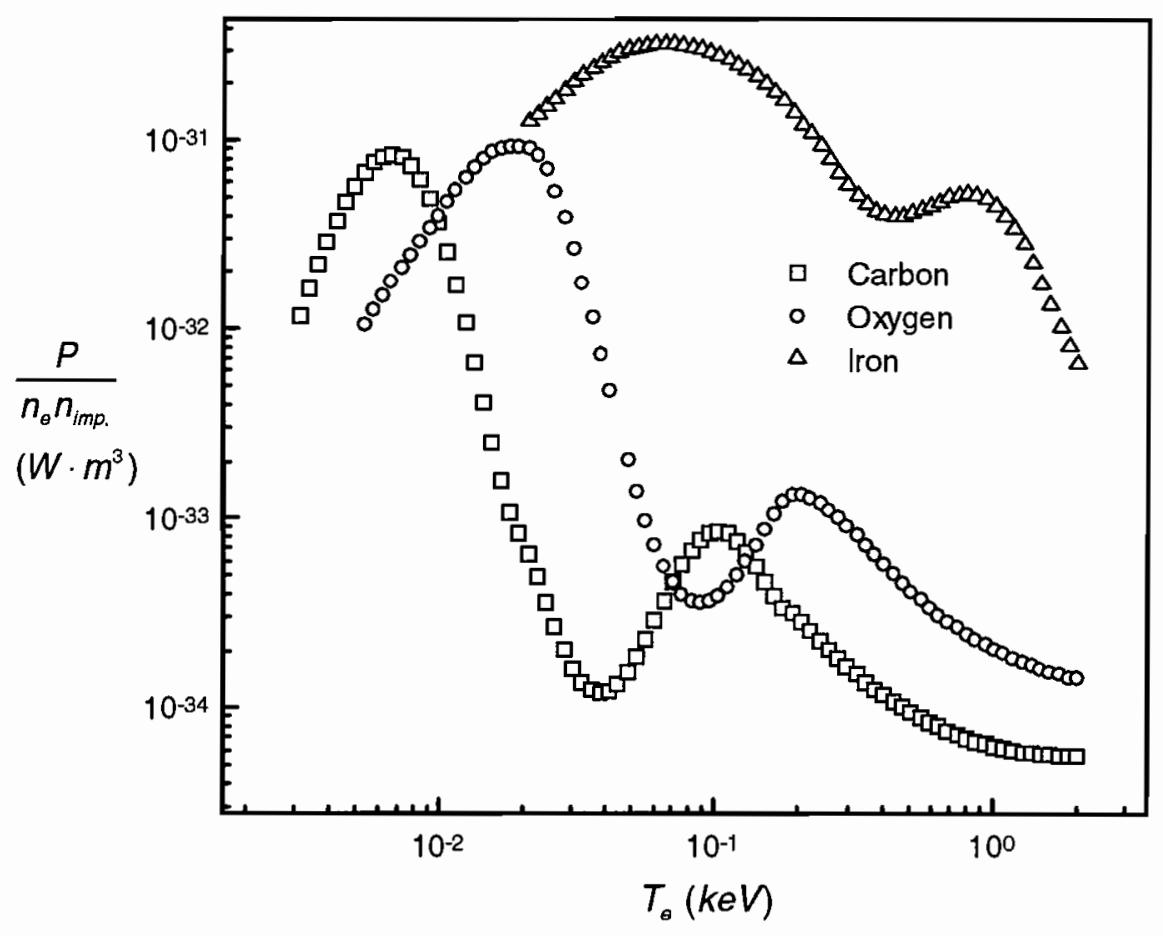

Fig. 2.1 Taxa de Emissão Radiativa para as impurezas mais frequentemente encontradas em tokamaks.[4] 


\section{Capítulo 3}

\subsection{Teoria Geral do Bolômetro}

Tendo descrito as características da radiação emitida pelo plasma, coloca-se então o problema de efetivamente medir sua magnitude. A radiometria é a ciência cujo objetivo é determinar a quantidade de energia radiante[1], e dela faremos uso para nossos propósitos.

O formalismo adequado ao estudo do transporte da energia pelos campos eletromagnéticos depende bastante do grau de coerência da radiação. A energia emitida pode ser classificada como totalmente coerente, parcialmente coerente ou incoerente. As ondas planas descritas pelo eletromagnetismo clássico são um exemplo de radiação totalmente coerente, uma vez que sua fase e amplitude são bem determinados em todo o espaço por onde se propagam. Conhecidas as magnitudes dos campos elétrico e magnético, as propriedades radiométricas da radiação totalmente coerente podem ser obtidas pelo calculo do vetor de Poynting e da densidade de energia eletromagnética.

O problema tradicional da radiometria, contudo, é estudar o fluxo de radiação essencialmente incoerente. Fontes térmicas, por exemplo, emitem radiação incoerente. Neste caso, a amplitude e a fase dos campos eletromagnéticos flutuam randomicamente através do espaço. Isto ocorre devido a independência com que cada elemento constituinte da fonte térmica emite radiação. O campo resultante nas proximidades da fonte é a superposição de uma enorme quantidade de ondas independentes, que se combinam de forma estocástica.

As leis da radiometria tradicional são baseadas em alguns princípios. O primeiro, que acabamos de discutir, diz respeito à incoerência da radiação. Devemos ainda impor que a propagação da energia pelo espaço se dá segundo as normas da ótica geométrica. Em particular, este transporte ocorre ao longo de raios retilíneos. Assim, ao longo deste trabalho vamos considerar desprezíveis os efeitos de interferência ou difração, pois sua presença 
implica em fluxo energético em outras direções que não as dos raios da ótica geométrica. Neste capítulo vamos derivar as equações gerais que descrevem as medições de radiação do bolômetro, utilizando os fundamentos da radiometria.

\subsection{Geometria}

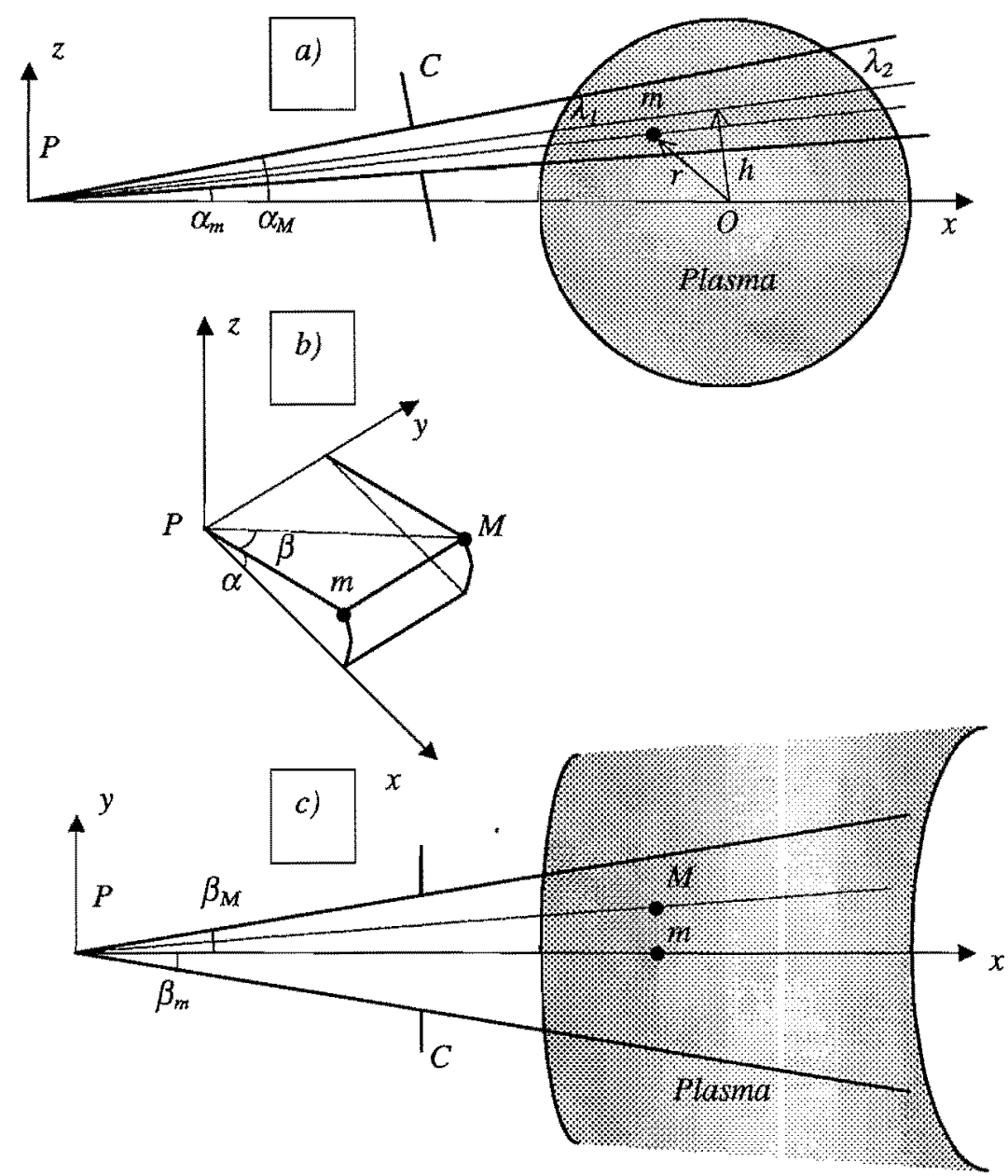

Fig. 3.1 Esquema mostrando o posicionamento relativo entre o detector $P, 0$ colimador $C$ e a coluna de plasma. 
A intensidade do sinal medido pelo bolometro deve ser calculada em função da radiação do plasma e, para tanto adota-se uma geometria esférica

Um ponto qualquer $M$ no interior da coluna de plasma irradia com uma densidade de potência $W(M)$. O detector encontra-se a uma certa distância fora da coluna, no ponto $P$, conforme mostrado na figura 3.1(a) e 3.1(b). A projeção de $M$ sobre o plano $x z$ é indicada pelo ponto $m$.

O ângulo sólido sob o qual o ponto $M$ vê o detector é igual a $S \cos (\alpha) \cos (\beta) / \overline{M P}^{2}$, onde $S$ representa a área da superfície do detector, $\alpha$ e $\beta$ são ângulos definidos na figura 3.1(b) e 3.1(c). No local do detector é medido o fluxo da potência irradiada $E_{P}(M)$ por unidade de área assumindo radiação isotrópica[2], dada por:

$E_{P}(M)=\frac{W(M)}{4 \pi \overline{M P}^{2}} \cos (\alpha) \cos (\beta)$

O fluxo total $E_{P}$ medido em $P$ é obtido integrando-se a equação (3.1) no volume de plasma visível pelo bolômetro, isto é:

$$
\begin{aligned}
& E_{P}=\int_{\text {VOLUME }} E_{P}(M) d v \\
& E_{P}=\frac{1}{4 \pi} \int_{\lambda_{1}}^{\alpha_{\alpha_{m}}^{\alpha_{M}}} \int_{\beta_{m}}^{\beta_{M}} W(M) \cos (\alpha) \cos (\beta) d \beta d \alpha d \lambda
\end{aligned}
$$

Aqui, o colimador $C$ define os limites $\alpha_{m}, \alpha_{M}, \beta_{m}, \beta_{M}$ e fizemos ainda $\overline{M P}=\lambda$. 
Assumimos agora que $W(M)$ depende somente da distância do ponto $M$ ao eixo da coluna de plasma (raio da coluna), e que existe uma simetria com respeito ao plano $x z$, ou seja, $\beta_{m}=-\beta_{M}$. No apêndice $\mathrm{B}$ estão listados os valores das constantes geométricas empregadas no projeto do sistema bolométrico instalado no tokamak TCABR.

A superfície do bolômetro está localizada no plano yz. É claro que as dimensões do colimador irão determinar a resolução espacial desejada do plasma observado. Porém o limite inferior para esta resolução não é mais uma questão geométrica, mas sim a "potência equivalente de ruído"(NEP) do detector bolométrico.

A equação (3.2) é genérica e é valida para qualquer ângulo $\alpha$ ou $\beta$. Ocorre que para o projeto do sistema bolométrico instalado no TCABR, uma simplificação nesta equação é possível e ao mesmo tempo bem vinda. Trata-se de tornar a abertura $\Delta \alpha$ pequena de maneira que o termo $\cos (\alpha)$ no integrando de (3.2) possa ser uma constante de integração. A abertura $\Delta \alpha$ significa explicitamente a diferença $\alpha_{M}-\alpha_{m}$. Utilizando este procedimento, a expressão para o fluxo da potência irradiada total $E_{P}$ será:

$E_{P}=\frac{\operatorname{sen}\left(\beta_{M}\right)}{2 \pi} \cos (\alpha) \Delta \alpha \int_{\lambda_{1}}^{\lambda_{1}} W(\lambda) d \lambda$

A expressão sob a integral nesta expressão é caracterizada como a integral de linha $d a$ radiação $I(h)$, a uma distância $h$ do eixo da coluna de plasma, conforme mostrado na figura 3.1(a). Como o detector é pequeno, pode-se assumir que toda sua superfície recebe a mesma intensidade de radiação.

Através da relação (3.3) a integral de linha $I(h)$ pode ser relacionada com o fluxo medido pelo detector para a corda correspondente: 


$$
I(h)=\frac{2 \pi E_{P}}{\operatorname{sen}\left(\beta_{M}\right) \cos (\alpha) \Delta \alpha}
$$

Conhecendo-se o valor de $I(h)$ para vários valores da distância $h$ é possível obter a Emissividade local $W(r)$. O procedimento matemático envolvido neste calculo é a chamada inversão de Abel e será por nós empregada no decorrer deste trabalho.

\subsection{A Inversão de Abel}

Em física de plasmas é frequente a necessidade de conhecermos o perfil radial de uma grandeza a partir de medidas experimentais obtidas em algumas direções de observação da coluna de plasma. Este perfil é obtido através da inversão de Abel.

Esta ferramenta matemática assume que existe simetria cilíndrica da grandeza estudada. Ela é também o que os matemáticos chamam de "problema mal posto", isto é, pequenas variações nos dados de entrada provocam grandes variações no resultado final. Assim é necessário algum conhecimento adicional do comportamento da grandeza em questão para a obtenção de uma resposta confiável.

Uma discussão mais aprofundada desta ferramenta pode ser encontrado na referência [3]. Para os propósitos deste trabalho, vamos agora brevemente sintetizar o problema de Abel.

A figura 3.2 mostra uma seção da coluna de plasma de raio $a$ onde uma medida experimental $I(h)$ é realizada. Esta medida se relaciona com o perfil radial $W(r)$ da grandeza estudada da seguinte maneira: 


$$
I(h)=\int_{-\sqrt{a^{2}-y^{2}}}^{\sqrt{a^{2}-y^{2}}} W(r) d x
$$

Podemos observar que a coordenada radial $r$ se relaciona com as coordenadas ortogonais da maneira usual, ou seja $r^{2}=x^{2}+h^{2}$. Portanto temos que

$$
d x=\frac{r d r}{\left(r^{2}-h^{2}\right)^{1 / 2}}
$$

Substituindo a equação (3.6) na (3.5) temos:

$$
I(h)=2 \int_{y}^{a} W(r) \frac{r d r}{\left(r^{2}-h^{2}\right)^{1 / 2}}
$$

A inversão de Abel afirma que o perfil radial $W(r)$ é dado por: 
$W(r)=-\frac{1}{\pi} \int_{r}^{a} \frac{d I}{d h} \frac{d h}{\left(h^{2}-r^{2}\right)^{1 / 2}}$

Para ser utilizada na obtenção da potência total irradiada nas descargas do tokamak TCABR, a inversão de Abel é resolvida numericamente. Os dados experimentais $I(h)$ são aproximados por um polinômio de grau 5-7. É feita ainda a imposição de que $I(h)$ é nulo para $r>a$.

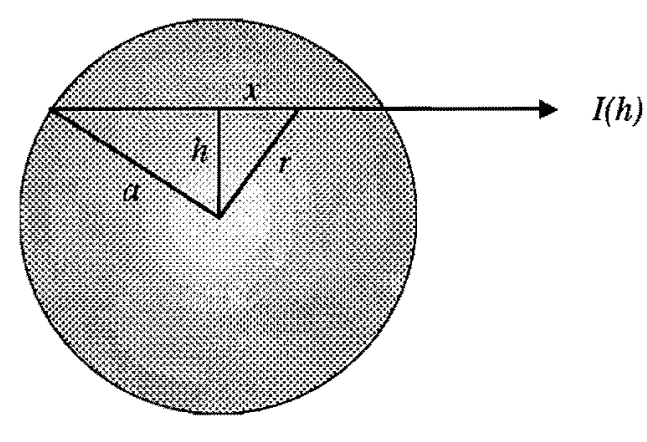

Fig. 3.2 Seção Transversal da coluna de plasma mostrando os parâmetros geométricos envolvidos na inversão de Abel.

\subsection{Referências}

[1] Robert W. Boyd; "Radiometry and the Detection of Optical Radiation", John Wiley \& Sons; New York, (1983) 
[2] "Bolometrische Messungen des Strahlungsverlustes am Tokamak TCA - Fakultät der Universität Freiburg in der Schweiz"- S. Nowak- LPR 300/86 -Dissertação de Mestrado -(1986).

[3] J. H. Hutchinson, "Principles of plasma Diagnostic", Cambridge University Press, EUA, (1987) 


\section{Capítulo 4}

\subsection{Detectores}

A medida da potência total irradiada pelo plasma é geralmente feita utilizando-se detectores térmicos principalmente porque sua sensibilidade é independente do comprimento de onda da radiação incidente, embora sejam bastante lentos.

Recentemente novos avanços tecnológicos [1-2] tornaram possível a confecção de detectores fotônicos (fotodiodos) capazes de operar em uma faixa bastante larga do espectro eletromagnético(1-6000 eV). Esta nova característica associada a já popular rapidez deste tipo de dispositivo tornou possível sua utilização nas pesquisas em física de plasmas. Contudo, a sensibilidade dos fotodiodos sofre alguma variação dependendo da região do espectro observada. Em nosso tokamak, o TCABR, utilizamos ambos os detectores. $\mathrm{O}$ detector térmico utilizado é um bolômetro e o detector fotônico é um sistema de fotodiodos. Vamos agora fazer uma descrição mais detalhada de cada um deles.

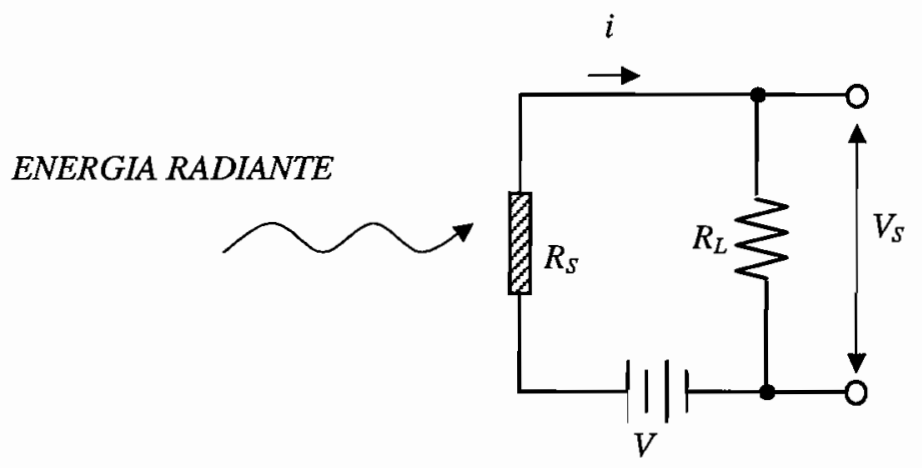

Fig. 4.1 Diagrama simplificado do bolômetro para medida de energia radiante. 


\subsection{Bolômetro Resistivo}

\subsubsection{Principio de Operação}

O bolômetro consiste de um metal ou semicondutor em formato capilar, conforme mostrado na figura 4.1[3]. A radiação incidente provoca um aumento em sua temperatura, o que produzirá uma mudança em sua resistência elétrica. A variação na resistência provocará uma alteração na corrente elétrica que flui pelo bolômetro devido à voltagem de polarização $V$. Como esta corrente é igual a que flui pelo resistor $R_{L}$, vamos detectar uma mudança $\Delta V S$ sobre esta resistência. Esta mudança na voltagem sobre $R_{L}$ é o sinal eletrônico de saída do bolômetro.

Quando nenhuma energia radiante incide sobre o material sensor, o aquecimento do material devido á voltagem de polarização $V$ é balanceada pela dissipação através dos terminais do bolômetro e também por radiação térmica. Isto pode ser expresso da seguinte forma:

$d / d t(\Delta Q)=K \Delta T-i^{2} R_{S}$

onde $d / d t(\Delta Q)$ é a potência perdida pelo sensor, $\Delta T$ a diferença de temperatura entre o sensor e o meio ambiente, $K$ é a condutância térmica, $i$ a corrente devido à voltagem de polarização e $R_{S}$ a resistência elétrica do material sensor na ausência de energia incidente. Esta resistência depende da temperatura segundo a expressão: 
$R_{S}=R_{0}(1+\alpha \Delta T)$

onde $R_{0}$ é a resistência do material quando $\Delta T$ é nulo, e $\alpha$ o coeficiente resistênciatemperatura. Em metais $\alpha$ é positivo, mas em semicondutores é negativo.

Se agora fazemos incidir energia radiante sobre o bolômetro, sua resistência elétrica $R_{S}$ sofrerá uma variação. Se supusermos que a energia radiante é da forma $\Delta \Phi(t)=\Delta \Phi \exp (2 \pi j f t)$ e utilizando o resultado tomado da termodinâmica $\Delta Q=C_{T} \Delta T$, a solução da equação 4.1 será:

$\Delta T=\Delta \Phi /\left[K^{2}+\left(2 \pi f C_{T}\right)^{2}\right]^{1 / 2}$

onde $\Delta \Phi$ é a potência radiante absorvida e $C_{T}$ a capacidade térmica do sensor.

Analisando o circuito da figura 4.1 é fácil concluir que:

$$
\begin{aligned}
& \Delta V_{S}=R_{L} \Delta i \\
& \Delta i=\left(-i / R_{L}\right) \Delta R_{\mathcal{S}} \quad R_{L} \gg R_{S} \\
& \Delta R_{S}=R_{0} \alpha \Delta T
\end{aligned}
$$


Substituindo estas expressões na equação (4.3) obtemos a expressão para a voltagem de saída do bolômetro:

$$
\Delta V_{S}=i R_{0} \alpha \Delta \Phi /\left[K^{2}+\left(2 \pi f C_{T}\right)^{2}\right]^{1 / 2}
$$

A sensibilidade do bolômetro, que é a razão entre a tensão de saída e a potência radiante absorvida será então:

$$
R=\Delta V_{S} / \Delta \Phi=i R_{0} \alpha /\left[K^{2}+\left(2 \pi f C_{T}\right)^{2}\right]^{1 / 2}
$$

A sensibilidade do bolômetro em baixas frequiências $\left(f<<1 / 2 \pi\left(C_{T} / K\right)\right)$ será $R=i R_{0} \alpha / K$. Portanto a sensibilidade aumenta ao operarmos com um alto coeficiente resistência-temperatura, alta resistência do material sensor $R_{0}$, e baixa condutância térmica $K$. Embora pareça que devamos utilizar também um alto valor da corrente $i$, na verdade existe um valor ótimo de corrente para se operar.

Notamos que a sensibilidade em baixas freqüências não depende da capacidade térmica do material sensor. Contudo, a frequiência de corte para operação do bolômetro é de acordo com a equação (4.6):

$f_{\max }=1 / 2 \pi\left(C_{r} / K\right)$ 
que depende diretamente de $C_{T}$. Para maximizar $f_{\max }$ a capacidade térmica $C_{T}$ deve ser minimizada. Isto implica que para uma boa performance, o material sensor deve possuir pouca área e espessura.

\subsubsection{O Bolômetro utilizado no TCABR}

O bolômetro utilizado em nosso laboratório possui a estrutura básica descrita acima e ainda apresenta um refinamento em seu projeto. Detalhes completos de sua estrutura podem ser encontrados em [4].Neste dispositivo, a potência radiante é inicialmente absorvida por uma fina camada de ouro separada do material sensor através do qual fluirá a

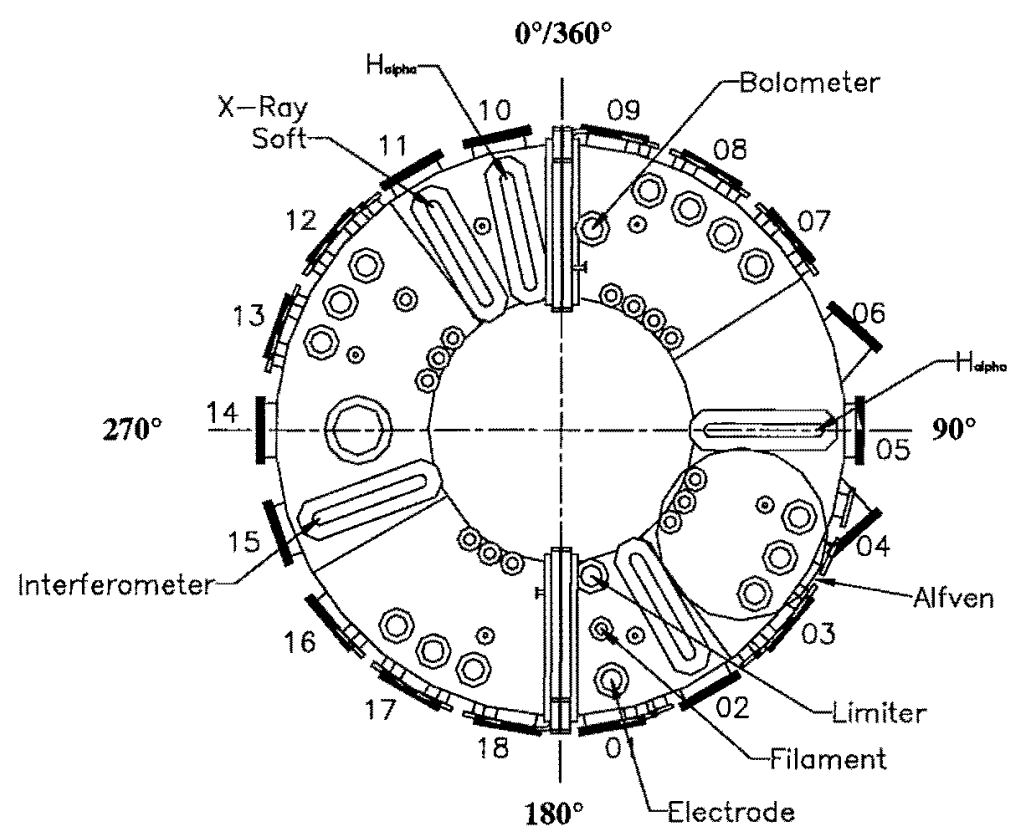

\section{Top View}

Fig. 4.2 Vista superior da câmera do tokamak TCABR mostrando a localização do bolômetro, bem como outros diagnósticos. 
corrente elétrica de polarização. Esta separação é feita por uma fina folha de kapton. Isto evita a direta exposição do material sensor (também feito em ouro) ao plasma, evitando efeitos danosos ao sensor. Os parâmetros de interesse deste dispositivo estão listados na tabela abaixo.

Tab. 4.1 Parâmetros do bolômetro utilizado no TCABR.

\begin{tabular}{|ll|}
\hline capacidade térmica $C_{T}$ & $0.0022 \mathrm{~J} / \mathrm{K}$ \\
condutância térmica $K$ & $0.011 \mathrm{~W} / \mathrm{K}$ \\
coeficiente resistência-temperatura $\alpha$ & $0.0027 \mathrm{~K}^{-1}$ \\
resistência elétrica $R_{0}$ & $4700 \Omega$ \\
\hline
\end{tabular}

Inicialmente o sensor foi montado em uma das janelas superiores do tokamak, de modo a observar a região central da coluna de plasma, conforme a figura 4.2 .

Para que pudéssemos coletar o sinal produzido pelo bolômetro nas descargas do tokamak TCABR, uma eletrônica foi especificamente projetada e implementada [4]. Este circuito fornecia em sua saída um sinal proporcional ao incremento de temperatura no bolômetro (evolução temporal). Após um ajuste por um polinômio de grau sete, o sinal era introduzido na equação 4.1 para obtenção da potência absorvida pelo sensor.

\subsection{Fotodiôdos}

\subsubsection{Princípio de Operação}

A figura 4.3(a) mostra um corte transversal da estrutura de um fotodiodo[5]. A camada semicondutora $\mathrm{P}$, onde se localiza a superfície ativa do dispositivo é disposta sobre a camada semicondutora $\mathrm{N}$ no substrato, formando a chamada junção $P N$. Esta junção funciona como um conversor fotoelétrico. A camada $\mathrm{P}$ do fotodiodo de silício é formada 
pela difusão de Boro até uma espessura de aproximadamente $1 \mu \mathrm{m}$ e a região neutra entre as camadas $\mathrm{P}$ e $\mathrm{N}$ é conhecida como a camada de depleção. Controlando-se a espessura da camada $\mathrm{P}$ externa, do substrato $\mathrm{N}$, bem como a quantidade de Boro empregada, a velocidade

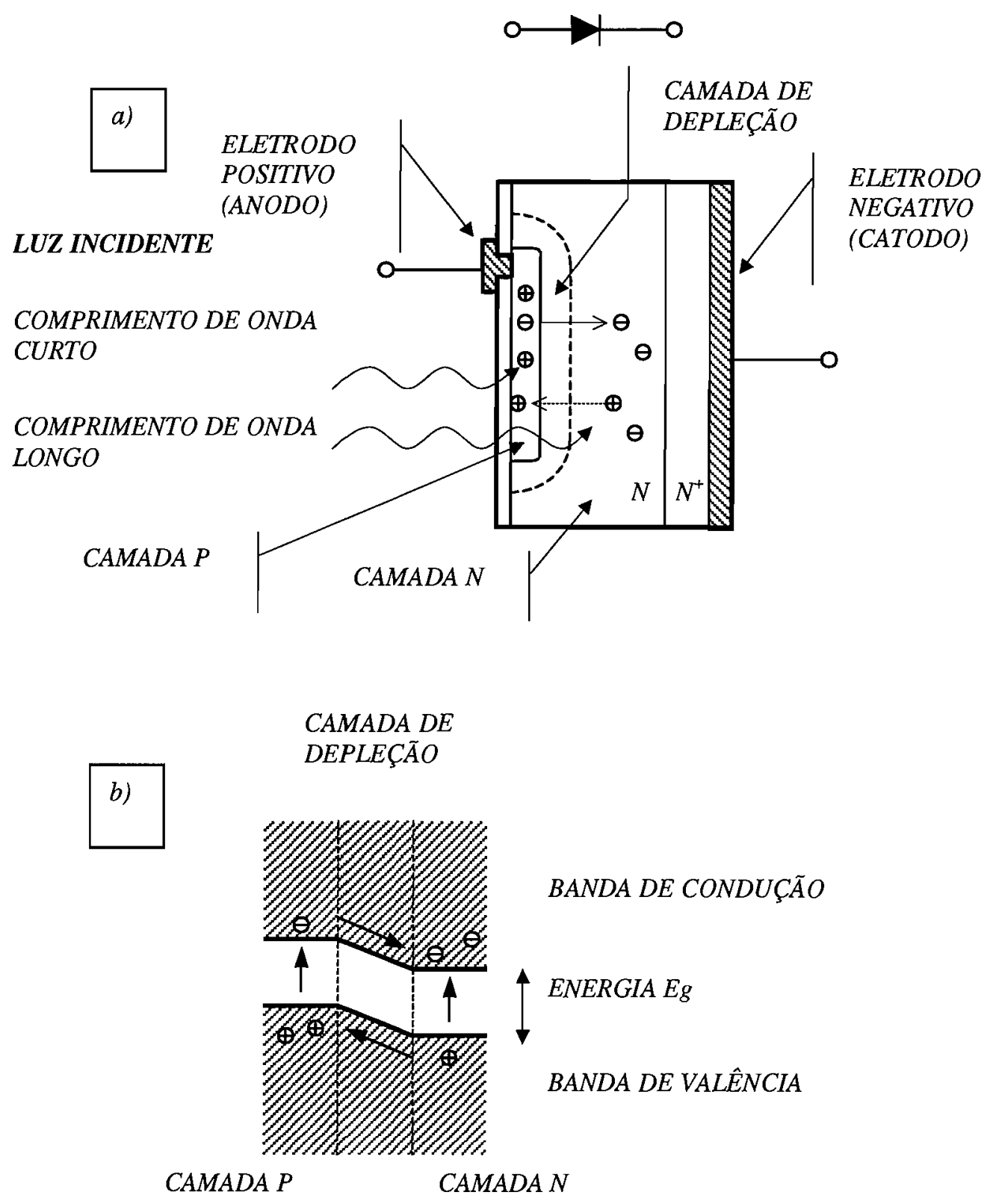

Fig. 4.3 Estrutura interna de um fotodiôdo 
e a resposta espectral do dispositivo podem ser controladas.

Quando os fótons atingem o fotodiodo, os elétrons na estrutura cristalina ficam excitados. Se a energia dos fótons for maior que um determinado valor $E_{g}$, os elétrons serão excitados até a camada de condução, deixando "lacunas" na camada de valência, conforme mostrado na figura 4.3(b). Estes pares elétron-lacuna se formam na camada semicondutora $P$, na camada de depleção e na camada semicondutora N. Na camada de depleção, o campo elétrico existente na junção acelera os elétrons na direção da camada $\mathrm{N}$, e as lacunas na direção da camada P. A quantidade de pares elétron-lacuna gerados é proporcional à quantidade de energia radiante absorvida. Este movimento de portadores provoca o acúmulo de carga positiva na camada $\mathrm{P}$ e de carga negativa na camada $\mathrm{N}$. Se um circuito externo é conectado entre as camadas $\mathrm{P}$ e $\mathrm{N}$, uma corrente elétrica será detectada nesta conexão.

\subsubsection{Circuito Equivalente}

O circuito equivalente do fotodiôdo é mostrado na figura 4.4 .

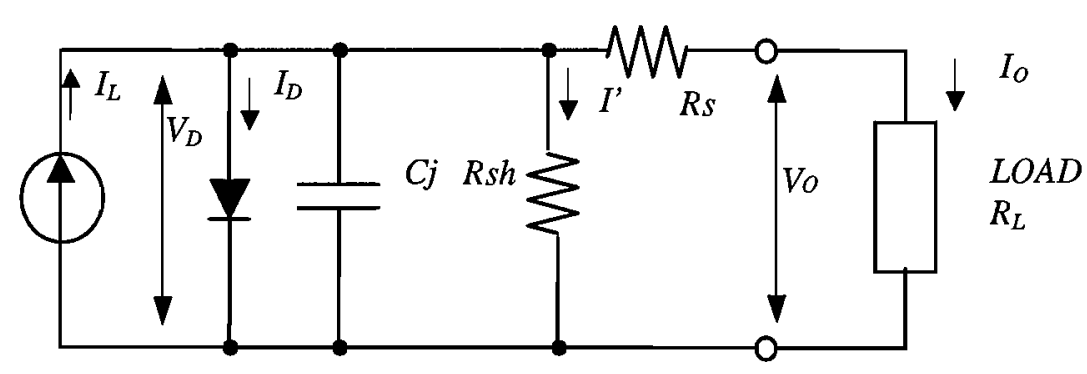

Fig. 4.4 Circuito equivalente do fotodiôdo conectado a uma carga resistiva. 
onde:

$I_{L^{-}}$corrente gerada pela luz incidente

$I_{D^{-}}$corrente no diodo

$C_{j}$ - capacitância da junção

$R_{s h}$ - resistência Shunt

$R_{S-}$ resistência de saída

$I^{\prime}$ - corrente pela resistência Shunt

$V_{D^{-}}$diferença de potencial sobre o diodo

Io- corrente de saída

$V_{0^{-}}$diferença de potencial na saída

Uma análise da figura 4.4 mostra que a corrente elétrica de saída $I_{O}$ é dada por:

$I_{o}=I_{L}-I_{D}-I^{\prime}=I_{L}-I_{S}\left(\exp \left(\frac{e V_{D}}{k T}-1\right)\right)-I^{\prime}$ 
onde:

$I_{S^{-}}$corrente de saturação do fotodiôdo

e- carga do elétron

$k$ - constante de Boltzmann

$T$ - temperatura absoluta do fotodiôdo

A tensão de saída em circuito aberto $V_{O C}$ é obtida fazendo-se $I_{O}$ igual a zero. Assim:

$V_{O C}=\frac{k T}{e} \ln \left(\frac{I_{L}-I^{\prime}}{I_{S}}\right)+1$

Assim, $V_{O C}$ é proporcional ao logaritmo da corrente $I_{L}$.

A corrente de curto-circuito $I_{S C}$ é a corrente de saída quando a resistência de carga $R_{L}$ tem um valor nulo. Pela equação (4.8) temos que esta corrente vale: 


$$
I_{S C}=I_{L}-I_{S}\left(\exp \left(\frac{e\left(I_{S C} R_{S}\right)}{k T}-1\right)\right)-\frac{I_{S C} R_{S}}{R_{s h}}
$$

Nesta expressão, o segundo e terceiro termo limitam a linearidade de $I_{S C}$. Contudo, como $R_{S}$ em geral vale algumas dezenas de ohms e $R_{s h}$ entre $10^{7}$ a $10^{11} \Omega$, estes termos são desprezíveis para uma extensa faixa de valores da corrente $I_{S C}$.

\subsubsection{Característica Corrente $\times$ Voltagem}

Quando uma diferença de potencial é aplicada aos terminais do fotodiodo sem incidência de luz, a curva corrente-voltagem observada é similar à curva de um diodo retificador comum conforme mostrado na figura 4.5. Porém, quando a luz incide sobre ele, esta curva sofre um deslocamento no sentido negativo do eixo de corrente. Este deslocamento é proporcional à intensidade de luz observada. Se, nestas condições ligarmos os terminais do dispositivo, uma corrente elétrica vai fluir, na direção do anôdo para o

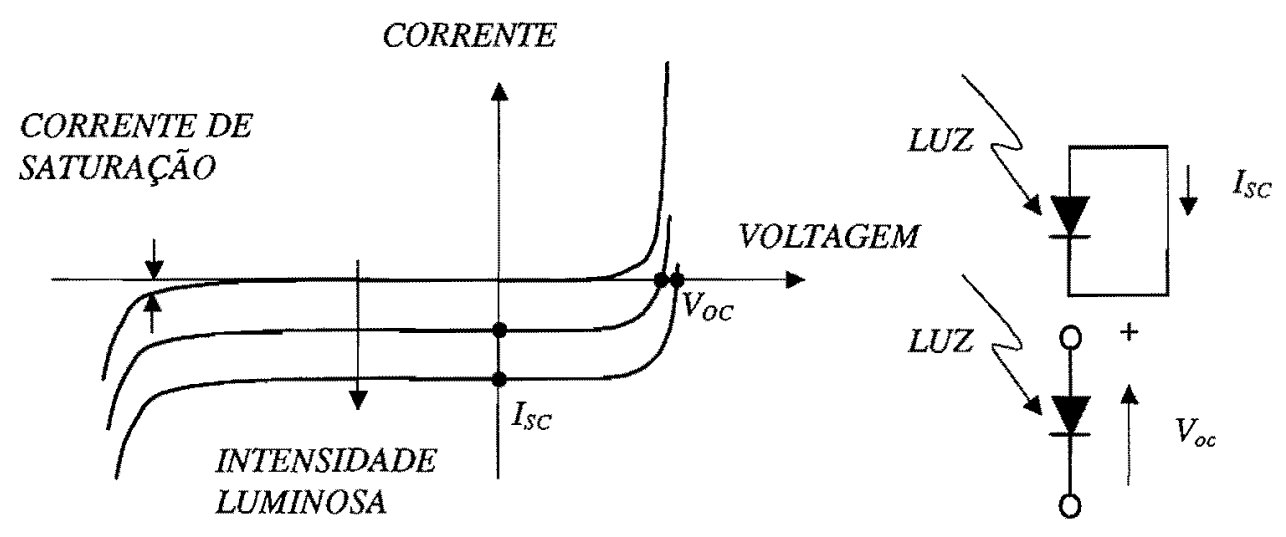

Fig. 4.5 Característica corrente-voltagem do fotodiodo. 
catodo. Se o circuito estiver aberto, uma diferença de potencial $V_{O C}$ irá surgir, com a polaridade positiva no anodo.

A corrente de curto-circuito $I_{S C}$ é extremamente linear com relação à intensidade de luz incidente. Quando esta intensidade se situa na faixa $10^{-12}$ a $10^{-2} \mathrm{~W}$ esta linearidade se estende por mais de nove ordens de magnitude, dependendo do tipo de fotodiodo e de seus circuitos associados.

O limite inferior desta linearidade é dado pelo parâmetro NEP(noise equivalent power), enquanto o nível superior pela resistência de carga $R_{L}$ e a tensão reversa de polarização. A expressão pertinente para o limite superior é dada por:

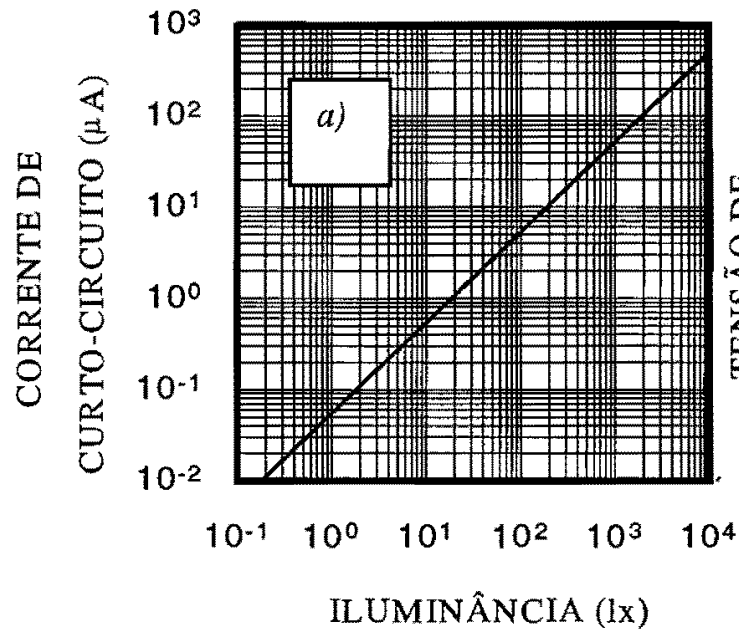

Fig. 4.6 Sinal de saída vs. Energia radiante incidente (a) corrente de curto circuito e (b) voltagem de circuito aberto.

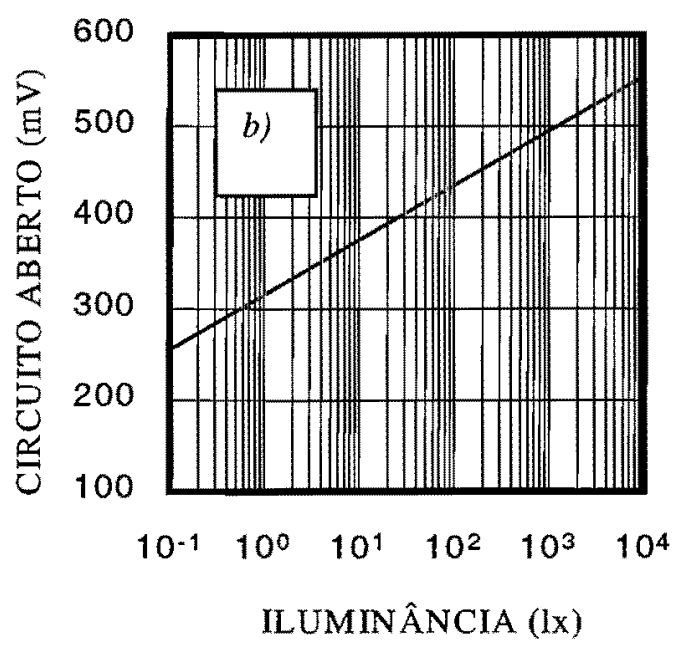

$P_{s a t}=\frac{V_{B i}+V_{R}}{\left(R_{S}+\dot{R}_{L}\right) S_{\lambda}}$ 
onde:

$P_{\text {sat }}$ Energia incidente (W), $P_{\text {sat }}<10 \mathrm{~mW}$

$V_{B i^{-}}$voltagem de contato $(0.2-0.3 V)$

$V_{R^{-}}$tensão reversa(V)

$R_{L^{-}}$resistência de carga $(\Omega)$
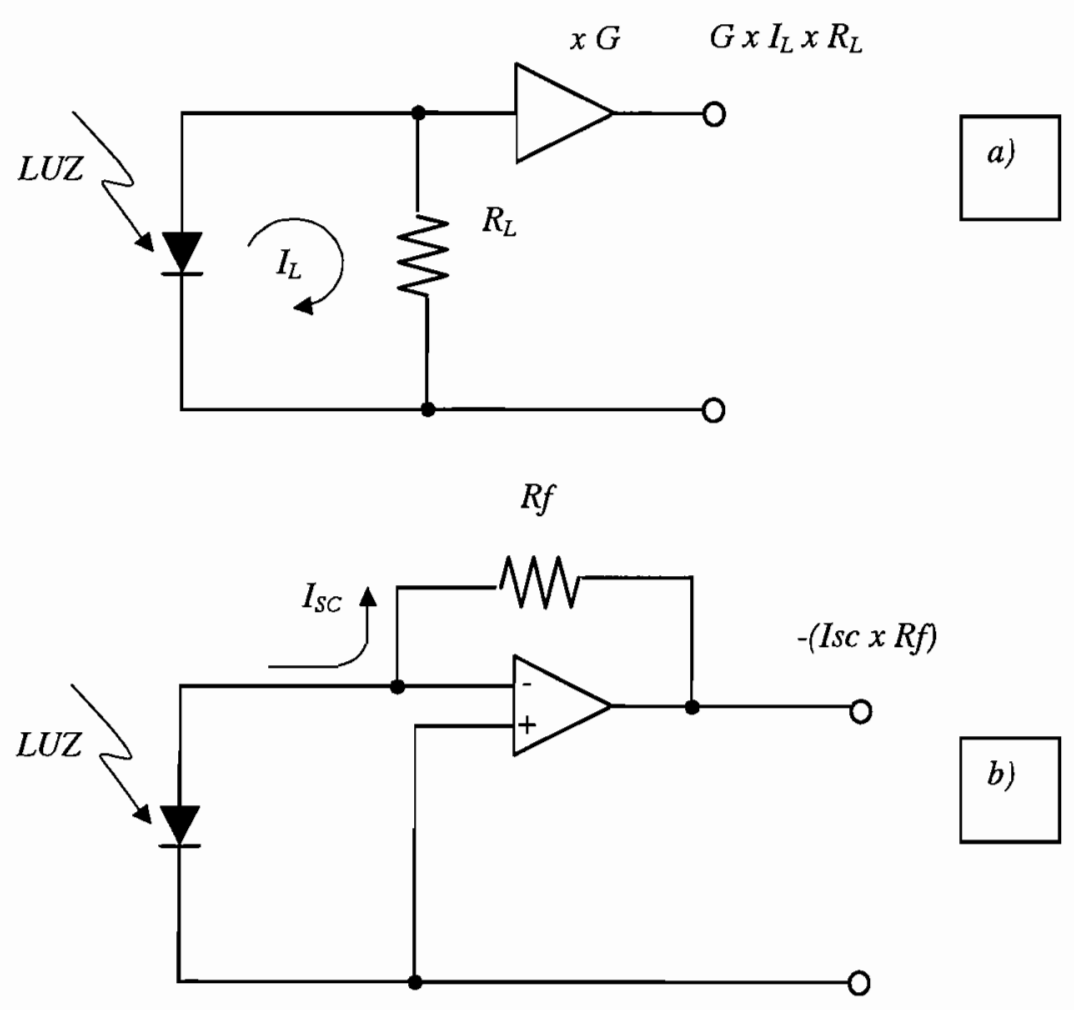

Fig.4.7 Possíveis configurações de operação do fotodiodo (a) com uma resistência de carga e (b) com um amplificador operacional. 


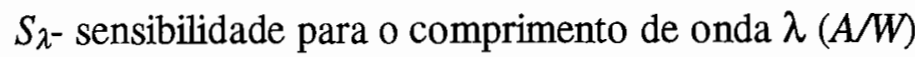

$R_{S^{-}}$resistência em série (dezenas de $\Omega$ )

Contudo, quando o fotodiodo é iluminado por um pequeno ponto de luz laser, a resistência série $R_{S}$ aumenta, deteriorando a linearidade. A tensão de curto-circuito $V_{O C}$ varia de forma logarítmica com a intensidade luminosa além de depender fortemente da temperatura ambiente, tornando-a inútil para medidas de intensidade luminosa. A figura 4.6 mostra o comportamento de $I_{S C}$ e $V_{O C}$ como função da iluminância da luz incidente.

A figura 4.7(a) e (b) mostra alguns métodos de medida da intensidade luminosa através da medida da corrente eletrônica $I_{L}$ ou $I_{S C}$.

No circuito mostrado em (a), a voltagem $\left(I_{L} \times R_{L}\right)$ é amplificada a um ganho $G$, embora tal configuração possua limitações na linearidade, conforme equação (4.11). Esta condição é mostrada na figura 4.8. A figura 4.7(b) é um circuito utilizando um amplificador operacional em uma configuração que apresenta impedância de entrada nula. Portanto esta montagem conserva a linearidade nas medidas por uma larga faixa da intensidade luminosa

\section{CORRENTE}

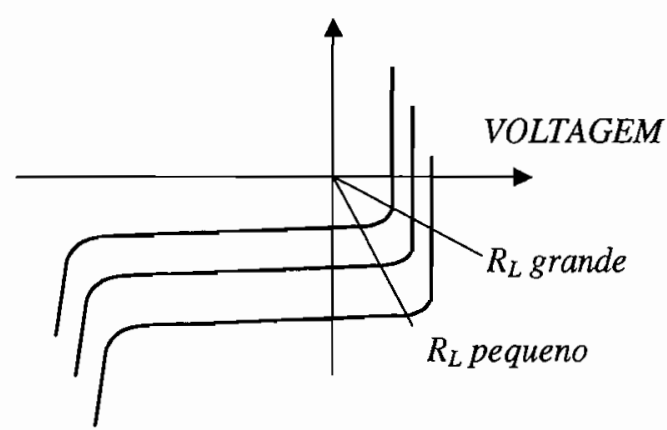

Fig. 4.8 Característica corrente vs. voltagem e linhas de carga para valores altos e baixos da carga $\mathbf{R}_{\mathbf{L}}$. 
incidente, bastando-se ajustar o resistor $R_{f}$.

\subsubsection{O Sistema de Fotodiodos utilizado no TCABR}

O sensor a ser utilizado no experimento é o fotodiodo semicondutor. Foi escolhido com base em recentes avanços na área de deposição de silício, fabricado pela International Radiation Detectors. A baixa taxa de recombinação na junção p-n permite que estes dispositivos sejam sensíveis em uma larga faixa do espectro eletromagnético. A única queda

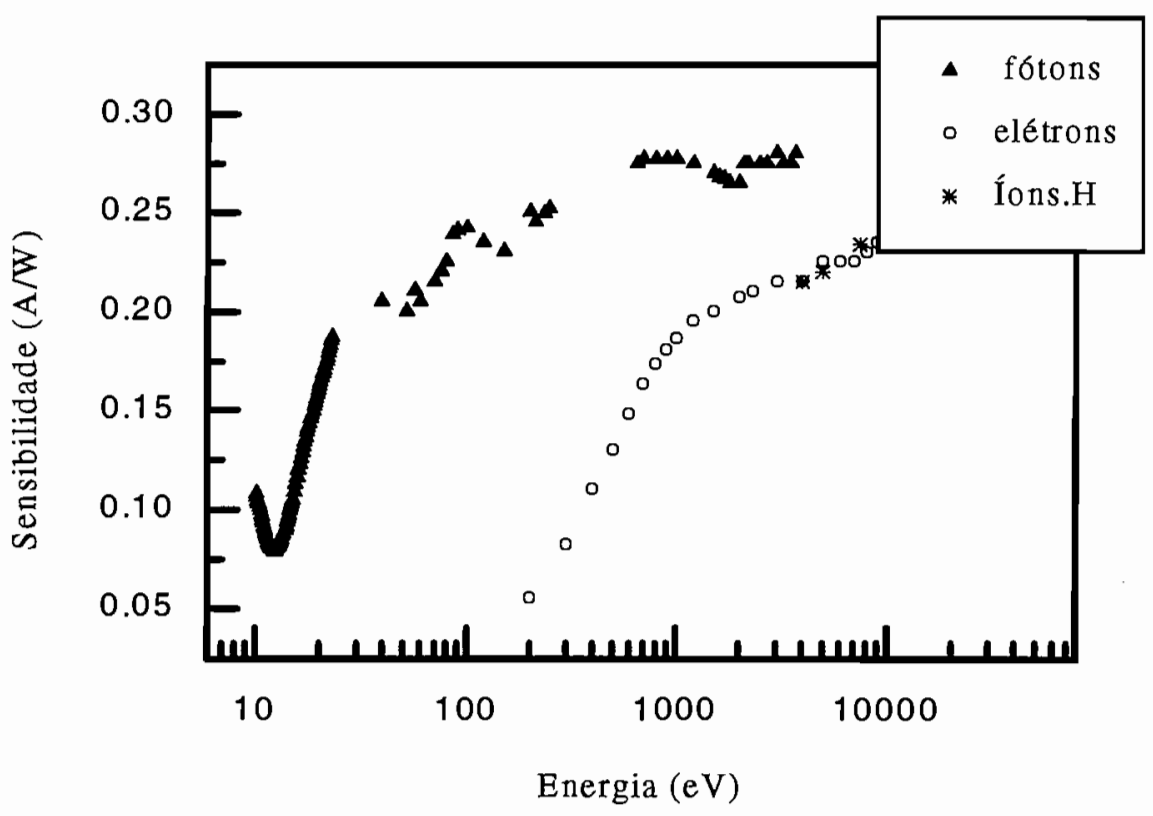

Fig. 4.9. Sensibilidade Típica do Fotodiodo para Fótons, Elétrons e Íons de Hidrogênio.

em sua eficiência ocorre para fótons na faixa de 8 a $100 \mathrm{eV}$, na qual a absorção e reflexão na camada $\mathrm{Si}_{-} \mathrm{SiO}_{2}$ não é desprezível. A Fig.4.9 mostra a curva de sensibilidade do dispositivo para fótons, elétrons e íons de hidrogênio. Outras características importantes são sua baixa sensibilidade para partículas neutras de baixa energia $(<500 \mathrm{eV})$ e seu rápido tempo de resposta. 
A área ativa do sensor é de $10 \mathrm{~mm}^{2}$, possibilitando uma resolução espacial bastante alta. Esta propriedade associada à sua grande velocidade fornecem uma indicação da alto poder de resolução espacial e temporal do diagnóstico

\subsection{Referências}

[1] R. L. Boivin, J. A. Goetz, E. S. Marmar, J. E. Rice, and J. L. Terry, Rev. Sci. Instrum. 70,260 (1999)

[2] I. Furno, H. Weisen, J. Mlynar, R. A. Pitts, X. Llobet, Ph. Marmillod, and G. P. Pochon, Rev. Sci. Instrum. 70, 4552 (1999)

[3] Franc Grum, Richard J. Becherer; "Optical Radiation Measurements", Academic Press; New York, 1979

[4] Bolômetro Metálico para Medida da Potência Irradiada no Tokamak TCABR Valdemar Bellintani Júnior - IFUSP -Dissertação de Mestrado- (1999)

[5] Hamamatsu, "Photodiodes", Manual do fabricante (1997) 


\section{Capítulo 5}

\subsection{Sistema Bolométrico do TCABR}

A bolometria é um dos principais diagnósticos em tokamaks, tais como o ASDEX e o JET. Os bolômetros medem quantitativamente a distribuição espacial da radiação e emissão de partículas neutras do plasma com uma resolução temporal da ordem de alguns milisegundos. A radiação de linha provém principalmente da região do ultravioleta de vácuo e raios-X moles. As perdas de partículas neutras são causadas por processos de troca de carga.

O sistema bolométrico do TCABR foi projetado de maneira a poder observar o plasma por uma sessão poloidal através de cordas localizadas em várias posições e ângulos. A região observada se estende além da área circular da coluna (18 cm de raio). Duas câmeras construídas em aço não magnetizável abrigam os bolômetros e são conectadas à câmara de vácuo do TCABR através de válvulas gavetas conectadas a portas de diagnóstico localizadas numa mesma seção transversal, uma no equador e outra na parte inferior, como mostrado na Fig. 5.1. Isto permite a retirada das câmeras bolométricas, para reparos e calibrações, sem quebrar o vácuo na câmara principal do tokamak, e também a proteção dos bolômetros durante 0 processo diário de descargas de rádio-frequiência para limpeza e condicionamento da câmara de vácuo.

Cada câmera do sistema bolométrico possui colimadores posicionados junto à face de acoplamento da câmera com o tokamak.. A primeira câmera bolométrica observa a coluna de plasma através do plano equatorial da coluna. A segunda câmera observa o plasma por uma porta de diagnostico localizada abaixo da coluna (Fig. 5.1). O sistema bolométrico foi instalado na região oposta a aquela ocupada pelo limitador físico da coluna de plasma, feito de carbono.

Os bolômetros utilizados são fotodiodos, cujas características já foram descritas no capítulo quatro. Dada a natureza do efeito fotoelétrico interno, a resolução temporal primária é menor que microssegundo, sendo porém deteriorada devido a relação sinal-ruído, 
para a região de milisegundo. Os fotodiodos são encapsulados em uma única pastilha contendo dezesseis unidades, sendo que em geral, somente seis são efetivamente utilizados, devido a resolução espacial desejada (menor que centímetro no centro da coluna de plasma). O sistema é composto por cinco pastilhas dispostas ao redor da coluna. Três destas pastilhas estão na primeira câmera, observando a coluna de plasma através do colimador posicionado no plano equatorial do tokamak. As outras duas pastilhas estão posicionadas na segunda

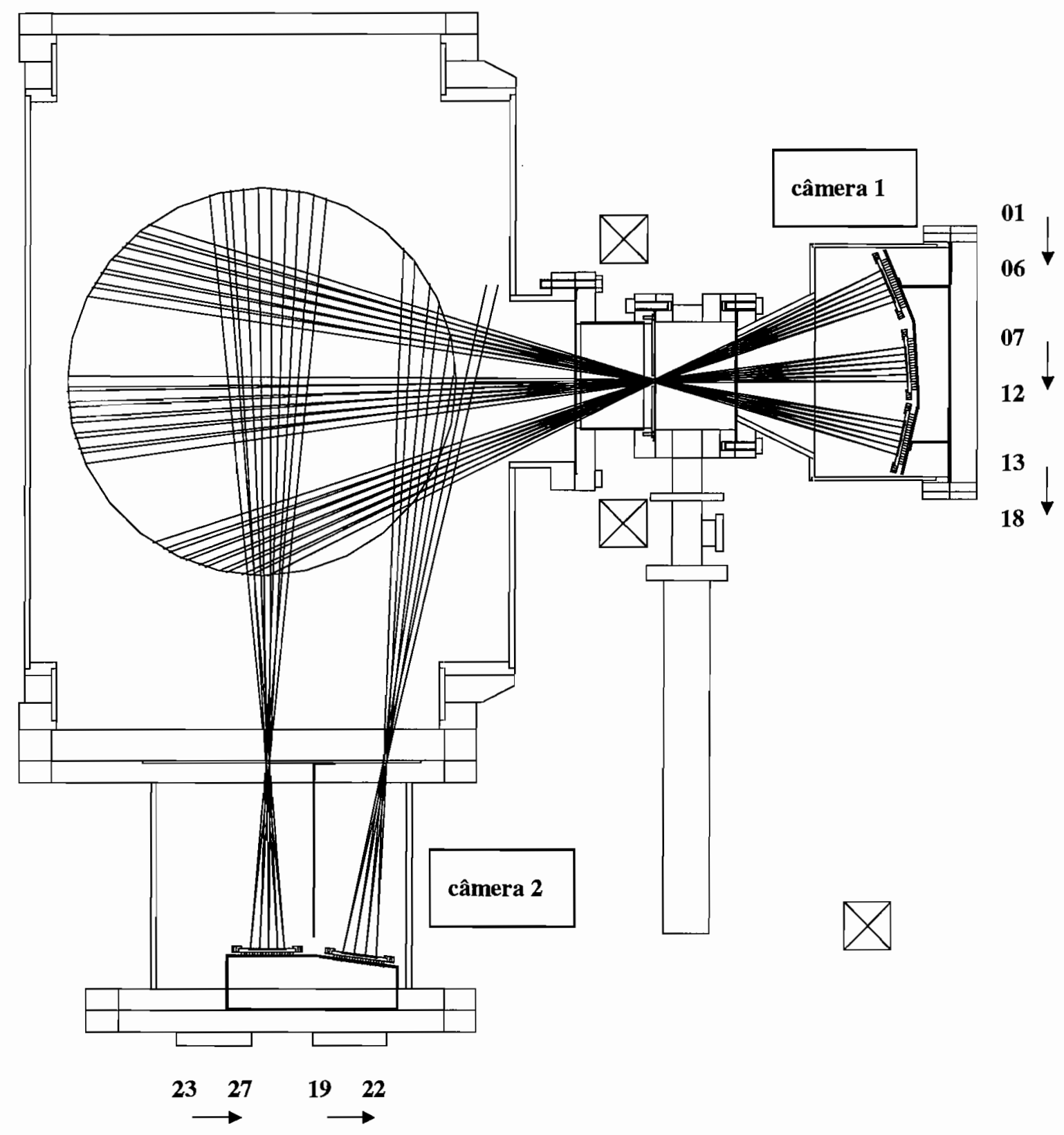

Fig. 5.1 Diagrama mostrando o diagnóstico bolométrico instalado no tokamak TCABR. As cordas que interceptam a coluna de plasma também estão desenhadas. Os números de identificação de cada bolômetro encontram-se ao lado de cada uma das câmeras bolométricas. 
câmera. Elas possuem colimadores individuais e observam o plasma por aberturas localizadas abaixo da coluna de plasma (Fig. 5.1).Todas as pastilhas são recobertas com uma mascara feita em aço, evitando que partículas altamente carregadas provindas do plasma danifiquem os delicados filamentos condutores dos sensores.

O posicionamento relativo entre as pastilhas da câmera 1 e o colimador do plano equatorial foi dimensionado de modo que praticamente toda a sessão poloidal da coluna pudesse ser observada (desde o centro ate $\mathrm{r}=16 \mathrm{~cm}$ ), mesmo com o reduzido acesso fornecido pela porta circular disponível para instalação do diagnóstico.

Nesta câmera, duas pastilhas observam a região da coluna localizada abaixo do plano equatorial, e a pastilha restante observa a região localizada acima deste plano. Na região da coluna abaixo do plano equatorial, uma pastilha é responsável pelas cordas que distam entre 0 e $5 \mathrm{~cm}$ do centro da sessão poloidal. A outra pastilha é responsável por cordas com distâncias entre 10 e $16 \mathrm{~cm}$ do centro. A porção da coluna localizada acima do plano equatorial é observada por cordas que distam entre 6 e $9 \mathrm{~cm}$ do centro da sessão poloidal. Desta forma, todas as cordas de diagnóstico da câmera 1 possuem distâncias ao centro da coluna de plasma que estão espaçadas de um valor aproximadamente constante, igual a 1 cm.

A região restante da sessão poloidal (acima de $16 \mathrm{~cm}$ ) é observada por uma das pastilhas abaixo da coluna, pertencente à câmera 2. A outra pastilha localizada nesta câmera destina-se ao diagnóstico do centro do plasma.

Os colimadores são de formato retangular, com dimensões $3 \times 30 \mathrm{~mm}^{2}$ para 0 colimador equatorial, e $3 \times 15 \mathrm{~mm}^{2}$ para os dois colimadores situados embaixo da coluna.

Esta diferença em suas dimensões deve-se a reduzida abertura disponível abaixo (4 $\mathrm{cm}$ na direção toroidal) relativamente a abertura da porta de diagnostico equatorial $(15 \mathrm{~cm}$ de raio ). Isto no entanto não constitui problema para o diagnostico, pois o ruído inerente à operação do tokamak só é representativo com a utilização de colimadores de dimensões bem menores que as aqui utilizadas. Além disto, a diferença se manifesta principalmente na direção toroidal, onde geralmente podemos supor simetria na emissão do plasma. 
Os colimadores são projetados de modo que suas bordas de maior dimensão possuam uma espessura não maior que alguns décimos de milímetro (limite imposto pelo processo de construção), evitando reflexões indesejáveis capazes de influir nas medidas.

A potência total emitida pelo plasma é calculada a partir das intensidades registradas por cada fotodiodo, conforme descrito no capítulo 3.

\subsection{Eletrônica de Aquisição do Sinal Bolométrico}

O sistema eletrônico responsável pela aquisição do sinal bolométrico foi desenvolvido procurando minimizar a quantidade de componentes eletrônicos utilizados. Desta forma, as áreas ocupadas pelas placas de circuito impresso são pequenas, reduzindo ao mínimo a indução indesejada provocada pelos fortes campos eletromagnéticos presentes no tokamak.

A fonte de alimentação primária utilizada é um conjunto de baterias recarregáveis com capacidade de cinco ampere-hora (12V). Isto evita o ruído presente nas linhas de alimentação convencionais $(60 \mathrm{~Hz})$. Os circuitos são condicionados em gabinetes de alumínio, sendo aí aterrados. Atenção especial foi dedicada no sentido de reduzir ao máximo a formação de "loops" de terra.

Os cabos responsáveis tanto pelo transporte do sinal adquirido, quanto pela alimentação, são todos blindados, contendo dez fios em seu interior dispostos de forma helicoidal (testes realizados com cabos tipo par trançado não resultaram em melhora significativa na relação sinal-ruído). 


\subsection{Arquitetura do Sistema de Aquisição}

A disposição dos elementos eletrônicos é tal como mostrado na figura 5.2. As pastilhas contendo os bolômetros estão sob vácuo nas câmeras bolométricas. Os fios utilizados nesta região são de cobre esmaltado, conectados sem o auxilio de solda elétrica, pois esta prejudica a qualidade do vácuo produzido. Cada pastilha possui, alem dos pinos de saŕda de sinal (catodo), um pino "Terra" (anodo comum).Um conector especial (feedthrough) é responsável por transportar o sinal bolométrico da região de vácuo ao meioambiente. No feedthrough, os pinos "Terra" das pastilhas são unidos em um só ponto.

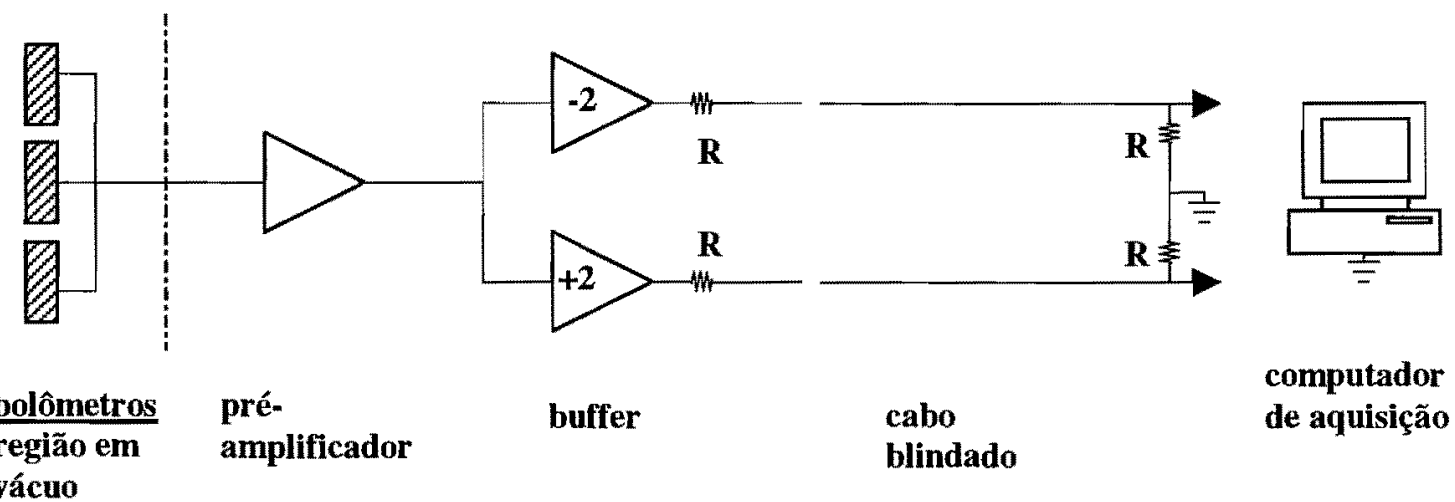

$(\mathbf{8 m})$

Fig.5. 2 Diagrama dos circuitos responsáveis pela aquisição do sinal bolométrico. A figura mostra o esquema para um dos 27 bolômetros instalados.

Utiliza-se então um cabo blindado (10 fios) para levar o sinal ao módulo préamplificador. Neste módulo são utilizados amplificadores operacionais configurados como amplificadores de corrente. Para a maioria dos bolômetros, um ganho de $2 \times 10^{4}$ V/A é utilizado, ou $3,57 \times 10^{4}$ V/A para os sinais coletados da borda da coluna de plasma. Um 
diagrama mais detalhado dos módulos eletrônicos utilizados pode ser encontrado no apêndice $\mathrm{C}$.

A blindagem do cabo de entrada é conectada ao terra local do circuito préamplificador. Esta conexão é feita no local mais próximo possível aos pinos de entrada positivos dos amplificadores operacionais que compõem o modulo pré-amplificador. Isto é importante para que o ruído induzido na blindagem do cabo não apareça sob a forma de sinal válido na saída do pré-amplificador, o que certamente ocorreria caso a conexão da blindagem fosse feita no conector feedthrough.

A saída do módulo pré-amplificador é então conectada à entrada do modulo contendo os "drivers", necessários para o transporte do sinal por cabos longos $(8 \mathrm{~m})$ que conduzem o sinal bolométrico ao computador de aquisição de dados.

Nos "drivers", os sinais são convertidos da configuração de terra comum (vários sinais, um só terra), para uma configuração diferencial (terras individuais para cada sinal). Isto torna os sinais compatíveis com a entrada (também diferencial) do computador de aquisição/digitalização. Este módulo multiplica o sinal de saída dos pré-amplificadores por quatro. Um ganho unitário seria ideal; porém a presença no driver de amplificadores operacionais ligados em configuração não inversora tornou isto impossível.

Ao chegar ao computador de aquisição, os sinais bolométricos são conectados a dois resistores em série, conforme mostrado na figura 5.2. Estes resistores formam, em conjunto com outros dois resistores ligados na saída do modulo driver, um divisor de tensão. O ponto de ligação entre os resistores próximos ao computador de aquisição é conectado ao terra do laboratório do TCABR, evitando que induções indesejáveis nos longos cabos bolométrios possam danificar o computador. Qualquer indução é aterrada por estes resistores antes da entrada do computador. Devido ao divisor de tensão, o sinal bolômétrico armazenado pelo computador de aquisição é o dobro do sinal de saída do módulo pré-amplificador.

A digitalização reproduz o sinal analogico, fornecendo 50000 pontos em 0,2 s (250 $\mathrm{kHz}$ ), o que é suficiente para o estudo da maioria dos fenômenos de plasma produzido no 
TCABR. Além da digitalização, o computador armazena em um disco rígido, os sinais coletados para posterior análise.

\subsection{0 sinal bolométrico}

Antes de prosseguirmos, vamos definir uma grandeza física muito importante que caracteriza qualquer detector, a sensibilidade. Esta grandeza foi citada brevemente quando descrevemos o bolômetro resistivo (capítulo 4), mas é importante aprofundarmos um pouco mais este assunto aqui. A sensibilidade é uma razão entre o sinal de saída do detector $(\mathrm{V}$ ou A) e o produto entre o fluxo luminoso nele incidente $\left(\mathrm{W} / \mathrm{m}^{2}\right)$ e sua área ativa $\left(\mathrm{m}^{2}\right)$. A sensibilidade $S$ pode ser expressa por:

$S=\frac{I}{E_{P} A} \quad(V / W$ ou $A / W)$

onde: $I$ - intensidade do sinal de saída (V, se o sinal for uma tensão) ou (A, se o sinal for uma corrente elétrica); $E_{P}$ - fluxo luminoso incidente no detector $\left(\mathrm{W} / \mathrm{m}^{2}\right)$ e $A$ - área sensível do detector $\left(\mathrm{m}^{2}\right)$. Estabelecida esta definição, vamos prosseguir.

No caso do bolômetro, o sinal de saída é uma corrente, e portanto a dimensão correta da sensibilidade é (A/W). A evolução temporal da corrente medida é armazenada no computador de aquisição na forma do dobro da diferença de potencial (V) presente na saída do modulo pré-amplificador. Isto ocorre devido ao produto entre o ganho quatro imposto pelo "driver" e o ganho 0,5 imposto pelo divisor de tensão formado pelos resistores de 
saída. Vamos descrever agora como é feita a conversão do sinal adquirido para a grandeza física necessária para calcular a energia emitida pelo plasma.

Conforme descrito no capítulo 3, equação 3.4, a grandeza física de interesse é a densidade de potência $W\left(\mathrm{~W} / \mathrm{m}^{3}\right)$, ou emissividade, dentro da coluna de plasma. A emissividade é obtida pela inversão de Abel a partir do conhecimento da integral de linha $I(h)$, medida ao longo das várias cordas na coluna de plasma, isto é:

$$
I(h)=\frac{2 \pi E_{P}}{\operatorname{sen}(\beta) \cos (\alpha) \Delta \alpha} \quad\left(W / m^{2}\right)
$$

Nesta expressão, os ângulos $\alpha, \beta$ e a distância ao centro da coluna $h$ são os parâmetros geométricos associados a cada um dos bolômetros. O fluxo de potência radiante $E_{P}$ é obtido do sinal bolométrico digitalizado através da expressão para a sensibilidade, Eq. (5.1), sendo conhecida a área sensível do fotodiodo $\left(10^{-5} \mathrm{~m}^{2}\right)$.

O valor utilizado para a sensibilidade, obtido da curva mostrada no capítulo 4 (Fig. 4.9), é igual a $0,24 \mathrm{~A} / \mathrm{W}$. Nas descargas do tokamak TCABR, as potências coletadas na superfície dos bolômetros são da ordem de $(0,3-20) \times 10^{-5} \mathrm{~W}$. O limite inferior é determinado pelo ruído presente nas vizinhanças do tokamak. O limite superior corresponde à potência emitida em descargas de alta densidade e corrente do TCABR.

\subsection{Parâmetros Geométricos dos Bolômetros}


Como já dissemos, a integral de linha $I(h)$ da densidade de potência $W$ é a grandeza física medida. Vamos descrever agora de que forma foram obtidos os parâmetros geométricos que comparecem na equação (5.2), ou seja, os ângulos $\alpha, \beta$, a diferença angular $\Delta \alpha$, e as distâncias $h$ ao centro da coluna.

A figura 5.1 mostra que, na câmera posicionada no plano equatorial, os bolômetros são dispostos ao longo de um arco de circunferência com centro no colimador. Na câmera bolométrica inferior, as pastilhas bolométricas são dispostas de forma que os bolômetros localizados nas duas bordas da pastilha pertençam a arcos de circunferência com centro em seus respectivos colimadores.

Os parâmetros geométricos foram obtidos a partir do desenho do projeto, feito em autoCAD. Este pacote possui imensos recursos para a leitura de ângulos e distâncias relativas, facilitando a consecução desta tarefa.

Para termos uma idéia do desvio cometido entre as dimensões mostradas no desenho e as dimensões efetivas do projeto após sua construção, o desenho impresso em escala 1:1 foi sobreposto ao projeto e os desvios avaliados. Este é um procedimento bastante prático, pois o desenho 1:1 é impresso em folhas de dimensão A4, de fácil manuseio.

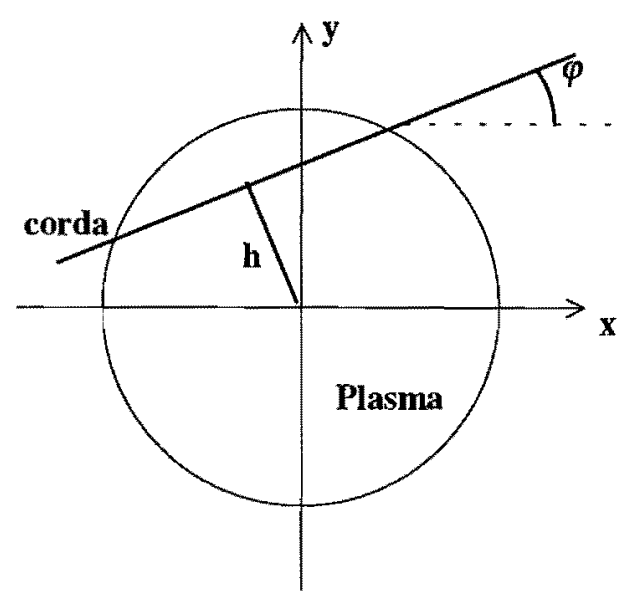

Fig. 5.3 Diagrama mostrando a coluna de plasma e os parâmetros geométricos envolvidos na definição das cordas. 
Utilizando este procedimento, observou-se um desvio de até dois milímetros em uma distância pastilha-colimador de $230 \mathrm{~mm}$. Assim, é possível afirmar que erros devidos à geometria não devem ser significativos no sinal eletrônico coletado pelos fotodiodos.

É possível reescrever a equação (5.2) de modo a separar os termos geométricos do termo dependente do sinal eletrônico coletado $E_{P}$. Assim, $I(h)=G . E_{P}$, onde $G$ só depende da geometria do diagnostico. Na tabela 5.1 listamos os valores de $G$ para todos os bolômetros utilizados.

Na figura 5.3 mostramos como foi tomada a distância $h$ das cordas ao centro da coluna de plasma. As cordas são retas, e como tal precisam de dois parâmetros para serem determinadas. Tendo determinado $h$, resta-nos uma parâmetro para sua completa identificação. O parâmetro restante é o ângulo $\varphi$ que a corda faz com o eixo coordenado horizontal $x$. A equação da corda será então dada por:

$$
h+x \operatorname{sen}(\varphi)-y \cos (\varphi)=0
$$

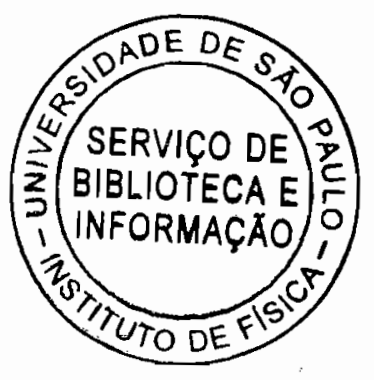

O ângulo $\varphi$ é especificado no intervalo $[0, \pi]$ e a distância $h$ no intervalo $[-a,+a]$, onde $a$ é o raio da coluna de plasma. A tabela 5.1 mostra os valores de $h$ e $\varphi$ para todos os bolômetros.

Tab. 5.1 Parâmetros geométricos do diagnóstico bolômétrico.

\begin{tabular}{|llll|}
\hline $\begin{array}{l}\text { identificação } \\
\text { do } \\
\text { bolômetro }\end{array}$ & $\begin{array}{l}\mathrm{G} \\
\text { (adimensional) }\end{array}$ & $\begin{array}{l}\mathrm{h} \\
\text { (cm) }\end{array}$ & $\begin{array}{l}\varphi \\
\text { (graus) }\end{array}$ \\
\hline 1 & 8743 & -16.0 & 26.2 \\
2 & 8599 & -15.1 & 24.6 \\
3 & 8482 & -14.2 & 23.0 \\
4 & 8393 & -13.3 & 21.0 \\
\hline
\end{tabular}




\begin{tabular}{|llll|}
\hline 5 & 8329 & -12.4 & 19.9 \\
6 & 8292 & -11.5 & 18.4 \\
7 & 7954 & -4.8 & 7.7 \\
8 & 7897 & -3.9 & 6.1 \\
9 & 7865 & -2.9 & 4.6 \\
10 & 7855 & -1.9 & 3.0 \\
11 & 7868 & -0.9 & 1.5 \\
12 & 7904 & -0.0 & 179.9 \\
13 & 8014 & -5.8 & 170.9 \\
14 & 8021 & -6.7 & 169.3 \\
15 & 8052 & -7.7 & 167.8 \\
16 & 8106 & -8.6 & 166.2 \\
17 & 8185 & -9.6 & 164.7 \\
18 & 8289 & -10.5 & 163.2 \\
19 & 9516 & -18.9 & 77.4 \\
20 & 9317 & -17.0 & 80.7 \\
21 & 9247 & -15.1 & 84.1 \\
22 & 9304 & -13.1 & 87.4 \\
23 & 8597 & -3.7 & 84.8 \\
24 & 8506 & -2.4 & 86.9 \\
25 & 8456 & -0.7 & 89.7 \\
26 & 8486 & 1.0 & 92.4 \\
27 & 8597 & 2.7 & 95.2 \\
\hline
\end{tabular}

\subsection{Calibração}

Os fotodiodos utilizados neste trabalho foram fornecidos junto a uma curva mostrando o comportamento da Sensibilidade (em A/W) como função da energia do fóton incidente ( em eV). Devido as dificuldades em encontrar fontes luminosas em várias regiões do espectro eletromagnético, uma nova calibração absoluta não foi aqui realizada.

Porém, uma calibração relativa, mostrando diferenças na sensibilidade entre os fotodiodos foi feita. 
Inicialmente, todo o sistema bolométrico foi colocado sobre uma bancada de laboratório. O ambiente da calibração era desprovido de aberturas por onde pudesse penetrar luz externa, podendo-se conseguir uma escuridão quase completa durante 0 experimento.Uma lâmpada fluorescente de formato cilindrico e de utilização caseira foi colocada na posição do colimador de cada câmera bolométrica, conforme mostrado na figura 5.4.

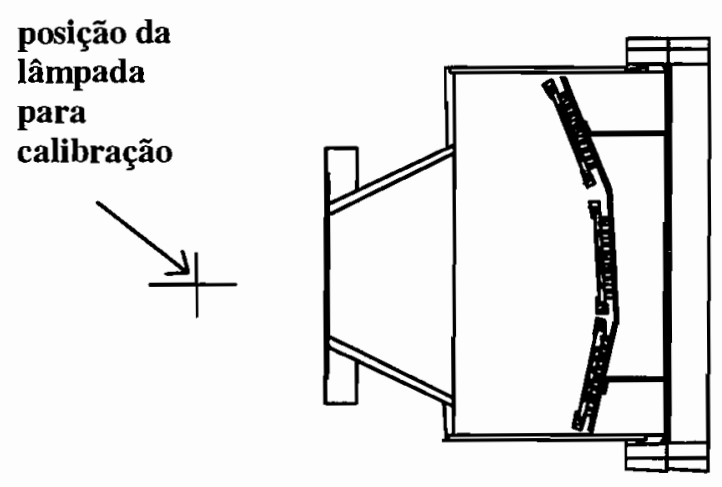

Fig. 5.4 Esquema mostrando a câmera bolômétrica e a posição da lâmpada fluorescente durante a calibração.

O eixo deste cilíndrico foi posicionado de modo a coincidir com a direção onde os colimadores possuem sua maior abertura. Assim, a lâmpada simulou a geometria do colimador. $\mathrm{O}$ diâmetro cilíndrico da lâmpada é de aproximadamente $1 \mathrm{~cm}$, três vezes maior que a abertura menor dos colimadores.

Os fotodiodos foram conectados aos seus respectivos pré-amplificadores e drivers, ou seja, procurou-se reproduzir o melhor possível a condição de operação normal para aquisição nas descargas tokamak.

Um osciloscópio foi utilizado para medição dos sinais dos bolômetros. A evolução temporal do sinal obtido é como mostrado na figura 5.5. Devido à alimentação da lâmpada ser feita através da rede elétrica, observou-se uma flutuação de frequiência bem determinada $(120 \mathrm{~Hz})$, deslocada no sentido positivo do eixo das tensões de um nível constante. 
O osciloscópio possui recursos de medição automática, possibilitando determinar o nível médio de tensão do sinal mostrado. Este valor médio é o produto final do experimento, e portanto a grandeza utilizada para comparação entre os fotodiodos.

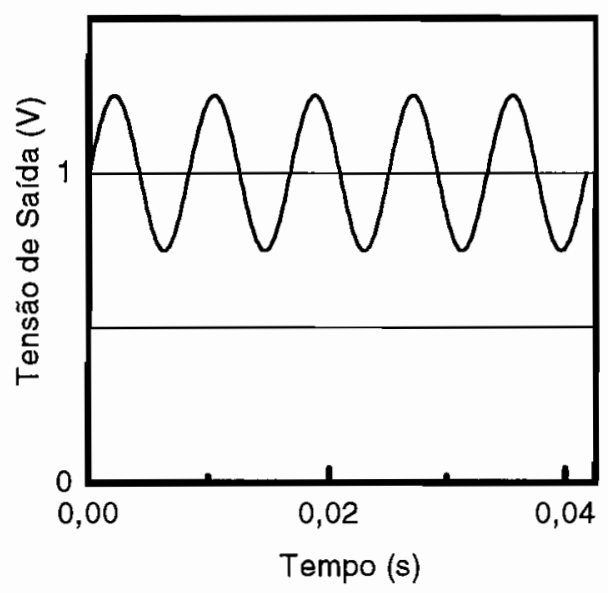

Fig. 5.5 Sinal de saída do bolômetro durante a calibração. $O$ valor médio do sinal é a grandeza de interesse.

Os resultados obtidos estão mostrados na figura 5.6. Os valores de tensão foram normalizados pela média, pois só estamos interessados em medidas relativas. Assim, o valor médio da série de medidas é igual a 1, com desvio padrão igual a 0,095. 


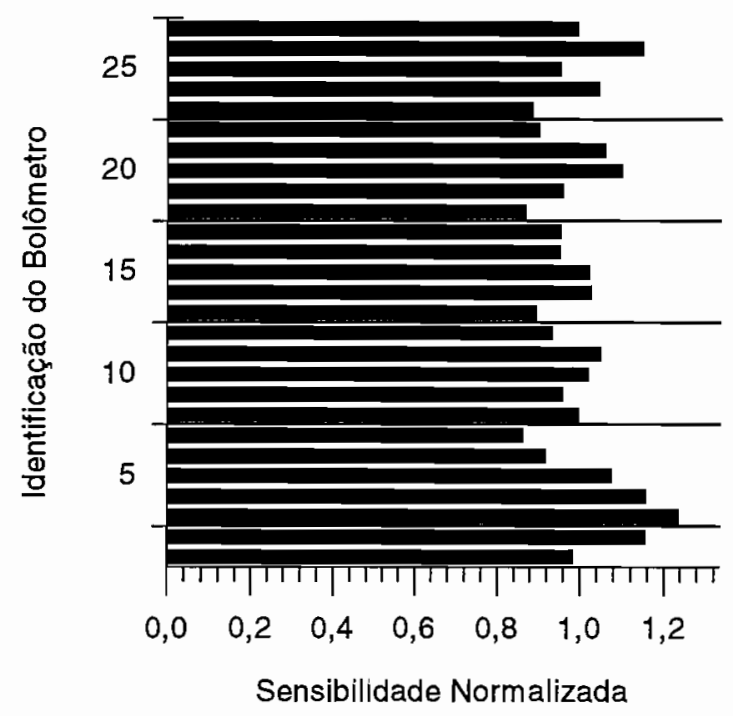

Fig. 5.6 Sensibilidade relativa dos bolômetros utilizados no diagnóstico. A unidade corresponde a sensibilidade de 0,24A/W.

É interessante verificar de passagem, que os fotodiodos fornecidos possuem variações na sensibilidade da ordem de $9,5 \%$.

Os dados obtidos são individualmente atribuídos ao respectivo fotodiodo. Assim a sensibilidade absoluta individual é o produto do valor fornecido pelo fabricante $(0,24 \mathrm{~A} / \mathrm{W})$ pelo fator obtido da calibração. 


\section{Capítulo 6}

\subsection{Resultados Experimentais}

\subsection{Introdução}

Neste capítulo, vamos descrever o processo de tratamento dos dados bolométricos obtidos a partir das descargas realizadas no tokamak TCABR. As informações foram colhidas a partir dos vários diagnósticos instalados em nosso laboratório.

Tensão de Enlace (V)
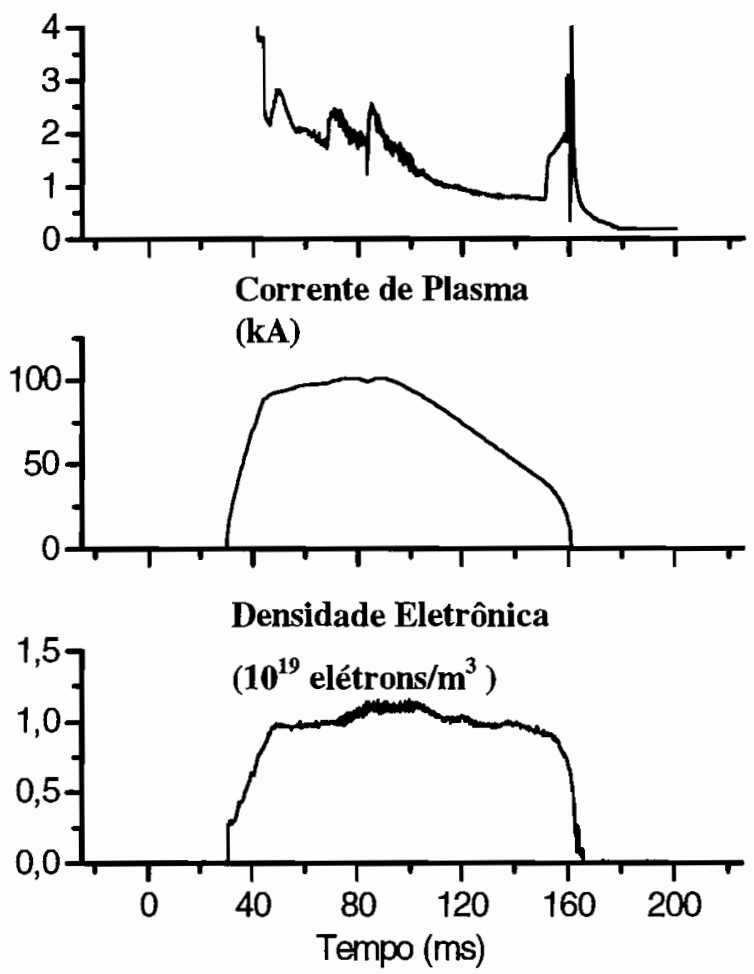

Fig. 6.1 Evolução temporal da tensão de enlace, corrente de plasma e densidade eletrônica média para a descarga \#16310 do tokamak TCABR. 
Procuraremos mostrar, em detalhe, como foi calculado o perfil da potência total emitida, bem como apontar as dificuldades encontradas nesta fase. Ao final, faremos alguns comentários acerca destes resultados.

\subsection{Método para obtenção do perfil da potência irradiada.}

Escolhemos uma das descargas para ilustrar o método utilizado. A figura 6.1 mostra a evolução temporal da tensão de enlace, corrente e densidade eletrônica para uma descarga com aquecimento ôhmico, apresentando um estado estacionário de corrente de plasma de aproximadamente $50 \mathrm{~ms}$. A densidade eletrônica mostrada representa o valor médio para uma corda que passa pelo centro da coluna de plasma.

A evolução temporal obtida pelo diagnóstico bolométrico para a descarga \#16310 é mostrada na figura 6.2. Nela, são expostos quatro sinais, dentre os vinte e sete disponíveis.

No gráfico da parte superior da figura, observamos a integral de linha da potência emitida ao longo de duas cordas centrais. O sinal da corda (1) foi obtido por um bolômetro que observa a coluna de plasma através do plano equatorial do tokamak. O sinal da corda (2) foi registrado por um bolômetro localizado em baixo da coluna.

No gráfico da parte inferior, mostramos o sinal obtido para duas cordas periféricas.

As cordas centrais (1) e (2) distam, 0 e $0,7 \mathrm{~cm}$ do centro da coluna de plasma, respectivamente. As cordas periféricas (1) e (2) distam 16 e 15,1 cm do centro.

Devido ao intenso ruído introduzido pelas bobinas responsáveis pelo campo magnético toroidal, os sinais mostrados foram suavizados digitalmente, fazendo uma média, para cada instante da descarga, num intervalo de tempo de $5 \mathrm{~ms}$ adjacentes ao instante considerado. 
Os dados obtidos numa descarga, na qual foram fechadas as aberturas de acesso do diagnóstico bolométrico ao plasma, foram utilizados como "sinais de fundo", e subtraídos dos sinais dos bolômetros correspondentes. Este procedimento foi realizado diariamente durante a campanha de tomada de dados, de maneira que os dados colhidos em um determinado dia possuem sua própria "descarga de referência".

Bolometria :

Integral de Linha da Potência

Irradiada $\left(\mathbf{k W} / \mathrm{m}^{2}\right)$ - Evolução

Temporal
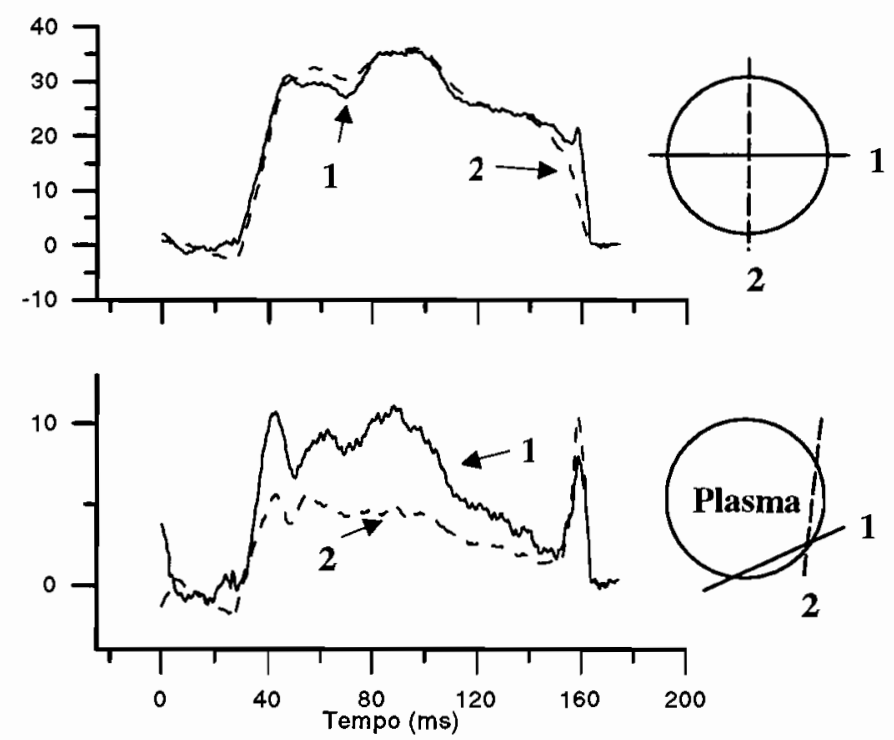

Fig. 6.2 Evolução Temporal do diagnóstico bolométrico. Em cima: Sinal obtido para duas cordas centrais. Em baixo: Sinal para duas cordas periféricas. A localização das cordas com relação a coluna de plasma é mostrada nos diagramas a direita dos gráficos.

Quanto ao comportamento dos sinais mostrados na fig. 6.2, nota-se que, a partir de $t$ $=70 \mathrm{~ms}$, ocorre um aumento na potência emitida, principalmente nas cordas centrais do sistema bolométrico, concordando com um pequeno aumento observado na densidade eletrônica a partir deste instante. Este acréscimo na potência é menos evidente nas cordas periféricas. 
Após este pequeno comentário, retornemos ao nosso objetivo, que é a obtenção do perfil radial da potência irradiada. Escolhido o instante da descarga para o qual deseja-se obter o perfil, os valores das integrais de linha, da potência emitida medidos por todos os sensores, são considerados. Estes dados são colocados em um gráfico, em função da distância ao centro da coluna de plasma. Para a descarga que estamos considerando, \#16310, este gráfico pode ser visto na parte superior da figura 6.3.

Escolhemos $\mathrm{o}$ instante $\mathrm{t}=60 \mathrm{~ms}$, para leitura das integrais de linha, pois neste instante a descarga apresenta um estado estacionário de corrente de plasma. Relembramos

Bolometria: Integral de Linha da

Potência Irradiada $\left(\mathrm{kW} / \mathrm{m}^{2}\right)$ - Perfil

Radial e Inversão de Abel

(Emissividade).
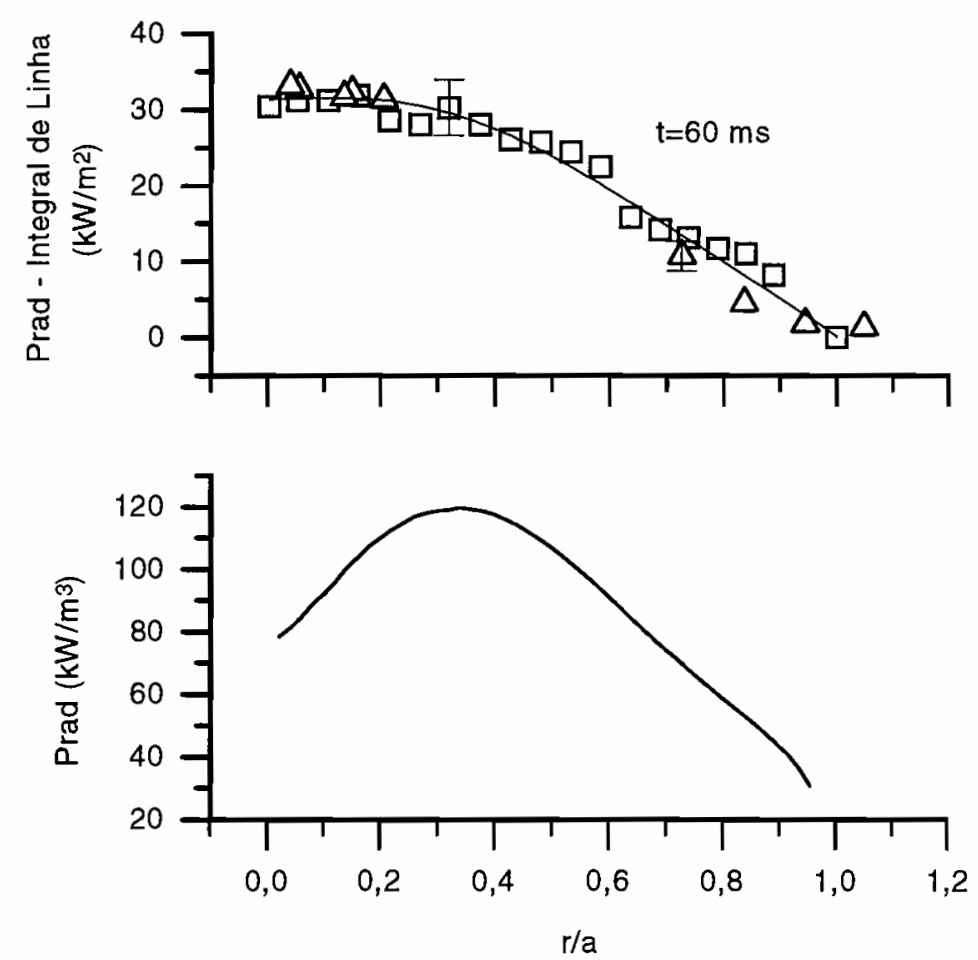

Fig. 6.3 Em cima: Integrais de linha da potência irradiada em função da distância normalizada ao centro da coluna de plasma. Dados assinalados em quadrados foram tomados a partir do plano equatorial , e os assinalados em triângulo, a partir dos sensores localizados abaixo da máquina. A curva sobre os dados experimentais é um polinômio de ajuste, utilizado na inversão.

Em baixo: Emissividade da coluna obtida pela inversão de Abel. Nota-se que a região de maior emissão não se localiza no centro da descarga. 
que foi adotada simetria cilíndrica para a emissão, e que esta emissão é nula para distâncias maiores que o raio da coluna $(18 \mathrm{~cm})$. Os dados mostrados em quadrados correspondem a linhas de visada ao longo do plano equatorial do tokamak e os mostrados em triângulos a linhas de visada no sentido vertical.

Resta agora calcularmos o perfil desejado, invertendo os dados das integrais de linha. Aqui, foram investigados dois processos numéricos. No primeiro, os dados obtidos eram interpolados através de um "spline" parabólico. No segundo, ajustou-se os dados a um polinômio de quinto grau. O segundo método apresentou melhor desempenho, pois só fazendo uso dele foi possível obter a convergência da integral de Abel. O gráfico mostrado na parte de baixo da figura 6.3 é a emissividade calculada para a descarga no instante considerado.

\subsection{Análise dos Dados Bolométricos}

Consideraremos uma série de descargas realizadas no tokamak TCABR para serem analisadas. Antes de prosseguirmos com os resultados, é importante mencionar brevemente estudos já realizados sobre o limite operacional de tokamaks.

A existência de um limite de densidade no espaço operacional das maquinas foi estabelecido por Murakami et al. (1976), utilizando como parâmetro a grandeza $\bar{n}_{e} R / B_{\phi}$, onde $\bar{n}_{e}$ é a densidade eletrônica média de linha, $R$ é o raio maior da descarga e $B_{\phi}$ é o campo magnético toroidal. Os valores obtidos para $\bar{n}_{e} R / B_{\phi}$ em descargas ôhmicas para diferentes tokamaks situam-se na faixa de 4-6 x $10^{19}$ Weber $^{-1}$.

Um grande esforço tem sido feito para compreender este limite operacional, principalmente como função das perdas por radiação das impurezas no balanço térmico. $\mathrm{O}$ parâmetro reduzido $B_{\phi} / R$ é proporcional à densidade de corrente no eixo magnético, $j(0)$, considerando-se fixo 0 fator de segurança nesta região $\left(q_{0}\right)$, através de 
$j(0)=B_{\phi} / R \times 2 / \mu_{0} q_{0}$. Portanto, este parâmetro também está relacionado à densidade de potência ôhmica no eixo, $P_{o h}(0)=E(0) j(0)$.

O limite operacional é uma função do fator de segurança na borda [1] $q_{a}$, na forma $q_{a} \bar{n}_{e} R / B_{\phi}=$ constante. Para um perfil fixo da densidade eletrônica, esta relação é equivalente a $e N_{e} / I_{p}=$ constante, onde $N_{e}=\int n_{e}(r) \mathrm{d} S$, e $I_{p}$ é a corrente de plasma. Desta forma, $e N_{e} / I_{p}$ significa o inverso da velocidade média de deriva dos elétrons.

Descargas Ôhmicas - Diagrama Operacional

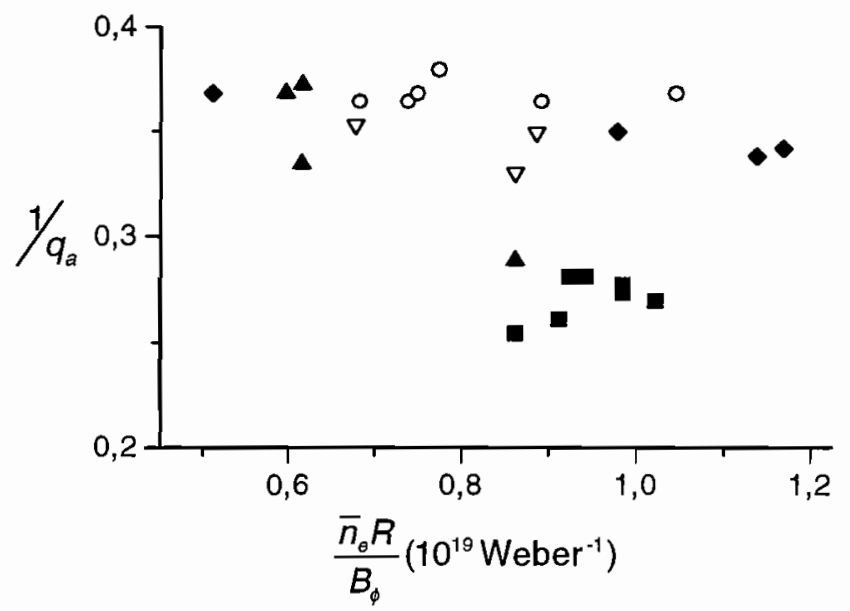

Fig. 6.4 Diagrama operacional das descargas avaliadas. Círculos, triângulos, quadrados... representam diferentes campanhas de tomada de dados.

Feita esta pequena introdução, passemos à analise proposta. $\mathrm{Na}$ figura 6.4, as descargas avaliadas são mostradas em um diagrama operacional, $1 / q_{a}$ contra $\bar{n}_{e} R / B_{\phi}$.

As descargas foram obtidas operando com um limitador físico de carbono. Procurou-se variar a corrente de plasma e a densidade eletrônica na faixa mais ampla possível de operação. Disrupções durante as descargas não foram observadas. Diferentes campanhas de tomada de dados são assinaladas no diagrama com diferentes símbolos (quadrados, círculos, triângulos...). 
De acordo com [1], o limite operacional para o TCA em sua fase inicial de operação em Lausanne era tal que $q_{a} \bar{n}_{e} R / B_{\phi} \approx 1.3 \times 10^{20} \mathrm{Weber}^{-1}$. Podemos notar que estamos operando bem abaixo deste limite, em parte por razões de segurança, pois esta máquina se encontra em operação desde meados dos anos 80. Mesmo assim, os limites operacionais estão aquém dos obtidos em Lausanne devido às piores condições do vácuo de base, causado por uma velocidade de bombeamento insuficiente e condicionamento insatisfatório da câmara de vácuo.Atualmente, operamos com correntes de plasma menores que $100 \mathrm{kA}$, contra usuais $135 \mathrm{kA}$ utilizados em [1]. O campo magnético toroidal de operação $B_{\phi}$ é também menor neste trabalho.

Na figura 6.5 é mostrada a variação da potência emitida integrada no volume da coluna de plasma, normalizada pela potência ôhmica, como função do inverso da velocidade eletrônica média de deriva para todas as correntes e densidades indicadas na figura 6.4.

O gás utilizado nas descargas foi hidrogênio. A potência emitida foi obtida integrando-se as emissividades mostradas na figura 6.3 (para uma única descarga) dentro do volume de plasma. A potência ôhmica foi obtida pelo produto da tensão de enlace pela

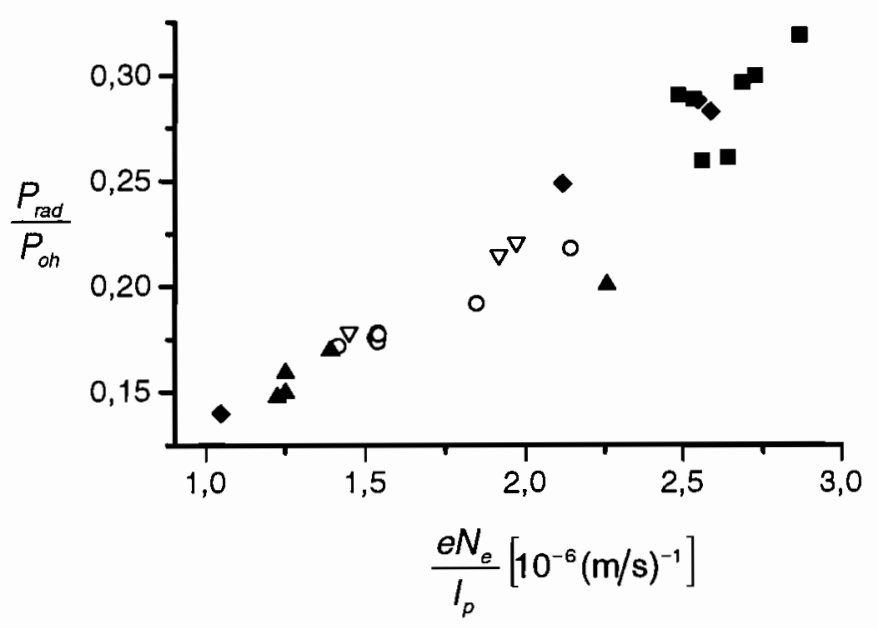

Fig.6. 5 Perdas por potência emitida normalizada, como função do inverso da velocidade eletrônica de deriva. Diferentes representações para os pontos mostrados significam diferentes campanhas de tomada de dados.

corrente de plasma. Para todas as descargas, o instante escolhido para aferição dos dados foi $\mathrm{t}=60 \mathrm{~ms}$, dentro da fase estável da corrente de plasma. É importante observar que a 
potência irradiada é medida em uma sessão poloidal situada no lado oposto do limitador físico, onde certamente as perdas são maiores.

Por este motivo, é interessante observarmos o que ocorre com a potência irradiada no centro da descarga. Devido à distância com relação a borda, os dados referentes ao eixo da coluna são bem menos sensíveis à presença do limitador, tornando a hipótese de simetria toroidal bem mais sensata. Na figura 6.6 mostramos a dependência da potência emitida axial reduzida $P_{\text {rad }}(0) / P_{\text {oh }}(0)$, com relação ao inverso da velocidade de deriva.

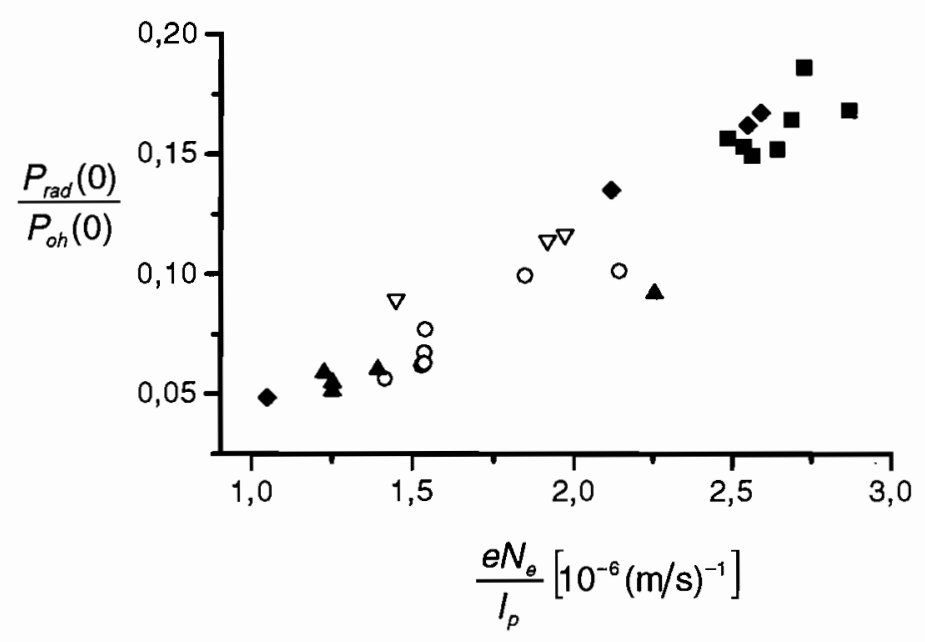

Fig. 6.6 Potência emitida axial normalizada em função do inverso da velocidade média eletrônica de deriva.

A potência ôhmica no eixo foi estimada como sendo $V_{s} / 2 \pi R \times j_{0}\left(q_{0}=0,95\right)$, onde $V_{s}$ é o valor experimental da tensão de enlace. O valor obtido para jo foi constante, pois todas as descargas foram obtidas utilizando um campo magnético toroidal de 1T.

Podemos notar que a potência irradiada integrada no volume da coluna de plasma, normalizada pela potência ôhmica cresce continuamente com o inverso da velocidade eletrônica média de deriva. Comportamento semelhante é observado para a potência irradiada axial reduzida. Na medida em que relacionamos a velocidade de deriva com o limite operacional estabelecido por Murakami, este resultado mostra que as perdas aumentam quando nos aproximamos mais deste limite. 
A distribuição dos dados obtidos ao redor do comportamento linear sugerido é igual para os dois gráficos considerados. Este fato é uma indicação da acuracia da inversão de Abel realizada, tanto para a emissividade calculada no eixo, quanto para o obtida no restante da sessão poloidal. Este mesmo experimento realizado para o TCA, quando instalado em Lausanne, mostrava uma dispersão maior dos dados para a potência irradiada axial reduzida, atribuída à incertezas no valor da emissividade obtida para o centro da descarga pelo processo numérico de inversão utilizado na ocasião.

A quantidade de impurezas desempenha papel fundamental no balanço térmico da descarga. Na seqüência utilizaremos os resultados obtidos para estimar a concentração das impurezas metálicas presentes no plasma.

\subsection{Impurezas}

Foi possível utilizar os dados bolométricos para estimar a quantidade de impurezas metálicas no centro da descarga, para uma certa faixa de densidades eletrônicas. Das descargas utilizadas, escolhemos aquelas caracterizadas por um alto valor de corrente de plasma.

Estas descargas possuem temperatura eletrônica alta no centro, tornando desprezável a quantidade de radiação proveniente das impurezas mais leves. Utilizamos os perfis medidos da potência irradiada, e estimamos a densidade eletrônica no centro a partir de um perfil suposto, associado ao valor medido da densidade de linha. As taxas de emissão radiativa para o equilibrio corona foram empregadas[2]. A razão entre a concentração metálica e a densidade eletrônica foi calculada utilizando a seguinte expressão.

$$
\eta_{M}=\frac{P_{\mathrm{rad}}(0)}{n_{e}(0)^{2} C_{M}}
$$


onde $C_{M}$ significa a perda por radiação por átomo por elétron. O valor adotado foi $C_{M} \approx 0,5$ $\times 10^{-31}$ Watt/átomo/elétron [2]. O resultado é mostrado na Fig. 6.7.

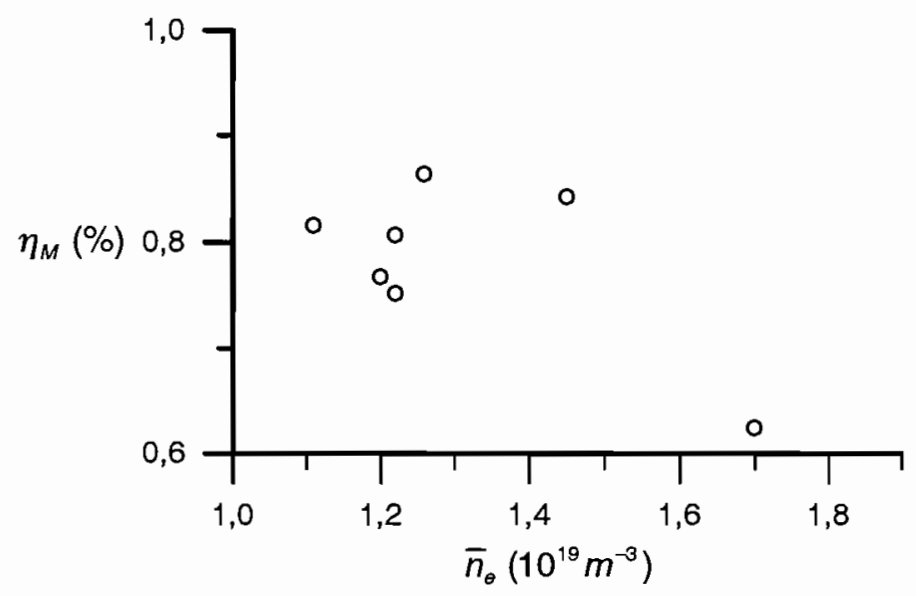

Fig. 6.7 Concentração de impurezas metálicas em função da densidade eletrônica média de linha.

$\mathrm{Na}$ faixa de densidades eletrônicas observadas, a concentração das impurezas metálicas se situa na faixa $0,9-1,2 \times 10^{17} \mathrm{~m}^{-3}$. Estes valores são maiores que o dobro dos obtidos anteriormente em Lausanne, indicando uma piora nas condições operacionais da máquina. Não se nota nenhuma dependência sistemática com a densidade eletrônica.

O valor da corrente de plasma influi diretamente no aspecto do perfil da potência irradiada no TCABR. Podemos observar, na figura 6.8, os perfis de potência obtido para uma descarga com alta corrente e outra com baixa corrente. A densidade eletrônica média de linha para as duas descargas vale respectivamente 0,97 e $1,4 \times 10^{19} \mathrm{~m}^{-3}$.

Podemos notar que, na descarga com alta corrente, o valor máximo da emissividade ocorre fora do centro, em $r / a \approx 0,35$. Este valor máximo encontra-se deslocado em direção ao centro para a descarga de menor corrente.

Este comportamento pode ser entendido como a manifestação da dependência com a temperatura das taxas de emissão radiativas, conforme discutido ao final do capítulo 2 , 
figura 2.1. Estas taxas de emissão apresentam um valor de pico para uma determinada temperatura. Portanto o deslocamento do máximo da emissividade observado nos perfis da potência irradiada deve-se a variação de temperatura entre as duas descargas mostradas. $\mathrm{O}$ aumento de temperatura eletrônica no centro devido ao aumento da corrente de plasma é um fato experimentalmente comprovado[1].

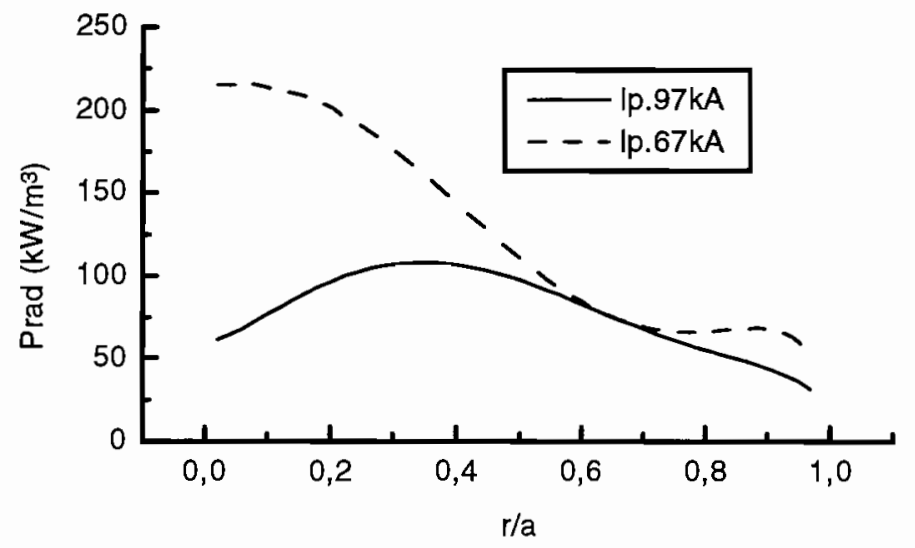

Fig. 6.8 Perfil da potência irradiada para duas descargas (\#16277 e \#16310) com diferentes valores de corrente de plasma. 0 máximo da emissividade ocorre em diferentes posições radiais nos dois casos.

O TCABR opera atualmente fornecendo uma temperatura eletrônica no centro de 400-500 eV. Para estes valores de temperatura, as perdas radiativas das impurezas metálicas são bem maiores que as perdas devido as impurezas leves. Assim, a posição observada do máximo de emissividade (próxima ao centro da descarga), nos leva a concluir que a potência irradiada em nosso tokamak é principalmente devida as impurezas metálicas.

Os resultados para o perfil da potência emitida obtidos para este tokamak em Lausanne mostram que a região da coluna onde a emissividade era máxima situa-se em $\mathrm{r} / \mathrm{a}=$ 0,9. A princípio, esta discrepância com relação ao valor obtido neste trabalho $(0,35)$ pode ser explicada pela maior temperatura eletrônica das descargas realizadas em Lausanne. Sob este ponto de vista, o aspecto do perfil das perdas por nós obtido está de acordo com o comportamento esperado em descargas de menor temperatura. 
A densidade eletrônica $n_{e}$ comparece como um fator de proporcionalidade nesta expressão, justificando os dados experimentais mostrados. Um estudo mais cuidadoso permite especular acerca da magnitude da densidade das impurezas $n_{i m p}$ e da taxa de emissão radiativa $L\left(T_{e}\right)$. Faremos isto em seqüência.
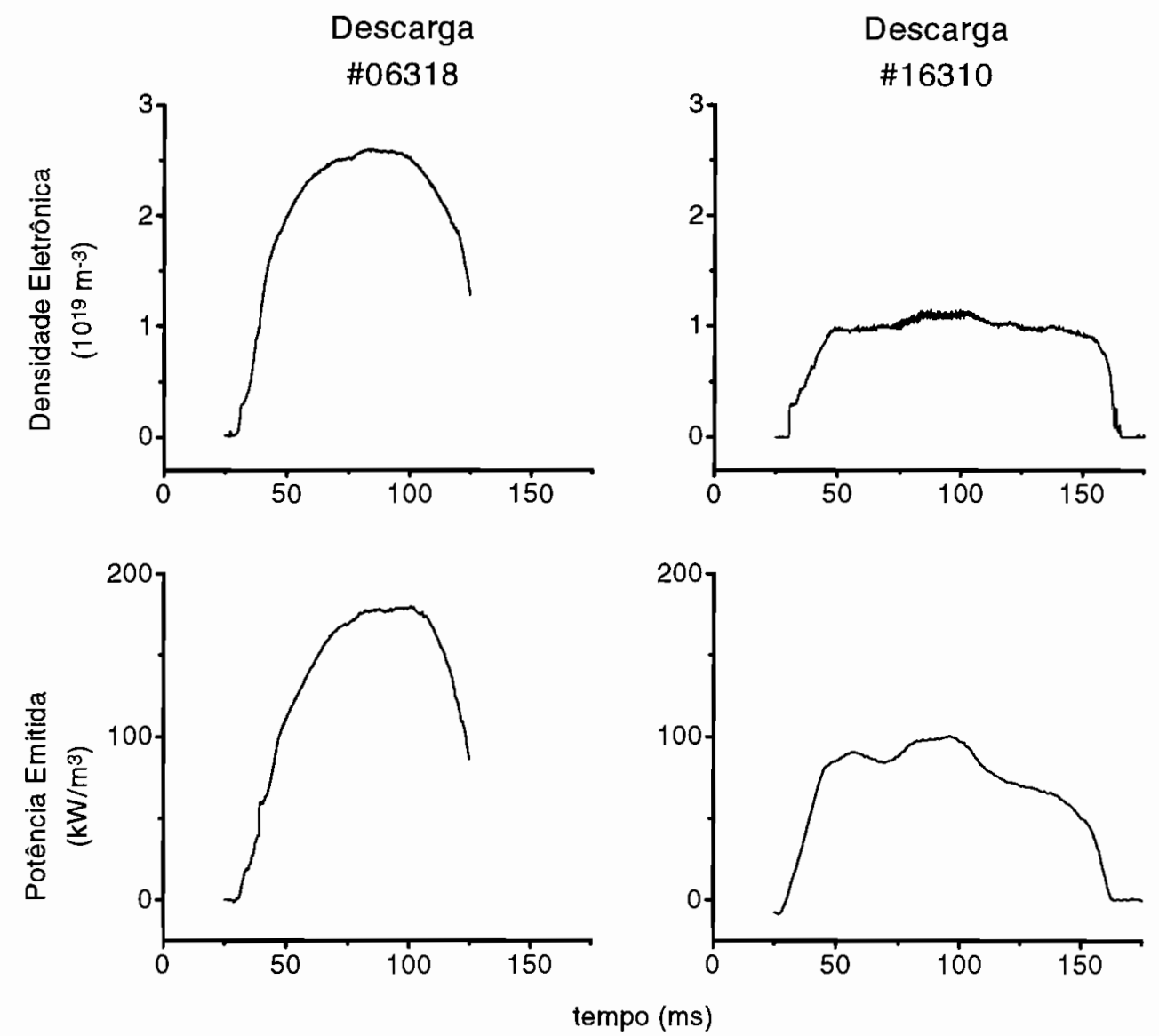

Fig. 6.9 Densidade eletrônica e potência emitida para duas descargas ôhmicas com aproximadamente $95 \mathrm{kA}$ de corrente de plasma. Nota-se a proporcionalidade e a semelhança na evolução temporal para os dois diagnósticos.

Na figura 6.10 são mostrados as evoluções temporais da potência emitida e da densidade eletrônica para a descarga \#6318, sobrepostas em um mesmo gráfico. Para facilitar a análise, a potência e a densidade foram normalizadas pelo seus respectivos valores máximos atingidos durante a descarga, cujas magnitudes já foram fornecidas. 
Podemos notar que na região de platô (fase estacionária da corrente de plasma), a potência emitida normalizada encontra-se abaixo da densidade eletrônica. A partir daí,

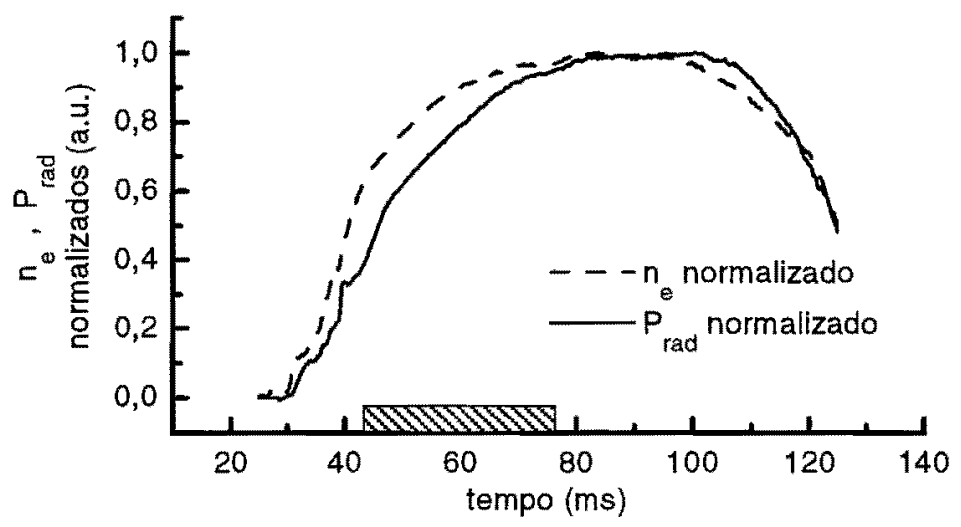

Fig. 6.10 Densidade eletrônica e potência emitida normalizadas para a descarga \#6318, indicando a fase onde a corrente de plasma é constante (platô).

gradativamente, os dois sinais experimentam uma inversão em suas posições relativas, com a potência emitida permanecendo acima dos valores normalizados da densidade eletrônica.

Uma possível explicação para este comportamento está no resfriamento do plasma após a fase de platô, ocasionando um aumento da taxa de emissão radiativa das impurezas,

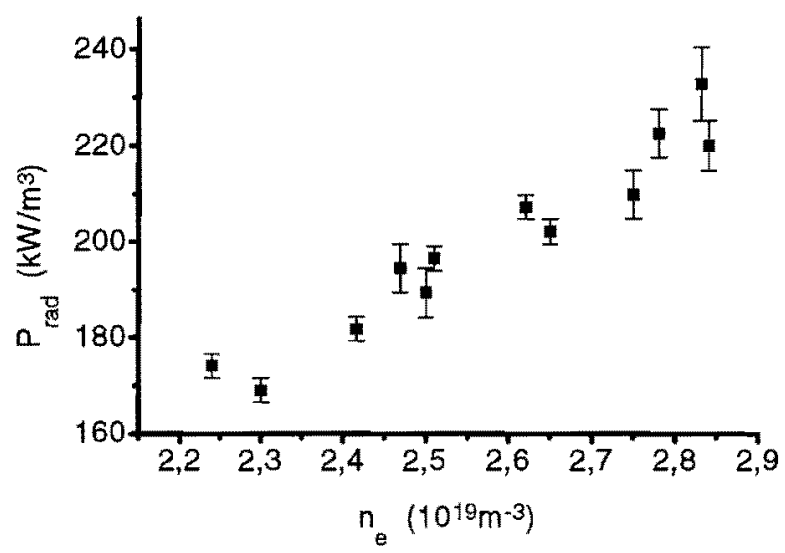

Fig. 6.11 Relação entre a potência emitida e a densidade eletrônica - estatística obtida para várias descargas ôhmicas.

cuja dependência com a temperatura eletrônica pode ser vista na figura 2.1. O resfriamento ocorre devido à diminuição da corrente de plasma na fase final da descarga. Quanto a densidade de impurezas, estamos supondo que seu valor permanece constante. 
A reprodutibilidade do comportamento que estamos estudando foi analisada tomando-se uma série de descargas ôhmicas. A figura 6.11 mostra a dependência da potência emitida média de linha com a densidade eletrônica média de linha para várias descargas com $I_{p} \approx 95 \mathrm{kA}$. Os valores da densidade foram anotados durante o estado estacionário deste parâmetro, que conforme pode ser avaliado da figura 6.10 , dura pouco menos que $10 \mathrm{~ms}$. Embora este platô de densidade não ocorra simultaneamente com o platô de corrente, a leitura da densidade é mais confiável nesta fase da descarga. As incertezas na potência emitida mostradas na figura 6.11, correspondem a magnitude de sua variação temporal durante o platô de densidade eletrônica.

Embora a faixa dos valores de densidade nestas descargas não representar todos os regimes experimentais possíveis no TCABR, podemos perceber que a proporcionalidade entre as duas grandezas é bastante reprodutível.

\subsection{O bolômetro em Descargas com Aquecimento Adicional por Ondas de Alfvén.}

O diagnóstico foi também utilizado no estudo de descargas com aquecimento por ondas de Alfvén. As antenas de RF instaladas no interior da câmara de vácuo são capazes de fornecer até $80 \mathrm{~kW}$ de aquecimento adicional ao plasma. Entretanto, sua aplicação provoca uma interferência indesejável na maior parte dos diagnósticos instalados em nosso laboratório. Felizmente, esta interferência não se manifesta no sinal bolométrico, tornando o diagnóstico essencial na caracterização das descargas com aquecimento por ondas de Alfvén.

O ruído gerado durante a aplicação das ondas de RF afeta substancialmente o sinal em todos os canais do interferômetro de microondas, impossibilitando de maneira consistente, tanto a determinação do perfil espacial, como também da evolução temporal da densidade eletrônica. Informações acerca do comportamento desta grandeza são fundamentais na análise da eficácia do aquecimento adicional. 
Através da utilização de um bolômetro instalado de modo a observar o plasma através de uma corda vertical passando pela região central da coluna, é possível obter uma estimativa da densidade eletrônica durante o aquecimento[7], corrigindo assim, o sinal do interferômetro. Neste caso, utiliza-se a dependência linear da potência emitida com relação a densidade, conforme discutido no tópico inicial deste suplemento. A figura 6.12 mostra a evolução temporal da potência emitida e da densidade eletrônica para a descarga \#10668, onde o aquecimento adicional é ligado em $\mathrm{t}=75 \mathrm{~ms}$. Nota-se o intenso ruído presente no sinal do interferômetro a partir deste instante.

O programa de aquecimento do TCABR, utilizando ondas de Alfvén, é único nesta modalidade sendo desenvolvido atualmente no cenário internacional. Sua principal característica reside na investigação experimental de estudos teóricos recentes dedicados à eficiência do acoplamento das ondas de RF com o plasma. Estes estudos são inovadores por abordar condições experimentais que podem ser importantes para o acoplamento, tais como o efeito devido a impurezas, influência da toroidicidade da coluna de plasma e partículas aprisionadas. Alguns destes estudos indicam ainda que as ondas de Alfvén podem ser utilizadas com vantagem na produção e manutenção de barreiras de transporte em regimes avançados de confinamento em tokamaks. Apesar do baixo nível de potência acoplada, em comparação com a potência ôhmica, algumas condições para bom acoplamento foram identificadas. Os resultados preliminares obtidos no TCABR são bastante animadores.

Na figura 6.13 podemos ver os sinais de alguns diagnósticos em uma descarga onde

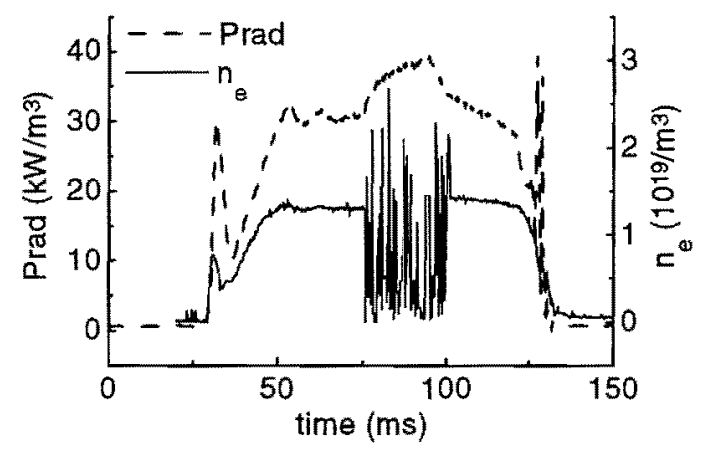

Fig. 6.12 Evolução temporal da potência emitida e da densidade eletrônica para uma descarga (\#10668) com aquecimento adicional. Nota-se o intenso ruído no interferômetro a partir de $t=75 \mathrm{~ms}$. 
foi utilizado aquecimento adicional. São mostrados a potência emitida, a corrente de plasma, a tensão de enlace, emissão eletrociclotrônica do centro da coluna e emissão de $H \alpha$. Nesta experiência, um reflectômetro operando a uma freqüência de $32.3 \mathrm{GHz}$ (densidade eletrônica de corte igual a $1,3 \times 10^{19} \mathrm{~m}^{-3}$ ) foi utilizado para determinar a posição radial de melhor acoplamento das ondas de Alfvén. Estas provocam oscilações na densidade de plasma em regiões bem determinadas da coluna, permitindo sua localização pelo reflectômetro. Na descarga mostrada, o aquecimento adicional foi ligado entre os instantes $\mathrm{t}=75 \mathrm{~ms}$ e $\mathrm{t}=95 \mathrm{~ms}$. Durante sua aplicação, a injeção de gás (hidrogênio) foi programada de modo a realizar uma varredura da posição radial correspondente ao corte do reflectômetro.

Podemos notar que o sinal bolométrico começa a aumentar a partir do instante de aplicação do aquecimento, como conseqüência da injeção controlada de hidrogênio. Ao final deste período, este sinal é aproximadamente $28 \%$ maior que seu valor antes da

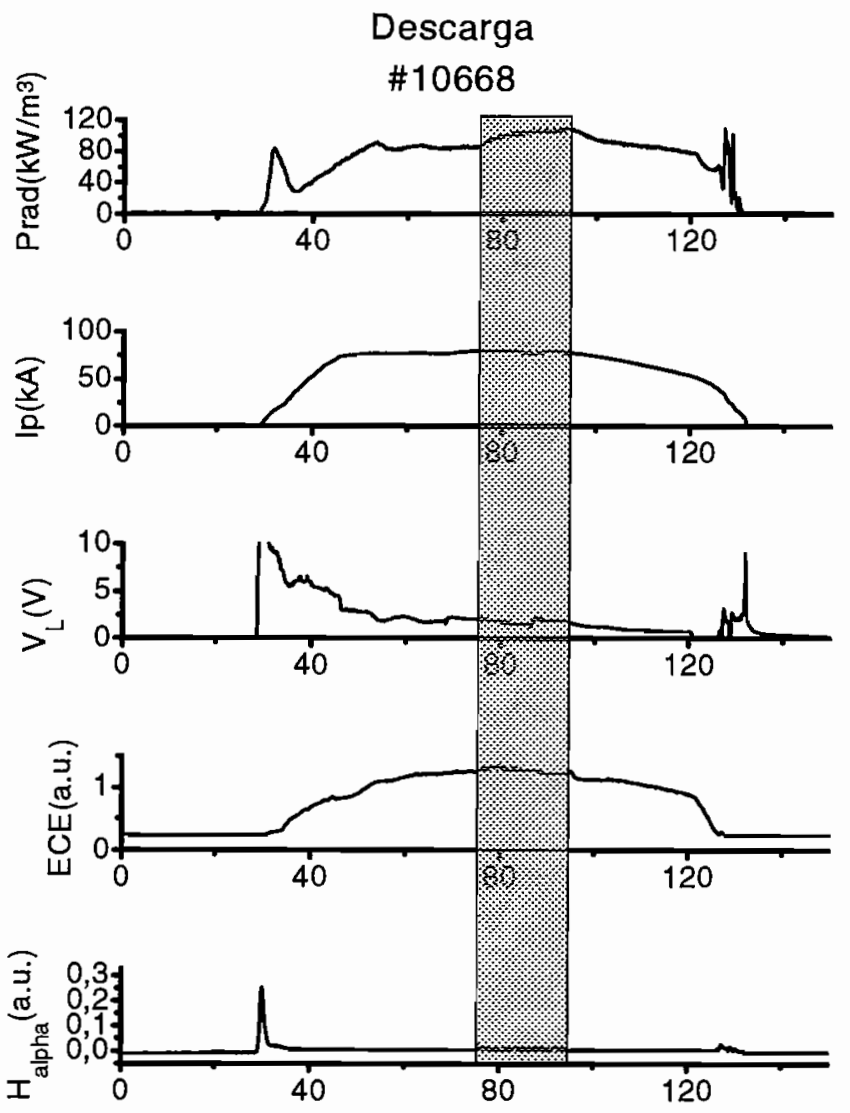

Fig. 6.13 Descarga onde foi utilizado aquecimento adicional por ondas de Alfvén. São mostrados a potência emitida, a corrente de plasma, a tensão de enlace, emissão eletrociclotrônica do centro da coluna e emissão de H $\alpha$. Em destaque, o período na descarga onde foi ligado o aquecimento. 
aplicação das ondas de Alfvén. Esta variação associada ao valor experimental da corrente de plasma e dados do reflectômetro foi introduzida em um código cinético 2D [8] para determinação da região de deposição das ondas de RF, tendo-se obtido $\mathrm{r} / \mathrm{a} \approx 0.6$ para 0 modo de excitação $\mathrm{M}=-1, \mathrm{~N}=-2$.

\subsection{O Bolômetro em Descargas em Regime Runaway}

Um novo regime de descargas runaway de alta densidade foi encontrado no tokamak TCABR. A relevância do estudo e caracterização desta espécie de descarga para viabilização do reator à fusão fica evidenciada pela produção de elétrons fugitivos nas instabilidades disruptívas [6-7]. A vantagem da realização destes estudos em tokamaks de menor porte encontra-se no maior controle das condições experimentais nestas máquinas.

O regime é obtido com uma baixa injeção de gás no início da descarga, aumentandoa após o término da subida da corrente de plasma. A densidade eletrônica mantêm-se aproximadamente constante em $10^{19} \mathrm{~m}^{-3}$ durante a rampa de subida da corrente, caindo de um fator 3 durante a fase estacionária da descarga, quando se estabelece o regime. A característica fundamental destas descargas é a intensa manifestação de instabilidades, observadas em vários diagnósticos, tais como picos periódicos na emissão de $H \alpha$, tensão de enlace e densidade eletrônica. Verificou-se ainda que a freqüência das instabilidades está relacionada com a magnitude da injeção de hidrogênio. A coluna de plasma sofre um pequeno deslocamento, no sentido de aumentar o seu raio maior $R$.

Os picos periódicos podem ser vistos também no sinal bolométrico. A figura 6.14 mostra a evolução temporal deste sinal em conjunto com a densidade eletrônica média de linha. A descarga se inicia em $\mathrm{t}=28 \mathrm{~ms}$ e termina em $\mathrm{t}=165 \mathrm{~ms}$, quando são desligadas as bobinas responsáveis pelo campo magnético vertical de equilíbrio. Devido à limitações em nossos módulos digitais de armazenamento (VME), o sinal da densidade só foi coletado até 0 instante $\mathrm{t}=130 \mathrm{~ms}$.

Podemos observar que somente durante os $20 \mathrm{~ms}$ iniciais da descarga, região esta correspondente à rampa de subida da corrente de plasma e da densidade eletrônica, o sinal 
bolométrico assume valores significativos. A partir daí, como consequiência do aumento da injeção de hidrogênio e o estabelecimento do regime runaway, a coluna de plasma sofre uma diminuição em seu raio, desprendendo-se do limitador físico. A potência emitida medida pelo bolômetro praticamente desaparece, restando apenas uma pequena potência residual "de fundo". Esta queda é acompanhada pela densidade eletrônica, conforme mostrado no gráfico logo abaixo do sinal bolométrico. Porém, de forma geral, a diminuição da densidade parece não ser proporcional à queda da potência emitida, ocorrendo à uma taxa menor.

Os picos observados no bolômetro encontram-se em fase com os mostrados pelo sinal de densidade eletrônica, como podemos ver de forma ampliada no lado direito da figura 6.14. Durante este período, o sinal de emissão eletrociclotrônica (ECE) apresenta picos em contra-fase com o bolômetro. Ocorre que o feixe relativístico de elétrons de aproximadamente $3 \mathrm{MeV}$ formado no interior da coluna encontra-se imerso em um plasma relativamente frio. Durante a maior parte do processo, a emissão é dominada pela radiação

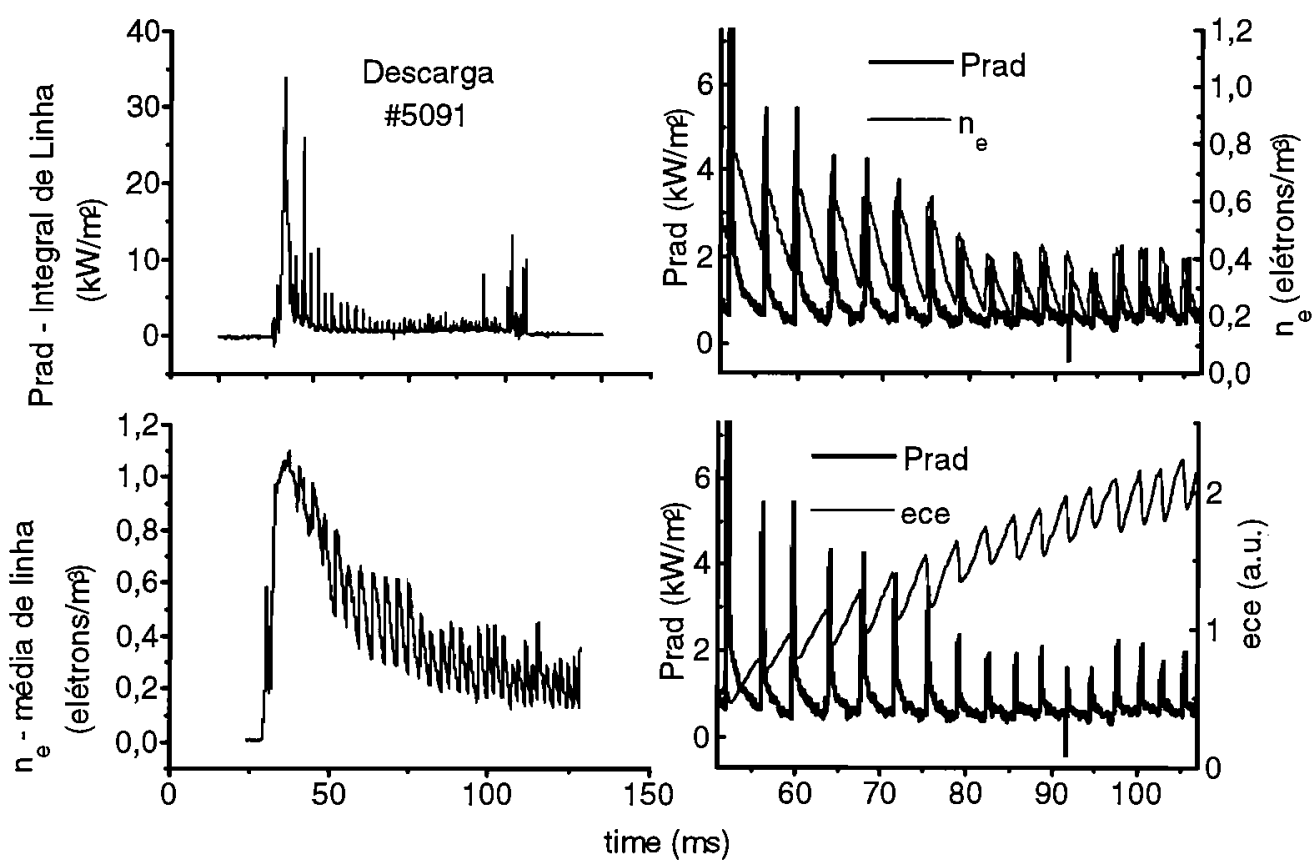

Fig. 6.14 Evolução temporal da potência irradiada, densidade eletrônica média de linha e emissão eletrociclotrônica (ece). A direita, é mostrada uma ampliação com os sinais sobrepostos. A descarga se inicia em $\mathrm{t}=28 \mathrm{~ms}$ e termina em $\mathrm{t}=165 \mathrm{~ms}$, quando são desligadas as bobinas responsáveis pelo campo magnético vertical de equilíbrio. 
sincrotrônica advinda do feixe, ocasionalmente transferindo energia para o plasma periférico. No instante em que se dá esta transferência, ocorre um aumento na ionização do plasma, aumentado a densidade eletrônica e a potência emitida.

No lado direito da figura 6.14 mostramos de forma ampliada os sinais do bolômetro e da densidade sobrepostos, para o intervalo temporal compreendido entre $51 \mathrm{~ms}$ e $106 \mathrm{~ms}$. Nesta figura, é possível relacionarmos as magnitudes dos picos entre as duas grandezas. De forma proposital, a origem da escala da potência emitida foi deslocada com relação a escala da densidade, para melhor visualização. Contudo, o eixo dos tempos para as duas grandezas é simultâneo.

No intervalo (51-75) ms, as variações na potência emitida são bem maiores que as de densidade. A partir de $t=75 \mathrm{~ms}$ até o final, quando as variações na densidade eletrônica tornam-se menores que $2 \times 10^{18} \mathrm{~m}^{-3}$, ocorre uma equalização, permanecendo as variações das duas grandezas aproximadamente proporcionais. Supondo que o principal canal de perdas seja por radiação, um aquecimento brusco do plasma periférico devido à interação com o feixe eletrônico levaria a uma diminuição da taxa de emissão radiativa das impurezas leves, provocando as instabilidades[8]. Contudo, uma análise mais cuidadosa necessita de diagnósticos ainda não disponíveis no TCABR, em particular uma medida direta da temperatura eletrônica.

\subsection{O Bolômetro em Descagas com Eletrodo}

Recentemente, uma nova linha de pesquisas visando a obtenção de um regime avançado de confinamento (modo-H) vem sendo desenvolvida no TCABR. Este regime foi obtido pela primeira vez no ASDEX[9], utilizando aquecimento adicional por partículas neutras. Verificou-se mais tarde que ele poderia ser alcançado também através de aquecimento por RF e com a utilização de um eletrodo polarizado. Esta ultima opção parece ser a mais adequada para implementação em laboratórios de médio porte, devido à relativa simplicidade do aparato experimental necessário. 
Os resultados preliminares são bastante animadores, tendo-se verificado a obtenção do modo-H através de análises de perfis temporais e radiais dos parâmetros da descarga. $\mathrm{O}$ eletrodo utilizado é móvel, construído em grafite, possuindo um formato de disco com diâmetro $2 \mathrm{~cm}$ e espessura $0,9 \mathrm{~cm}$. Durante os experimentos verificou-se que os melhores resultados eram obtidos com o eletrodo posicionado no interior da coluna de plasma, à 16 cm do centro da descarga.

A fonte de polarização é capaz de fornecer até $300 \mathrm{~A}$, operando à uma tensão máxima de $750 \mathrm{~V}$ e com opção de troca de polaridade. A injeção de hidrogênio era ajustada de forma que o valor da densidade eletrônica de linha ficasse ao redor de $1 \times 10^{19} \mathrm{~m}^{-3}$ imediatamente antes da aplicação do eletrodo, aumentando até um fator 2,6 após a aplicação[10].

O array bolométrico foi utilizado para avaliarmos mudanças na eficiência do confinamento. Na figura 6.15, podemos ver a evolução temporal da potência emitida para a descarga \#15925, onde são mostrados os sinais para cordas com diferentes distâncias ao centro da descarga. $\mathrm{O}$ instante de aplicação do eletrodo $(\mathrm{t}=70 \mathrm{~ms})$ é marcado por um pronunciado aumento da emissão em todas cordas, comportamento também verificado no sinal do interferômetro. A razão entre as variações individuais das cordas entre o instante de
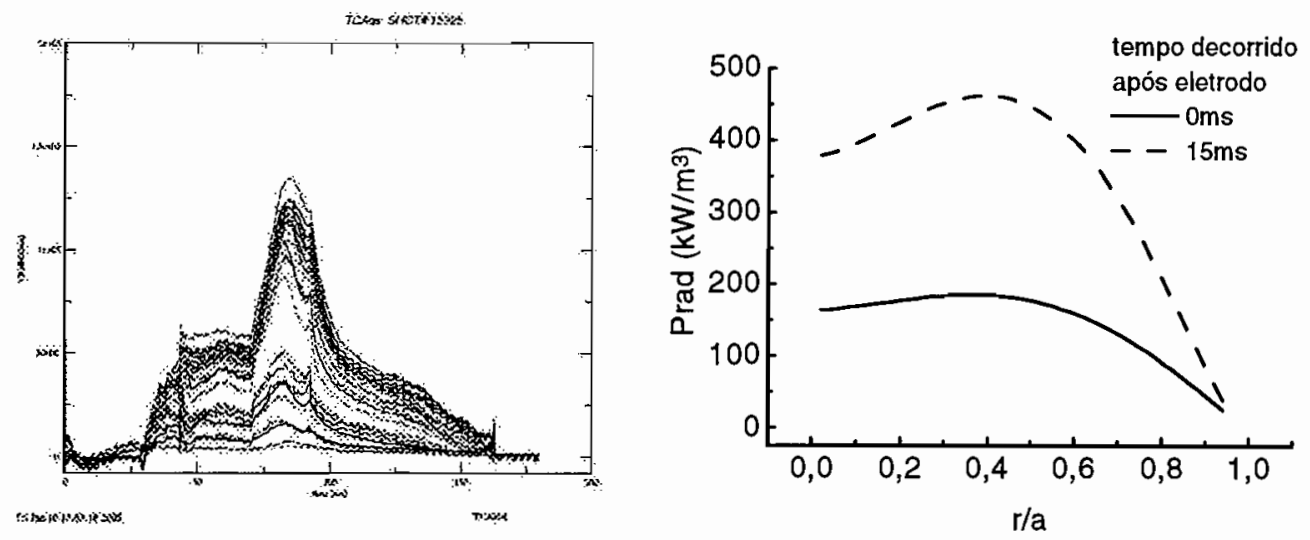

Fig. 6.15 Esquerda: evolução temporal de todas as cordas do array bolométrico para uma descarga utilizando eletrodo (\#15925). $O$ eletrodo foi ligado durante $15 \mathrm{~ms}$, iniciando em $t=70 \mathrm{~ms}$. Direita: perfil radial da emissividade imediatamente antes, e 15 ms após aplicação do eletrodo. 
aplicação e o instante em que o eletrodo é desligado, reproduz o valor de 2,6 verificado no caso da densidade eletrônica, principalmente para cordas próximas ao centro da descarga. Mas, as cordas mais distantes do centro, isto é, próximas da borda, mostram um aumento maior, em torno de 3,5 .

Supondo que a densidade eletrônica tenha acompanhado o comportamento da potência emitida na borda da coluna, aumentando o gradiente de densidade nesta região, estaremos diante de um forte indicador de aumento de eficiência do confinamento. Infelizmente, não existem cordas do interferômetro em número suficiente para obtenção de um perfil confiável da densidade em uma só descarga, para podermos confirmar este cenário. A recente instalação de um reflectômetro capaz de fornecer a densidade na borda da coluna pode ser importante para elucidar a questão.

No lado direito da figura 6.15, mostramos a emissividade obtida pela inversão de Abel do sinal bolométrico, para os instantes $70 \mathrm{~ms}$ e $85 \mathrm{~ms}$. Notamos que a forma do perfil foi pouco alterada pelo eletrodo, mas é possível confirmar o aumento do gradiente de emissividade na borda da coluna. Uma nova fonte para o eletrôdo, com opção de controle do tempo de subida e queda da corrente, projetada, implementada e em vias de instalação no TCABR trará mais flexibilidade e alternativas ao experimento.

\subsection{Referências}

[1] B. Joye, J. B. Lister, J. -M. Moret and S. Nowak Plasma Physics and Controlled Fusion

29 (1987) 27

[2] D. E. Post and R. V. Jensen

Atomic Data and Nuclear Data Tables

20 (1977) 397

[3] de Chambrier, G.A. Collins, Ch. Hollenstein,B. Joye, J.B. Lister,J.M. Moret, S. Nowak, A. Pochelon, W. Simm, LRP 241/84, École Polytechnique Fédérale de Lausanne - Suisse

[4] L. F. Ruchko, R. Valencia, R. M. O. Galvão, E. A. Lerche, A. G. Elfimov, V. Bellintani Jr., J. I. Elizondo, A. N. Fagundes, A. M. M. Fonseca,

Yu. K. Kuznetsov, I. C. Nascimento, W. P. de Sá, E. Sanada, and R. P. da Silva, Rev. Sci. Instrum. , 75, 655 (2004). 
[5] G. Amarante-Segundo, A. Elfimov, D. Ross, R. Galvão et al., Phys. Plasmas 6, 2437 (1999).

[6] R. M. O. Galvão, V. Bellintani Jr., R. D. Bengtson, A. G. Elfimov, J. I. Elizondo, A. N. Fagundes, A. A. Ferreira, A. M. M. Fonseca, Yu K Kuznetsov, E. A. Lerche, I. C. Nascimento, L. F. Ruchko, W. P. Sá, E. A. Saettone, E. Sanada, J. H. F. Severo, R. P. da Silva, V. S. Tsypin, O. C. Usuriaga and A. Vannucci, Plasma Phys. Control. Fusion 43 A299 (2001).

[7] Yu. K. Kuznetsov, R. M. O. Galvão, V. Bellintani Jr., A. A. Ferreira, A. M. M. Fonseca, I. C. Nascimento, L. F. Ruchko, E. A. O. Saettone, V. S. Tsypin and O. C. Usuriaga, Nucl. Fusion 44631 (2004).

[8] W. M. Stacey, Fusion Technology 3638 (1999).

[9] F. Wagner et al., Phys. Rev. Lett. 491408 (1982).

[10] C. Nascimento, Yu. K. Kuznetsov, J. H. F. Severo, A. M. M. Fonseca, A. G. Elfimov, V. Bellintani, M. M. Machida, M. V. A. P. Heller and R. M. O. Galvão, a ser publicado na Nucl. Fusion. 


\section{Capítulo 7}

\subsection{Discussão dos Resultados}

Como podemos perceber da figura 6.5, a potência emitida integrada no volume da coluna de plasma, normalizada pela potência ôhmica, como função do inverso da velocidade eletrônica média de deriva exibe um comportamento bastante próximo do linear. Este comportamento é também observado para a potência emitida axial reduzida $P_{\mathrm{rad}}(0) / P_{\text {oh }}(0)$, conforme mostrado na figura 6.6 .

Estes resultados experimentais obtidos para o TCABR estão ligados à forma da dependência da potência emitida com a densidade eletrônica, e portanto, com a velocidade de deriva, de acordo com a equação (2.9). Nesta equação, obtida a partir do modelo corona, o produto da quantidade de impurezas pela taxa de emissão radiativa desempenha o papel de coeficiente de linearidade entre as perdas radiativas e a densidade eletrônica. Como o inverso da velocidade eletrônica de deriva é proporcional à densidade eletrônica, para uma

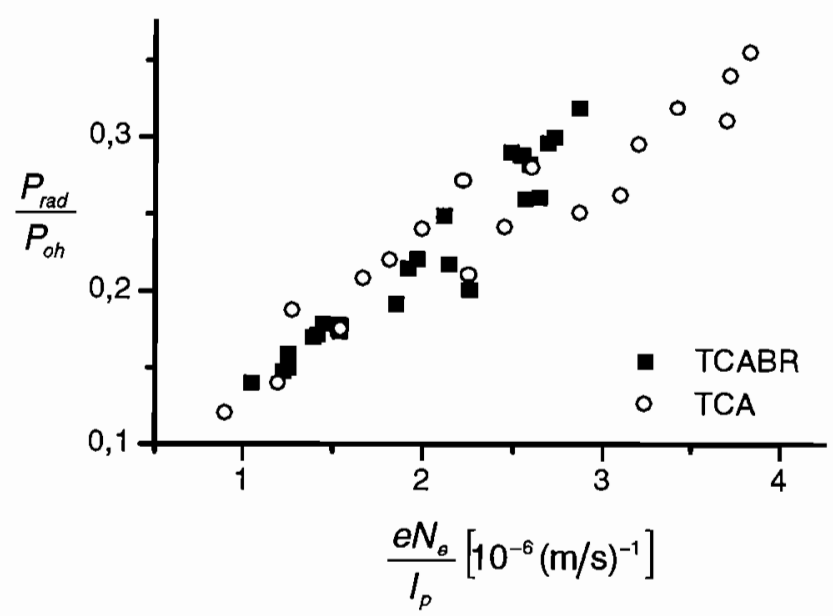

Fig. 7.1 Perdas Radiativas Normalizadas em função do inverso da velocidade eletrônica média de deriva - Comparação entre os resultados deste trabalho (TCABR) e os dados do TCA em sua fase inicial de operaçãa. 
corrente de plasma fixa, esta linearidade se manifesta nos dados experimentais da figura 6.5.

Desta forma, podemos concluir que o modelo corona descreve bem os eventos radiativos no TCABR.

Comparando as figuras 6.5 e 6.6 , verificamos que a potência irradiada normalizada no centro da coluna de plasma é aproximadamente $30 \%$ menor comparada com as perdas radiativas normalizadas integradas no volume. Isto se deve a menor temperatura eletrônica característica das regiões mais distantes do centro da descarga. As taxas de emissão radiativa crescem com a diminuição da temperatura, conforme mostrado na figura 2.1, provocando uma emissão maior nestas regiões. Assim, é natural que ao integrarmos a emissividade nas regiões mais frias do plasma, iremos detectar um aumento relativo entre as quantidades fracionais que estamos considerando. Estas considerações qualitativas mostram que nossos resultados experimentais estão de acordo com a teoria.

A figura 7.1 mostra a dependência entre a potência normalizada integrada no volume e o inverso da velocidade eletrônica de deriva para o TCA, quando ainda operando em Lausanne. Os resultados obtidos neste trabalho também são mostrados. Estes dados da potência emitida normalizada foram obtidos trabalhando-se com o deutério, para o TCA, e com hidrogênio, para o TCABR. Apesar desta diferença no gás de trabalho, notamos uma grande concordância entre os dois resultados. Mas se os dados são tão coincidentes, cabe perguntar porque obtivemos uma concentração de impurezas metálicas maior que o dobro da medida no TCA.

Uma explicação possível pode estar em utilizarmos no cálculo da concentração de impurezas, o mesmo valor de $C_{M}$ (perda por radiação por átomo por elétron) usado no calculo em Lausanne. Recordemos a equação utilizada para a razão entre a concentração metálica e a densidade eletrônica:

$$
\eta_{M}=\frac{P_{r a d}(0)}{n_{e}(0)^{2} C_{M}}
$$


Sabemos que $C_{M}$ cresce com a diminuição da temperatura eletrônica e como já dissemos no capítulo 6 , as temperaturas no TCABR são menores que as do TCA devido à menor corrente de plasma. Então, ajustando o valor utilizado de $C_{M}$ para o TCABR, teríamos obtido concentrações metálicas mais modestas. Uma investigação mais criteriosa, levando em conta o valor da temperatura para o TCABR deve ser realizada.

Outra explicação possível para a diferença encontrada nas concentrações metálicas é que os resultados da figura 7.1 são valores integrados no volume de plasma, mas as grandezas que comparecem na equação (7.1) são todas referentes ao centro da descarga. Vamos deixar esta questão em aberto, esperando um estudo mais detalhado.

\subsection{Conclusões}

Foi projetado, construído e instalado um sistema bolométrico no TCABR. Este sistema possibilita a observação da coluna de plasma através de cordas caracterizadas por diferentes direções e ângulos. Os bolômetros utilizados são fotodiodos especiais, sensíveis em uma larga faixa espectral $(1-6000 \mathrm{eV})$. A resolução temporal do diagnóstico é de $3 \mathrm{~ms}$ devido a interferência gerada pelo tokamak.

Os circuitos eletrônicos para tratamento do sinal bolométrico foram desenvolvidos e construídos. Os fortes campos eletromagnéticos presentes nas proximidades do tokamak foram considerados no projeto e na implementação destes circuitos.

Uma rotina escrita especificamente para o software XMGR foi utilizada para coleta dos dados armazenados no sistema de aquisição. Sua função é armazenar os dados das integrais de linha da potência irradiada em um instante de tempo escolhido pelo usuário. A partir destes dados, outra rotina calcula a emissividade do plasma. 
Foi obtido o perfil da potência emitida para a atual fase de operação do tokamak TCABR, sendo, talvez este o resultado mais original deste trabalho.

Nas descargas ôhmicas analisadas, a potência irradiada não ultrapassa $30 \%$ da potência ôhmica fornecida ao plasma. Contudo, descargas caracterizadas por uma densidade eletrônica maior que $2 \times 10^{19} \mathrm{~m}^{-3}$ (não consideradas neste trabalho) certamente apresentarão maiores perdas. Um resultado semelhante foi obtido para o tokamak START, onde as perdas radiativas representam apenas $6 \%$ da potência de aquecimento[1]. No centro da descarga esta fração é menor, atingindo $20 \%$. Esta queda pode ser explicada pela maior temperatura eletrônica característica desta região.

Observou-se que, dentro da sensibilidade dos sensores empregados, as impurezas metálicas são as principais responsáveis pelas perdas radiativas.

Esta contribuição das impurezas metálicas como principal fonte de perdas radiativas já foi observada em outras máquinas. Um processo de tratamento das paredes da câmera pode reduzir bastante as perdas por radiação.

\subsection{Sugestões para Trabalhos Futuros}

Uma comparação mais sistemática entre os fotodiodos e o bolômetro resistivo deve ser feita, investigando as consequiências para os dados da característica suposta de resposta espectral plana do bolômetro resistivo. Espera-se uma diferença, principalmente na investigação da borda da coluna de plasma, onde a sensibilidade dos fotodiodos é menor.

Seria importante avaliar as assimetrias toroidais da emissão da coluna., fazendo medidas da emissividade em posições toroidais diferentes. Especificamente, um sistema bolométrico auxiliar poderia ser projetado e instalado próximo ao limitador, sendo os dados ali obtidos sistematicamente comparados ao sistema bolométrico já instalado. 
A configuração do sistema bolométrico desenvolvido, possuindo cordas com várias direções, já pressupõe a utilização de métodos de inversão tomografia para análise dos dados. Com esta ferramenta será possível avaliar os desvios de nossa hipótese de simetria poloidal.

Estudos com o propósito de desenvolver um algoritmo de inversão já estão sendo feitos. O método analisado até o momento é de tipo interativo, denominado Técnica de Reconstrução Algébrica (ART).

\subsection{Referências}

[1] A. R. Field, "Total Radiation Measurements on START", Start OPS Note 9716 


\section{Apêndice A}

\section{O bolômetro resistivo}

O bolômetro resistivo é um sensor térmico, produzindo um sinal proporcional ao aumento de temperatura em sua superfície ativa. No TCABR, um único sensor foi instalado de forma a observar o centro da coluna de plasma através de uma janela localizada acima do tokamak e oposta ao limitador físico. O ângulo sólido de
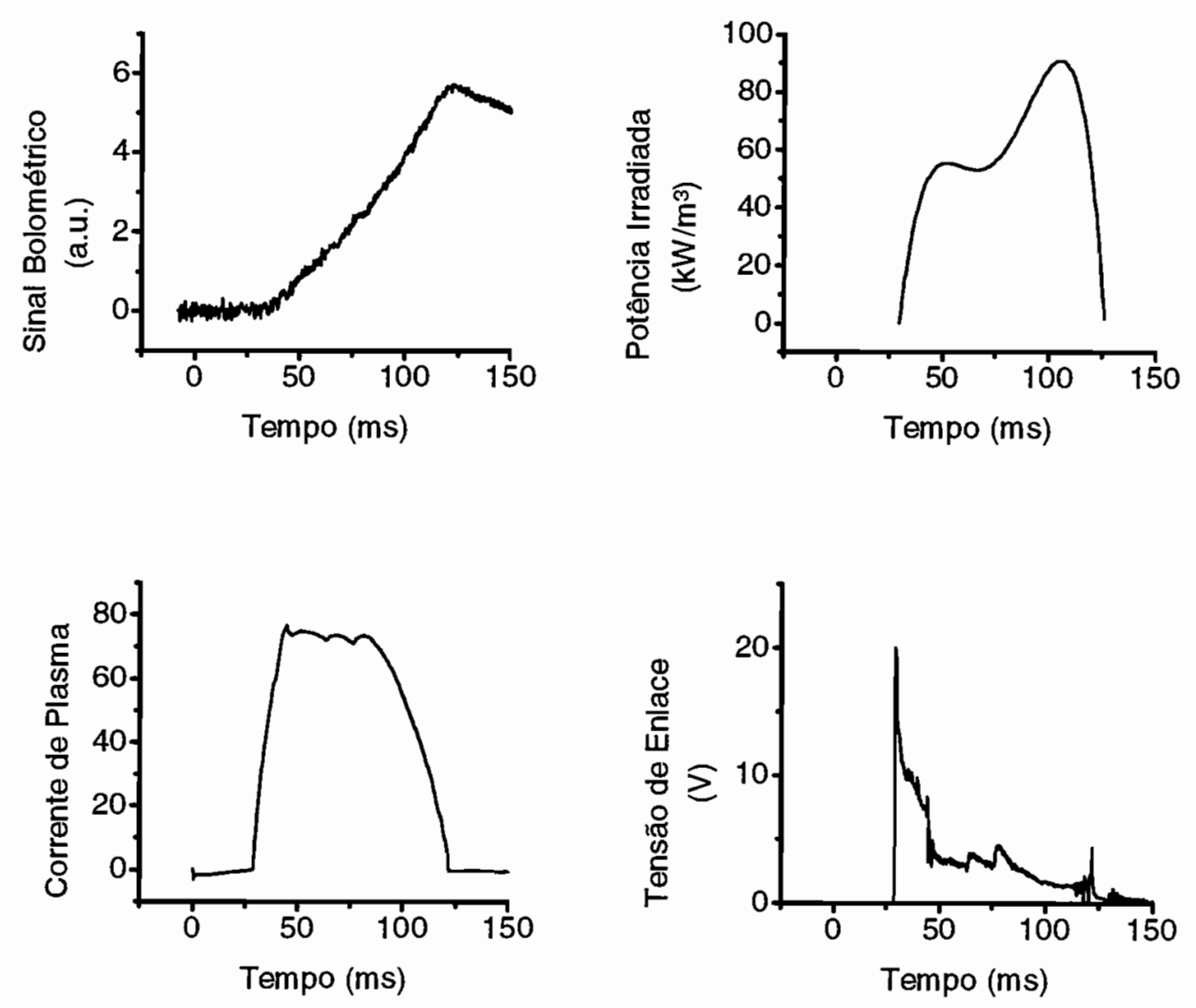

Fig. A1 Evolução temporal do sinal bolométrico, tensão de enlace, corrente de plasma para a descarga \#3031 do tokamak TCABR. Em cima, a direita: Integral de linha da potência irradiada calculada a partir do sinal bolométrico 
observação era de $70 \times 10^{-3}$ sr.

A figura Al mostra a evolução temporal do sinal bolométrico, da integral de linha da potência irradiada, da corrente de plasma e da tensão de enlace para a descarga \#3031. Nesta descarga a densidade eletrônica média da linha central, durante a fase plana de corrente de plasma, era aproximadamente $2.8 \times 10^{19} \mathrm{~m}^{-3}$. A potência irradiada era calculada a partir dos parâmetros do sensor, já descritos no capítulo 4, e da geometria conhecida da instalação.

Nota-se um aumento da potência irradiada na fase final da descarga, coincidindo com a queda da corrente de plasma. Isto pode estar ligado ao maior fluxo de partículas neutras nesta fase da descarga, associado à maior sensibilidade do bolômetro resistivo para estas partículas, relativamente aos fotodiodos. 


\section{Apêndice B}

\section{Sistema Bolométrico do TCABR - Parâmetros Geométricos}

Na figura 3.1 é mostrado um diagrama indicando as posições relativas entre a coluna de plasma, o bolômetro e o colimador. Neste apêndice listamos os fatores geométricos ali indicados para todos os bolômetros instalados no TCABR. Estes dados são utilizados no calculo do fluxo de potência medido pelos bolômetros, de acordo com a equação (3.3). O bolômetro 19 não corta a coluna de plasma.

\begin{tabular}{|llllll|}
\hline bolômetro & $\lambda_{1}(\mathrm{~mm})$ & $\lambda_{2}(\mathrm{~mm})$ & $\alpha_{\mathrm{m}}$ (graus) & $\alpha_{\mathrm{M}}$ (graus) & $\beta$ (graus) \\
1 & 479 & 644 & 3,3 & 3,9 & 7,2 \\
2 & 468 & 664 & 1,7 & 2,4 & 7,2 \\
3 & 459 & 680 & 0,14 & 0,81 & 7,2 \\
4 & 452 & 694 & $-1,4$ & $-0,74$ & 7,2 \\
5 & 446 & 707 & -3 & $-2,3$ & 7,2 \\
6 & 442 & 719 & $-4,5$ & $-3,8$ & 7,2 \\
7 & 422 & 769 & 3,1 & 3,9 & 7,2 \\
8 & 421 & 772 & 1,6 & 2,3 & 7,2 \\
9 & 419 & 775 & 0,039 & 0,77 & 7,2 \\
10 & 419 & 777 & $-1,5$ & $-0,78$ & 7,2 \\
11 & 418 & 778 & $-3,1$ & $-2,3$ & 7,2 \\
12 & 419 & 779 & $-4,6$ & $-3,9$ & 7,2 \\
13 & 423 & 764 & 3,1 & 3,8 & 7,2 \\
14 & 425 & 759 & 1,6 & 2,3 & 7,2 \\
15 & 427 & 752 & 0,014 & 0,73 & 7,2 \\
16 & 429 & 746 & $-1,5$ & $-0,82$ & 7,2 \\
17 & 433 & 737 & $-3,1$ & $-2,4$ & 7,2 \\
18 & 437 & 729 & $-4,6$ & $-3,9$ & 7,1 \\
19 & - & - & $-5,4$ & $-4,5$ & 2,4 \\
20 & 449 & 567 & $-2,1$ & $-1,1$ & 2,4 \\
21 & 419 & 615 & 1,3 & 2,2 & 2,4 \\
22 & 403 & 650 & 4,6 & 5,6 & 2,4 \\
23 & 347 & 700 & $-5,7$ & $-4,7$ & 2,5 \\
24 & 346 & 703 & $-2,9$ & $-1,9$ & 2,5 \\
25 & 345 & 705 & $-0,14$ & 0,84 & 2,5 \\
26 & 345 & 705 & 2,6 & 3,6 & 2,5 \\
\hline
\end{tabular}




\begin{tabular}{|llllll|}
\hline 27 & 347 & 703 & 4,7 & 5,7 & 2,5 \\
\hline
\end{tabular}




\section{Apêndice C}

\section{Circuitos Eletrônicos}

Aqui apresentamos os diagramas dos circuitos conectados aos sensores bolométricos responsáveis tanto pelo acondicionamento do sinal gerado, quanto pelo interfaceamento com o VME (computador de aquisição).

Dois módulos foram construídos. O primeiro módulo se constitui de 27 amplificadores de corrente, com ganho de $4 \times 10^{4}$ V/A e frequência de corte ajustada
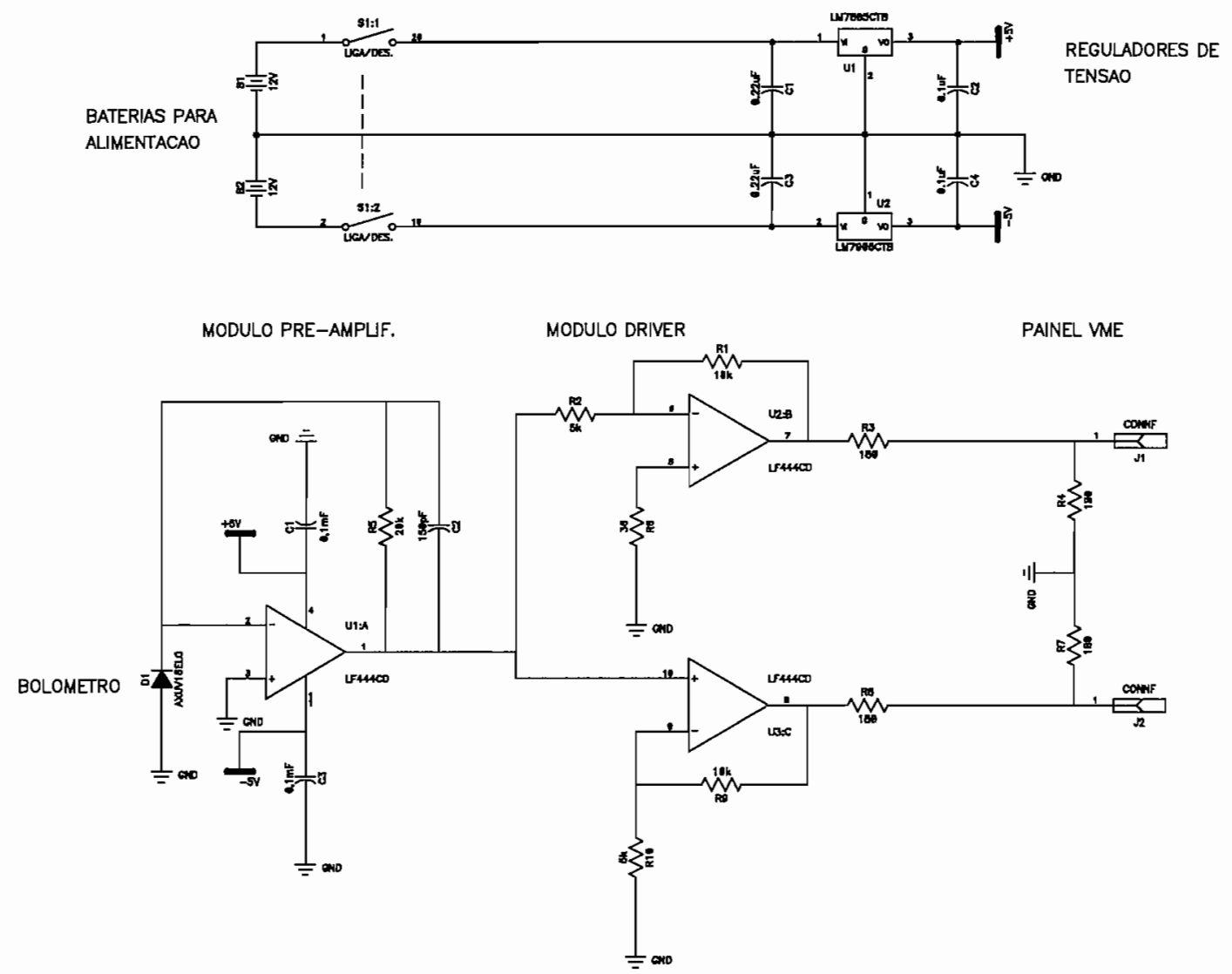

Fig. C1 Diagrama elétrico dos circuítos utilizados para aquisição de dados do sistema bolométrico. 
em 35kHz. O circuito integrado utilizado é o LF444, cujas entradas são do tipo FET.

O segundo módulo se constitui de 27 "seguidores" (drivers), responsáveis por
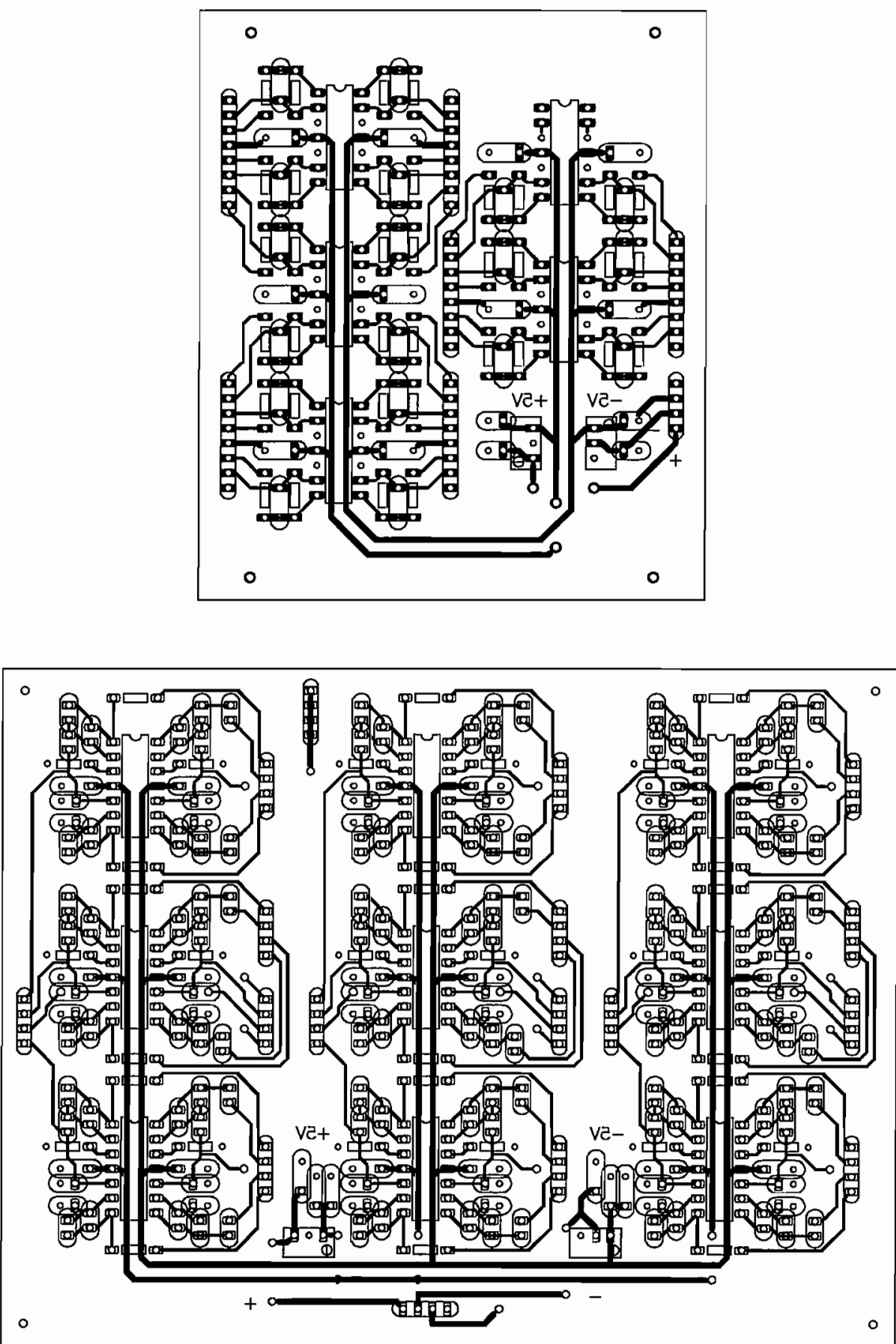

Fig. C2 Esquema das placas de circuito impresso construídas. (Em cima): Módulo pré-amplificador (Em baixo): Módulo "seguidor" (driver). 
transformar a saída para o VME em saídas diferenciais. Utiliza-se o mesmo circuito integrado já usado no primeiro módulo, porém polarizados de maneira diferente (dois amplificadores de tensão, sendo o primeiro polarizado como inversor e o segundo, como não-inversor). A figura $\mathrm{C} 1$ mostra o diagrama elétrico para os dois módulos. A figura C2 mostra o esquema das placas de circuito impresso confeccionadas. 


\section{Apêndice D}

\section{Fotos do Sistema Bolométrico}

Uma série de fotografias do diagnóstico construído são aqui mostradas.
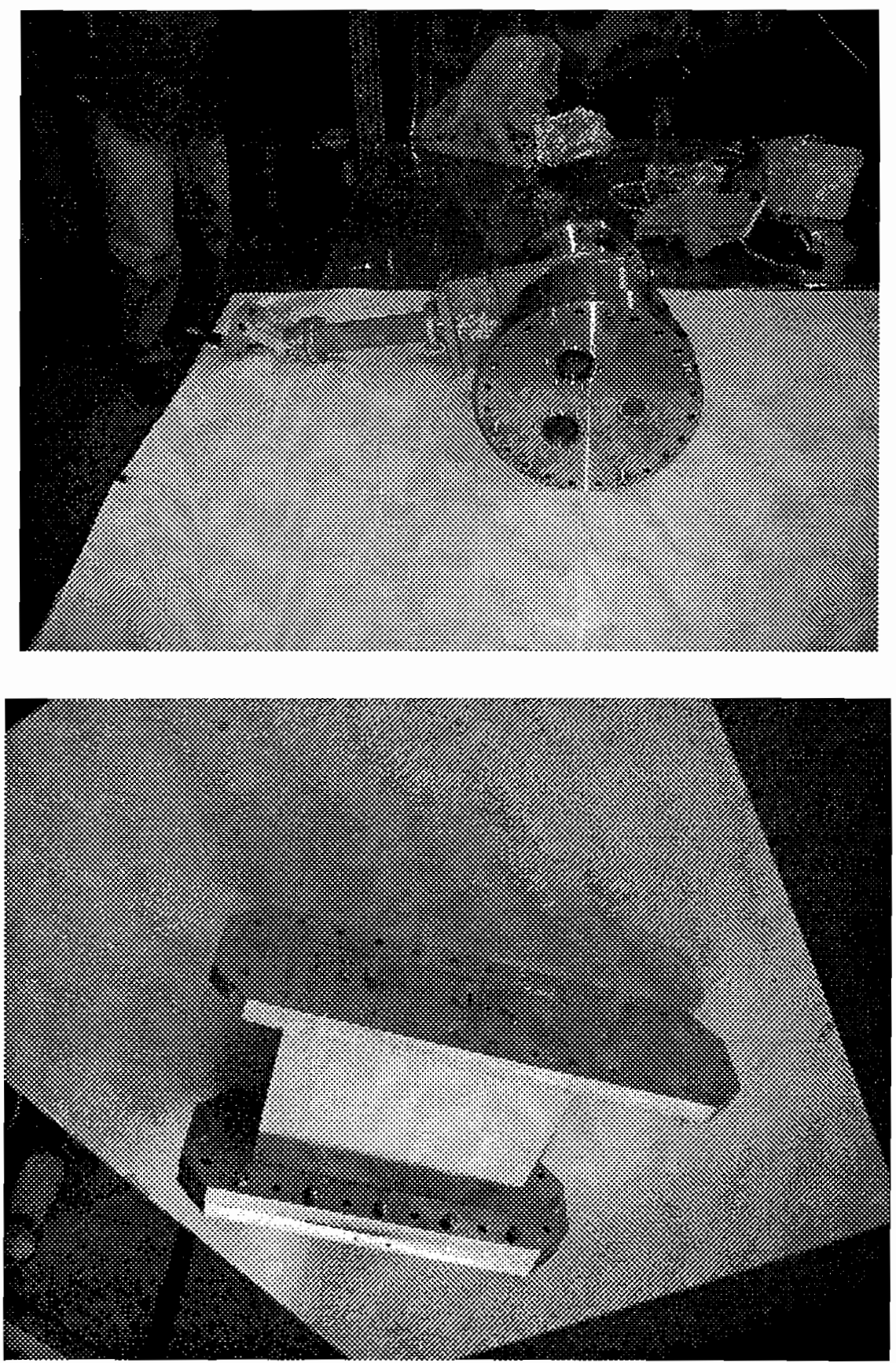

Fig. D1 (Em cima) Câmera bolométrica para observaçào da coluna de plasma através do plano equatorial. (Em baixo) Câmera bolométrica para observação da coluna por um ponto localizado abaixo da coluna de plasma. 

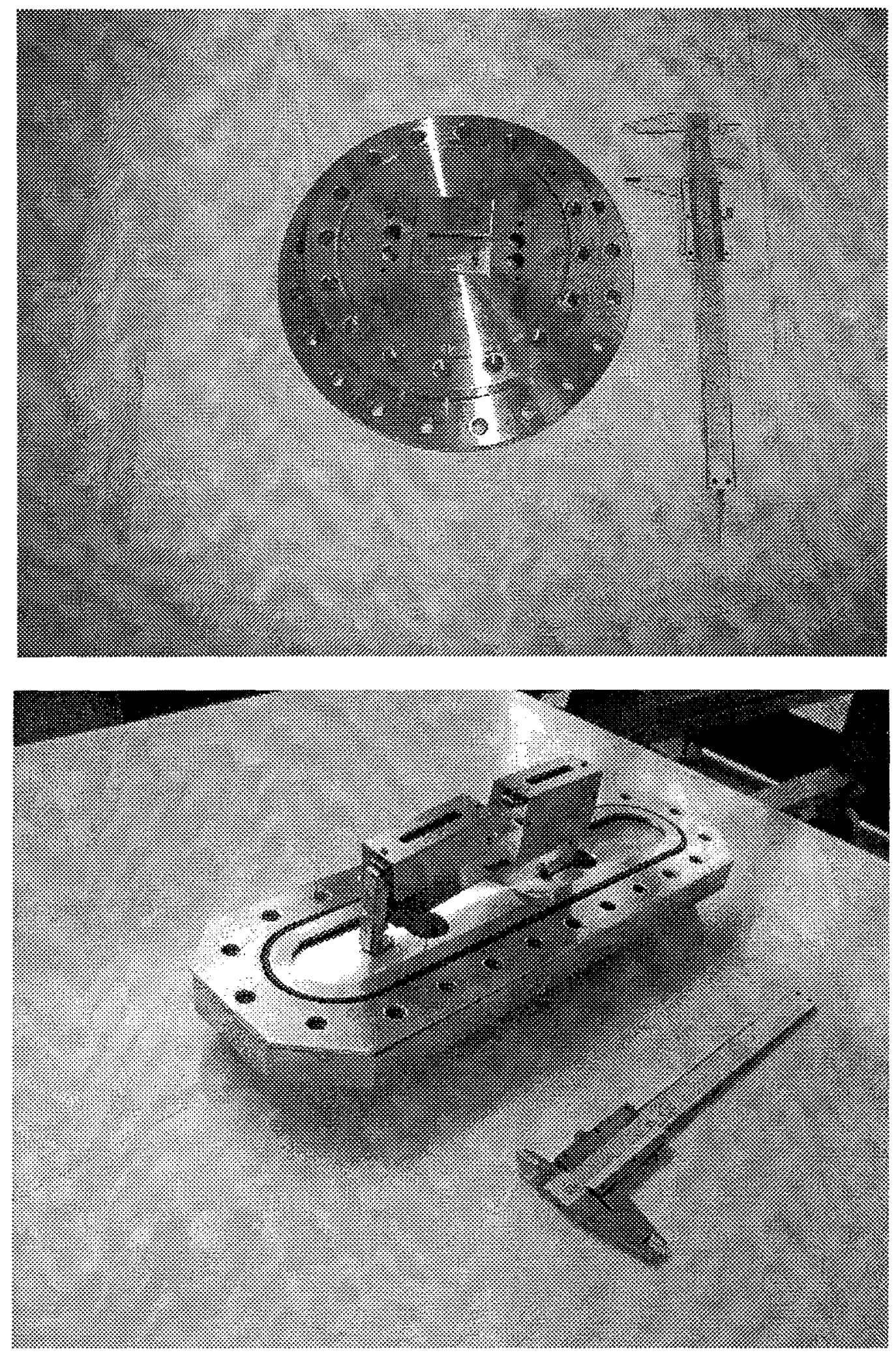

Fig. D2 (Em cima) Colimador da câmera bolométrica "equatorial". Os orifícios laterais destinam-se ao bombeamento para vácuo. (Em baixo) Montagem dos bolômetros da câmera inferior. Mostra-se também as máscaras em aço para proteção dos sensores. 

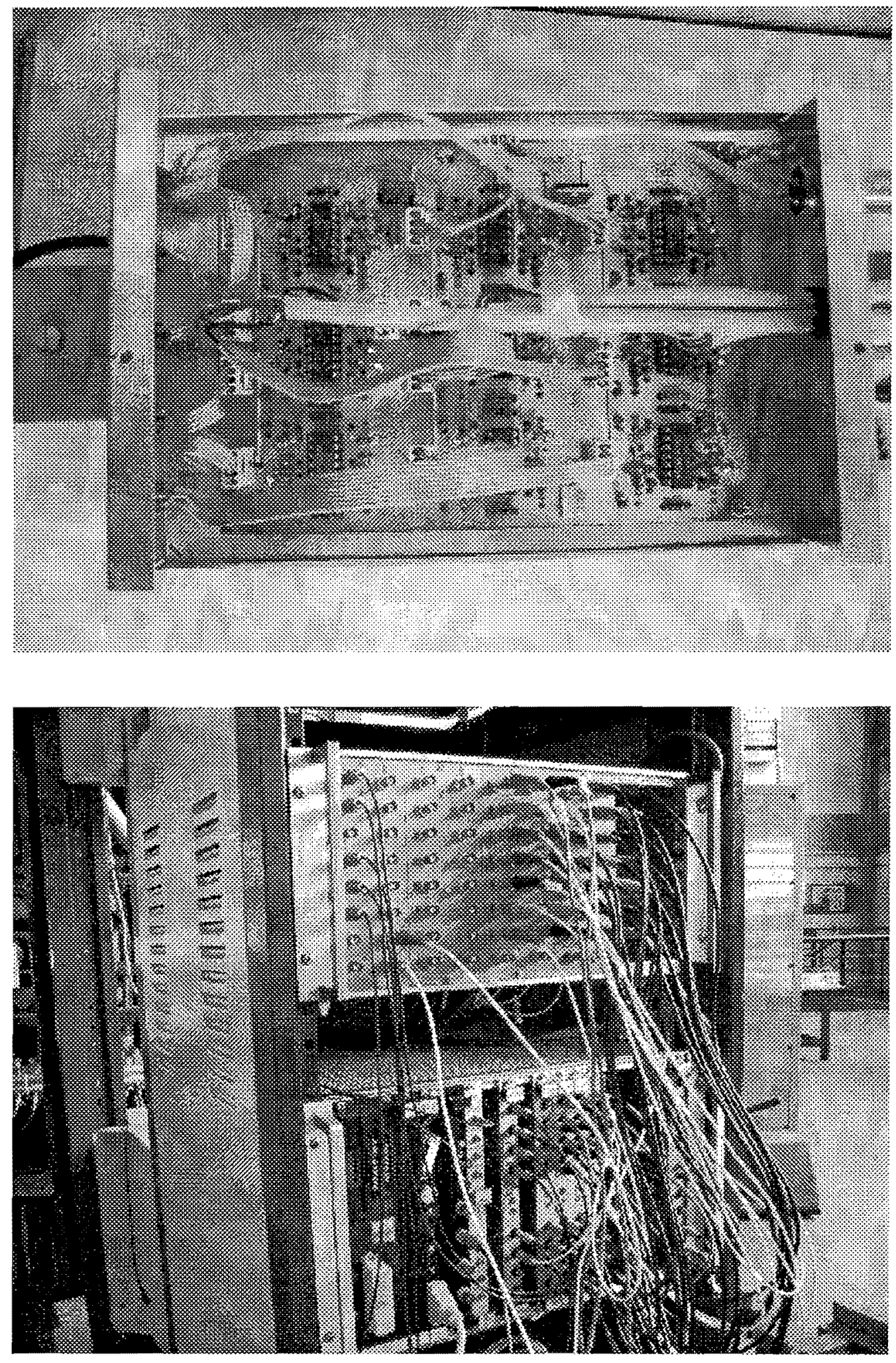

Fig. D3 (Em cima) Circuíto eletrônico que transforma o sinal proveniente dos pré-amplificadores bolométricos em sinais diferênciais, mais adequados ao VME. (Em baixo) VME - Sistema de aquisição do TCABR. 